Florida International University FIU Digital Commons

$11-4-2016$

\title{
Increasing the Elicitation of Truthful Information from Young Suspects: An Empirical Investigation of the Effects of Temporal Discounting
}

Andrea Arndorfer

Florida International University, aarnd001@fiu.edu

DOI: $10.25148 /$ etd.FIDC001233

Follow this and additional works at: https://digitalcommons.fiu.edu/etd

Part of the Criminology Commons, and the Developmental Psychology Commons

\section{Recommended Citation}

Arndorfer, Andrea, "Increasing the Elicitation of Truthful Information from Young Suspects: An Empirical Investigation of the Effects of Temporal Discounting" (2016). FIU Electronic Theses and Dissertations. 2989.

https://digitalcommons.fiu.edu/etd/2989 


\section{FLORIDA INTERNATIONAL UNIVERSITY}

Miami, Florida

\section{INCREASING THE ELICITATION OF TRUTHFUL INFORMATION FROM YOUNG SUSPECTS: AN EMPIRICAL INVESTIGATION OF THE EFFECTS OF TEMPORAL DISCOUNTING}

A dissertation submitted in partial fulfillment of the requirements for the degree of DOCTOR OF PHILOSOPHY

in PSYCHOLOGY

by

Andrea Arndorfer 
To: Dean Michael R. Heithaus

College of Arts, Sciences, and Education

This dissertation, written by Andrea Arndorfer, and entitled Increasing the Elicitation of Truthful Information from Young Suspects: An Empirical Investigation of the Effects of Temporal Discounting, having been approved in respect to style and intellectual content, is referred to you for judgment.

We have read this dissertation and recommend that it be approved.

$\begin{array}{r}\hline \text { Jacqueline R. Evans } \\ \hline \text { Nadja Schreiber Compo } \\ \hline \text { Ryan C. Meldrum } \\ \hline \text { Lindsay C. Malloy, Major Professor }\end{array}$

Date of Defense: November 4, 2016

The dissertation of Andrea Arndorfer is approved.

Dean Michael R. Heithaus

College of Arts, Sciences and Education

Andrés G. Gil

Vice President for Research and Economic Development and Dean of the University Graduate School

Florida International University, 2016 
C) Copyright 2016 by Andrea Arndorfer

All rights reserved. 


\section{DEDICATION}

To my parents, Dana and Lauri Arndorfer, for your unfailing love, support, and sacrifice. To my siblings, Alicia, Ashley, and Adam, and their spouses, for your love, encouragement, and lessons in perseverance. To my niece and nephews, who are the best stress relief and have brought only happiness, light, and fresh perspective to my life. Finally, to my grandparents, Don and Norma Reding, Marilyn Arndorfer, and to the memory of my paternal grandfather, Bob Arndorfer, who joined the heavenly choir of angels prior to the completion of this work. I am incredibly fortunate to have you all in my life. 


\section{ACKNOWLEDGMENTS}

I wish to express my sincere gratitude to everyone who has contributed to the completion of this work and the formation of my academic career. First, to my Major Professor, Dr. Lindsay Malloy. Thank you for sharing your knowledge and for offering your guidance, encouragement, and enthusiasm throughout my graduate training. I am honored and grateful to have you as a mentor and role model professionally and personally. Second, I would like to thank my committee members, Drs. Jacqueline Evans, Nadja Schreiber Compo, Ryan Meldrum, and Zoe Klemfuss. Your insight and support on this project has been invaluable.

I must also thank my dedicated and hard-working research assistants: Juliana Almeida, Rachel Fernandez, Claudia Guerra, Caridad Hierro, Malcolme Jones, Janelle Ramcharan, Jairo Ramos, Amanda Rodriguez, Natalie Rosa, and Michelle Trujillo. Your tireless efforts, commitment, and flexibility made the completion of this project possible. I am grateful to have had the opportunity to work with and get to know each of you. I wish to extend special thanks to Michelle Trujillo, who worked on this project from beginning to end and devoted extra time and effort to scoring the Miranda measures.

It is impossible to name all of the people who have contributed to the formation of my academic career, but I would be remiss not to include the individuals who were foundational in instilling my love for psychology and psychology and the law research. Thank you to my undergraduate mentors, Drs. Stephanie Madon, Max Guyll, and Gary Wells. I am tremendously grateful for the opportunity each of you gave me to learn about research and hone my research skills during my time as an undergraduate at Iowa State University. Your guidance and support was monumental in my transition to and 
success in graduate school. Without your instruction and the opportunities you afforded me, I would not be where I am today.

To my graduate student colleagues and friends, Dana Hirn Mueller, Daniella Villalba, Jillian Rivard, Jenna Kieckhaefer, and Allison Mugno. I am grateful to have completed this adventure with such kindhearted, intelligent, and supportive friends. Our time together has been the highlight of my years as a graduate student. Thank you for bringing me joy and laughter and for making Miami feel a bit more like home.

Most importantly, I would like to thank my family. I won the lottery of life by being born into this family. Words cannot encompass my gratitude for the limitless love, support, and sacrifices of my parents, Dana and Lauri Arndorfer. Thank you for demonstrating and instilling in me strong morals, values, work ethic, and perseverance. For my whole life, you have demonstrated all the qualities necessary to be successful in life, but, more importantly, you have modeled how to be a good person. Thank you for loving me so well and for providing me with strong roots from which to grow and to which I am always eager to return. I hope I have made you proud.

Finally, special thanks to the funding agencies that made the completion of this project possible. This dissertation was supported, in part, by Florida International University’s Psychology Department Seed Fund Awards, the Florida International University College of Arts, Sciences, and Education Doctoral Evidence Acquisition Fellowship, and the American Psychology-Law Society Student Grants-in-Aid award. The monetary support provided greatly assisted with the implementation and timely completion of this research. 


\begin{abstract}
OF THE DISSERTATION
INCREASING THE ELICITATION OF TRUTHFUL INFORMATION FROM YOUNG SUSPECTS: AN EMPIRICAL INVESTIGATION OF THE EFFECTS OF TEMPORAL DISCOUNTING
\end{abstract}

by

Andrea Arndorfer

Florida International University, 2016

Miami, Florida

Professor Lindsay C. Malloy, Major Professor

The criminal justice system relies heavily on eliciting truthful information from suspects to solve crimes. A paramount problem with this approach involves the questioning of young suspects. Numerous studies support the conclusion that youth is a risk factor for providing false information during police questioning. The present study examined the influence of temporal discounting (the tendency for individual's behavior to be influenced more strongly by proximal than distal factors; Berns, Laibson, \& Loewenstein, 2007; Critchfield \& Kollins, 2001) and other developmental factors (i.e., impulse control, future orientation, and sensation seeking) thought to underlie youths' increased interrogative vulnerability. In line with previous research examining developmental differences in confession decisions, it was predicted that youth would be more likely than adults to provide false admissions to escape the immediate consequences of the situation. Furthermore, it was predicted that youth demonstrating lower impulse control, deficits in future orientation, and increased sensation seeking would be most likely to engage in this tendency. Using a randomized experimental design 205 adult and youth participants 
were questioned about their engagement in 20 criminal and unethical behaviors. Participants were told responding "yes" or "no" to these questions would have either immediate consequences (i.e., answering a series of repetitive questions) or future consequences (i.e., meeting with a police officer in a few weeks). Analyses revealed evidence of temporal discounting: Participants provided more admissions when denials, rather than admissions, were punished with immediate consequences. Contrary to hypotheses, age, impulse control, future orientation and sensation seeking did not moderate this relationship. Similarly, hypotheses regarding the relationship between age group, impulse control, and future orientation were unsupported. Compared to adults, adolescents did not exhibit less impulse control or future orientation. The current study was the first to experimentally examine factors thought to underlie youths' increased proclivity to provide false information in interrogation. Justice system involved youth may differ from youth in the current study in key ways that help explain the lack of support for study hypotheses. Because of these differences, it is imperative that future research focuses on youth who are most at risk of encountering the justice system as suspects. 


\section{TABLE OF CONTENTS}

CHAPTER

PAGE

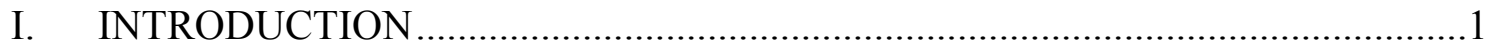

Historical Overview of Interrogation Practices .................................................. 3

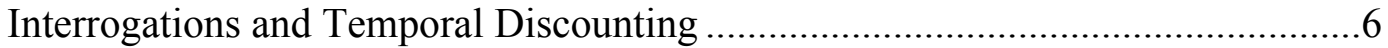

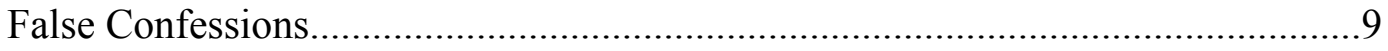

Impact of Confession Evidence …............................................................... 10

Risk Factors Associated with False Confessions..............................................13

Dispositional risk factors .............................................................. 13

Youth is a dispositional risk factor for false confession...............14

Why are youth susceptible to providing false information? ..........14

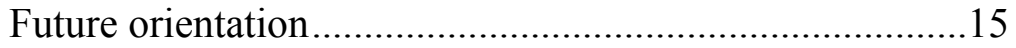

Impulse control ........................................................17

How can deficits in impulse control and future

orientation in adolescents be explained?.........................18

Experimental Laboratory Paradigms for Investigating Confession

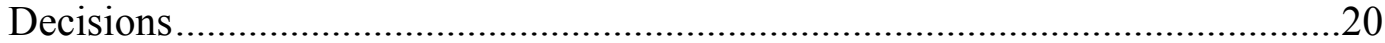

The Alt key paradigm ...................................................................21

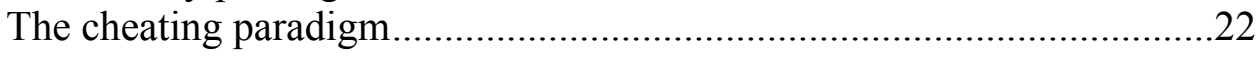

The repetitive question paradigm....................................................24

Expected Practical and Theoretical Contributions.............................................25

The Current Study ....................................................................................26

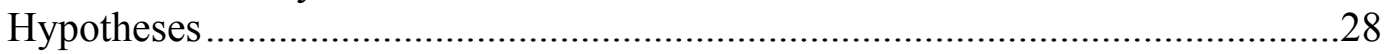

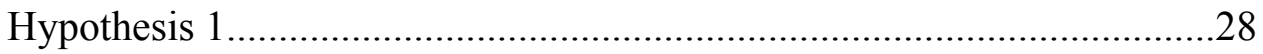

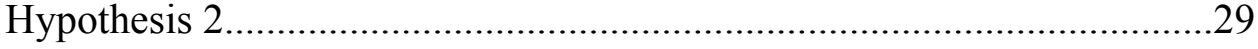

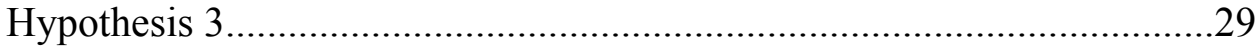

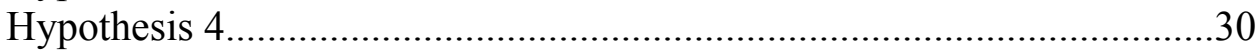

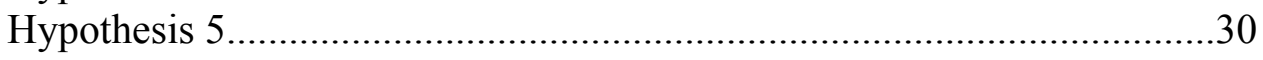

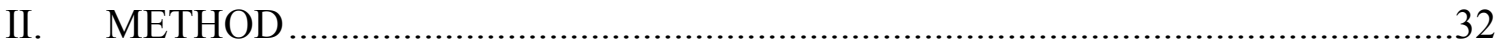

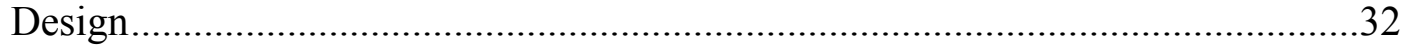

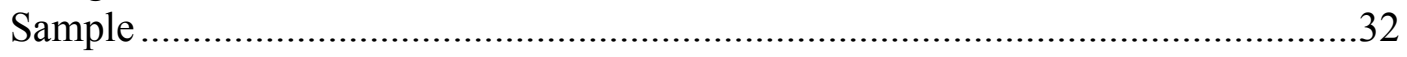

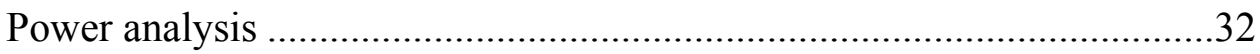

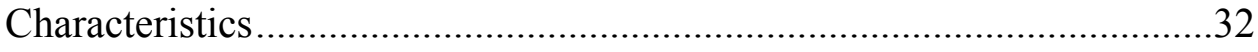

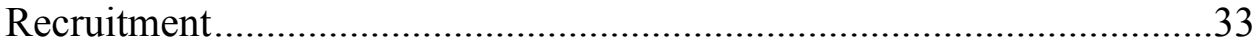

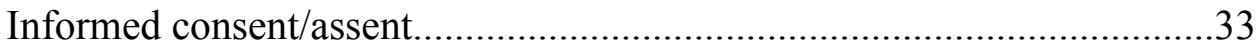

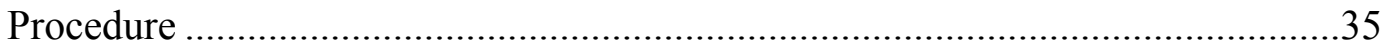

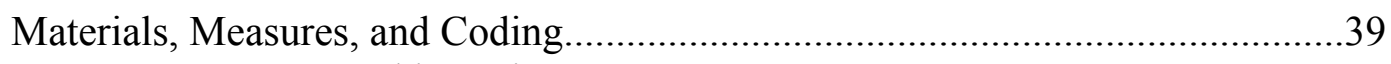

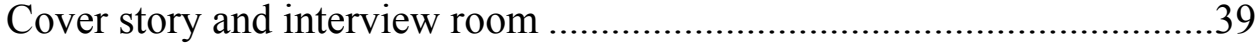

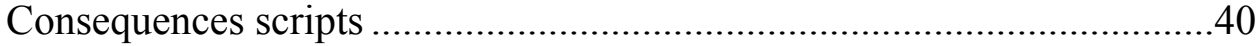

Proximal consequence: Repetitive questions.............................41

Distal consequence: Meeting with police officer.........................43 
Proximal consequence for admissions-distal consequence for denials

Proximal consequence for denials-distal consequence

for admissions

Interview questions

Measures

Counterbalancing

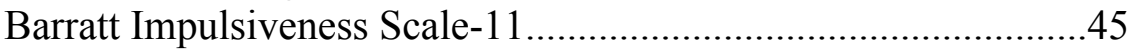

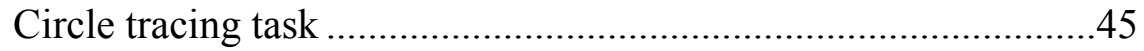

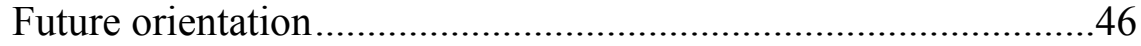

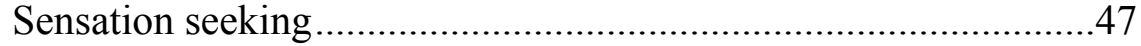

Miranda Rights Comprehension Instruments-II ..........................47

Comprehension of Miranda Rights-Recognition-II ............48

Function of Rights in Interrogation................................49

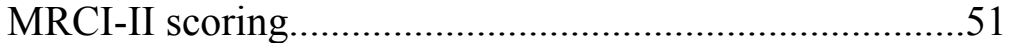

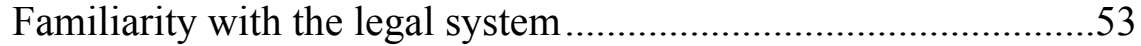

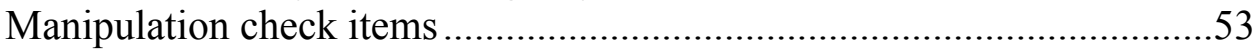

Perceived aversiveness of the repetitive questions (proximal

consequence)

Perceived aversiveness of the meeting with a police officer (distal

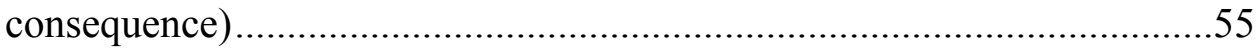

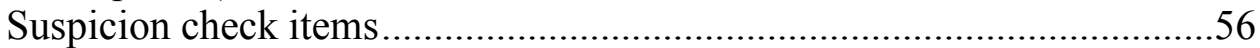

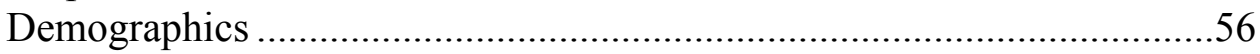

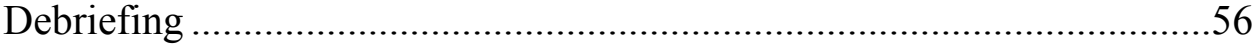

III. RESULTS

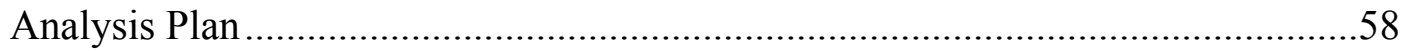

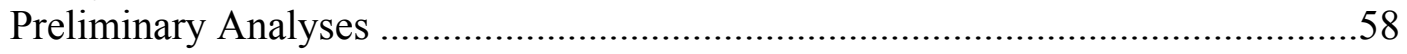

Testing normality of the dependent variable ......................................59

Assessment and removal of outliers ....................................................62

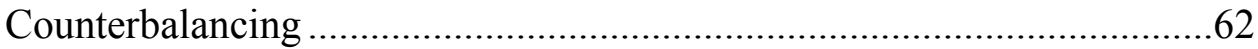

Gender.....................................................................................62

Perceived aversiveness of the repetitive questions (proximal consequence)

Perceived aversiveness of the meeting with a police officer (distal

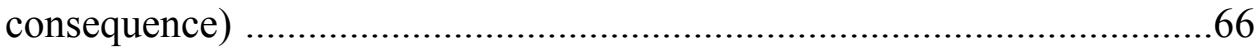

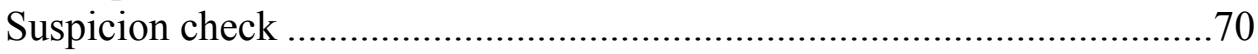

Consequences condition manipulation check .....................................71

Testing for differences between participants who were and were not excluded based on suspicion and a failed manipulation check.................72

Primary Analyses

The influence of consequences condition and age on admission decisions

The influence of consequences condition, age, and self-reported impulse control on admission decisions 
The influence of consequences condition, age, and behavioral

impulse control on admission decisions

The influence of consequences condition, age, and future orientation

on admission decisions

The influence of consequences condition, age, and sensation seeking

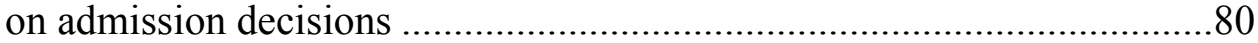

Proposed mediation analyses ...........................................................8

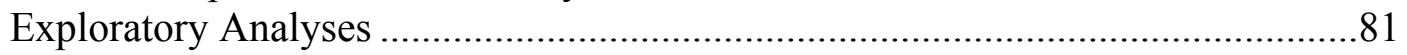

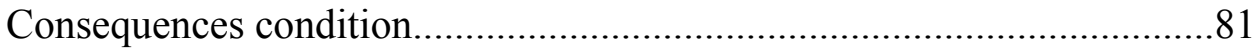

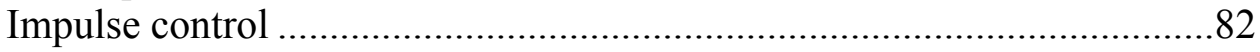

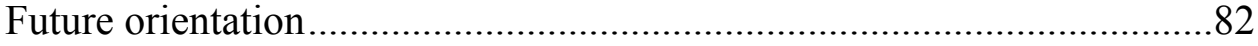

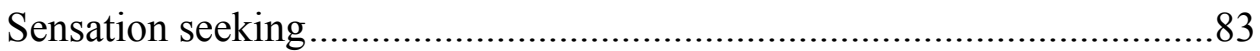

MRCI-II measures ....................................................................... 83

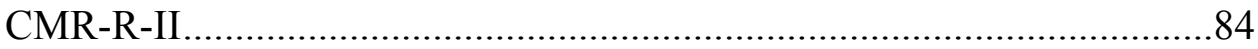

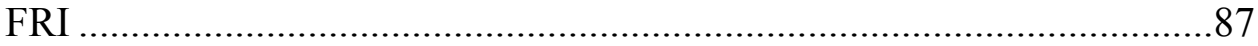

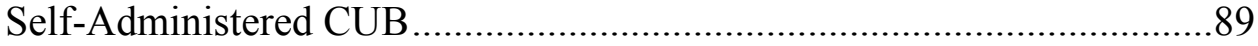

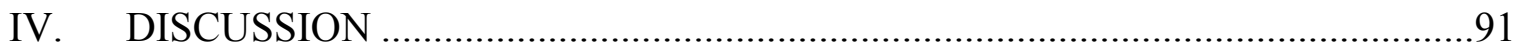

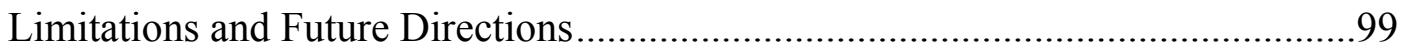

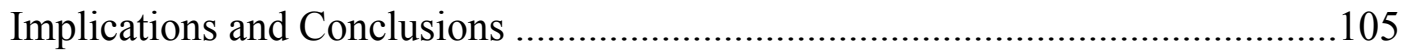

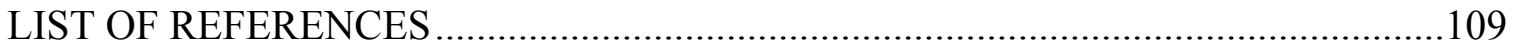

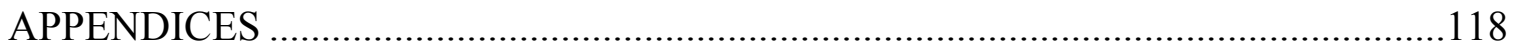

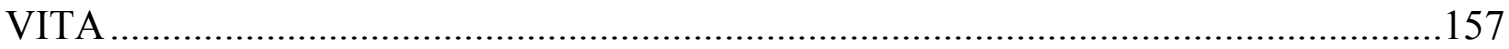




\section{LIST OF TABLES}

TABLE

PAGE

1. Sample Scoring Scheme for Function of Rights in Interrogation (FRI) 50

2. Inter-rater Reliability Estimates for the Function of Rights in Interrogation (FRI) ....52

3. Number (and Percent) of Participant Admissions to the Criminal and Unethical Behavior Interview Questions as a Function of Age Group .60

4. Means and Standard Deviations for Question Aversion Responses as a Function of Age Group and Consequences Condition

5. F Values, p Values, and Effect Sizes for Question Aversion Responses .66

6. Means and Standard Deviations for Police Aversion Responses as a Function of Age Group and Consequences Condition

7. F Values, $p$ Values, and Effect Sizes for the Police Aversion Response as a Function of Age Group and Consequences Condition.

8. The Influence of Age, Consequences Condition, and Self-Reported Impulse Control on Total Admission Decisions

9. The Influence of Age, Consequences Condition, and Behavioral Impulse Control on Total Admission Decisions

10. The Influence of Age, Consequences Condition, and Future Orientation on Total Admission Decisions

11. The Influence of Age, Consequences Condition, and Sensation Seeking on Total Admission Decisions

12. Means and Standard Deviations for the CMR-R-II Subtotals and Total Score as a Function of Age Group

13. Means and Standard Deviations for the FRI Subscales and Total Score as a Function of Age Group . 


\section{LIST OF FIGURES}

FIGURE

PAGE

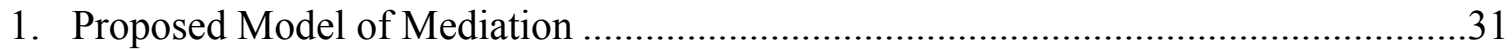

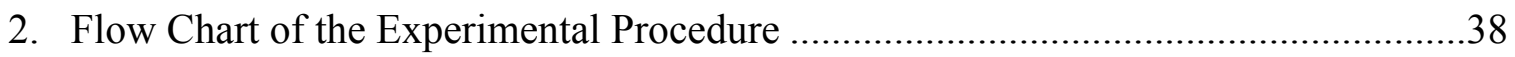

3. Mean Admissions as a Function of Consequences Condition and Age Group ...........74

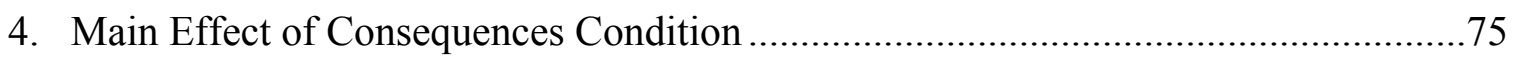

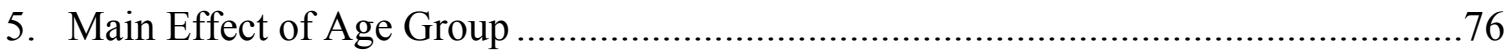




\section{ABBREVIATIONS AND ACRONYMS}

ADHD Attention Deficit Hyperactivity Disorder

BIS-11 Barratt Impulsiveness Scale-11

CMR-R-II Comprehension of Miranda Rights -

Recognition - II

CUB Criminal and Unethical Behavior

FRI Function of Rights in Interrogation

ICC Intra-class Correlation Coefficient

MRCI-II Miranda Rights Comprehension

Instruments-II

NI Nature of Interrogation

PCA-DCD Proximal Consequence for AdmissionsDistal Consequence for Denials

PCD-DCA Proximal Consequence for DenialsDistal Consequence for Admissions

RA Research Assistant

RC Right to Counsel

RS Right to Silence 


\section{INTRODUCTION}

The criminal justice system relies heavily on eliciting truthful information from suspects, often in the form of confession, as an expedient method for solving crimes. One study examining over 1,000 criminal cases found that police investigators obtained confessions from suspects in approximately $42 \%$ of interrogations (Moston, Stephenson, \& Williamson, 1992). However, a paramount problem in police interactions, especially with young suspects, is the elicitation of false information. Using various methodologies (e.g., laboratory incidents of wrongdoing, hypothetical vignettes, field studies, and analysis of DNA exoneration cases), researchers have found that youth are more susceptible to providing false information than adults, often in the form of false confession (Drizin \& Leo, 2004; Gross \& Shaffer, 2012; Redlich \& Goodman, 2003). The present study sought to understand why youth are more susceptible to providing false information during questioning about wrongdoing by examining, experimentally, characteristics of youth (e.g., poor impulse control, lack of future orientation, increased sensation seeking) possibly underlying their interrogative vulnerability.

Adolescence is an important developmental period psychologically and criminologically; it is a time when many individuals have their first encounters with law enforcement, especially as suspects to crimes (U.S. Department of Justice, Federal Bureau of Investigation, 2011, 2012). According to the Federal Bureau of Investigation's Uniform Crime Report (2013), over 700,000 juveniles were arrested between 2012 and 2013. However, this number only accounts for official arrests; many juvenile offenses go unreported and are handled informally because at times, such offenses are considered to be part of the normative process of adolescent maturation (Office of Juvenile Justice and 
Delinquency Prevention Statistical Briefing Book, n.d.). Youths' involvement with police could be attributed, in part, to increases in sensation seeking, low impulse control, and decreased consideration of the future or long-term consequences of one's behavior during this developmental time period (Steinberg, 2008, 2009; Steinberg et al., 2009). Many juveniles are also informally questioned by law enforcement, thereby increasing the opportunities for juveniles to provide false information. Perhaps the most striking finding in the interrogation literature is the overrepresentation of youth in proven false confession cases (i.e., youth comprised one third of the sample in one study; Drizin \& Leo, 2004). Furthermore, recent research suggests that a significant number of incarcerated 14- to 17 -year-olds indicate having falsely confessed to police (17\%) or having made a false guilty plea (18\%) at least once (Malloy, Shulman, \& Cauffman, 2014). Consequently, determining strategies and tactics to elicit the maximum amount of truthful information from young suspects is critical for exonerating the innocent and apprehending the guilty.

For several decades, there has been increased concern surrounding how young victims and witnesses are questioned; however, only recently has similar concern emerged about how youth are interrogated as suspects (The International Association of Chiefs of Police, 2012). Modern police interrogations are, by design, psychologically manipulative, stressful, and intimidating (see Kassin et al., 2010; Lassiter \& Meissner, 2010; Leo, 2008, for reviews). These modern tactics may be particularly likely to elicit false information and confessions from juveniles who, in comparison to adults, may: (1) have diminished capacity to regulate and suppress the expression of self-incriminating statements, (2) overvalue the immediate benefits of escaping the aversive interrogation 
situation, and (3) discount the potential for the aversive situation to continue in the future. Consequently, this study was driven by three main objectives. Specifically, the current study used a standardized experimental paradigm to examine the influence of (1) age (youth vs. young adults vs. older adults), (2) temporal discounting (the consideration of immediate vs. future rewards), and (3) factors characteristic of youth development (i.e., impulse control, future orientation, and sensation seeking) on individuals' decisions to provide true and false admissions during questioning. Each objective and the importance of its inclusion will be discussed in the sections that follow.

\section{Historical Overview of Interrogation Practices}

Historically, it was not uncommon for police to resort to physical violence (traditionally called "the third degree"; e.g., burning suspects with cigarettes; giving suspects electric shocks; twisting suspects' testicles; beating suspects with fists, guns, rubber hoses, etc.; dragging or lifting female suspects by their hair) and brutality to extract confessions from suspects (Leo, 2008). However, in 1931 a government commission issued a report (Report on Lawlessness in Law Enforcement) documenting these abuses. The report received much negative press and attention leading police investigators to abandon overt forms of physical abuse for more covert abuse and psychological coercion (e.g., pushing suspects' head into the toilet; forcing suspects to stand upright for hours; depriving suspects of sleep; physically isolating suspects from other individuals and the outside world; withholding food, water, and bathroom privileges). Several legal decisions in the early 1960s (see Culombe v. Connecticut, 1961; Davis v. North Carolina, 1966; Reck v. Pate, 1961; Townsend v. Swain, 1963) moved investigators away from physical brutality towards more purely psychologically 
manipulative techniques. Consequently, at present, confessions are generally ruled to be inadmissible if they have been acquired as a result of physical force, sleep and/or food deprivation, prolonged periods of isolation, explicit threats of violence, clear promises of leniency, and explicit promises of immunity from prosecution.

Modern day police investigators are allowed to employ a wide berth of tactics in the interrogation room. Many police officers and investigators have been trained in the Reid Technique - the most popular interrogation technique in the United States (Inbau, Reid, Buckley, \& Jayne, 2013; Kassin, 2008). The two stage interrogation technique is designed to instill a sense of loss of control in suspects and to increase suspects' feelings of vulnerability and anxiety. In the first stage, the Behavior Analysis Interview (BAI), investigators question suspects and observe both nonverbal and verbal behavior to determine whether they believe the suspect is being deceptive (Inbau et al., 2013). Police investigators do not move on to the second phase - the actual interrogation - if the suspect is classified as an innocent truth teller. However, if the suspect is classified as deceptive (and presumably guilty) investigators are then to seamlessly transition into a three-pronged (nine-step) interrogation approach.

The interrogation consists of three stages 1) custody and isolation, 2) confrontation, and 3) minimization of the crime and severity of the associated consequences (Kassin \& Gudjonsson, 2004). In the first step, investigators are advised that, once in custody, the suspect be isolated (from family, friends, co-workers, or any source of social or emotional support) and placed in a small, private, mostly empty room. Interrogators are instructed to begin the interrogation by confronting the suspect with a direct, accusatory statement of guilt ("We know you did this.") and are encouraged to 
support the accusations with the presentation of real or fabricated evidence ("We have an eyewitness who reported seeing you at the scene of the crime."). Furthermore, the investigator is to reject and silence all pleas of innocence (e.g., by interrupting and cutting the suspect off or by putting up their hand and turning away from the suspect as an indication to the suspect that $\mathrm{s} / \mathrm{he}$ should stop speaking). At this time, investigators may also employ maximization techniques (Kassin \& McNall, 1991). That is, accusations of guilt may be accompanied by exaggeration of the severity of the offense and exacerbation of the likelihood of the suspect receiving a harsh sentence if $\mathrm{s} / \mathrm{he}$ does not confess and is found guilty at trial (e.g., life imprisonment without the possibility of parole, the death penalty).

The Reid technique also encourages investigators to employ minimization techniques. Minimization techniques involve offering sympathy, face saving excuses, and moral justifications to the suspect regarding their role in the commission of the crime (e.g., "I'm sure you didn't mean to do it."; "If I were in your shoes, I may have done the same thing."; "I'm sure you didn't realize what a big deal this would be."). These strategies are designed to gain the suspect's trust and to have them view the police officer as being "on their side" while simultaneously minimizing the seriousness of the crime and potential consequences of confessing. Investigators end the interrogation by asking the suspect for a confession and to provide a detailed account of what happened (Kassin \& Gudjonsson, 2004).

Researchers have identified several concerning aspects of the Reid technique (see Drizin \& Leo, 2004; Kassin, 1997). A primary criticism is that, whereas this confrontational and accusatorial approach successfully elicits true confessions from 
guilty suspects, it also puts innocent suspects at risk for offering false confessions (Kassin et al., 2010).

While the methods used to interrogate suspects have changed over the decades (moving from physical torture to psychological coercion), the underlying structure of interrogation, whereby admissions are rewarded in the short-term (i.e., escaping the stressful interrogation), denials are continually punished (i.e., remaining in the stressful interrogation) and future outcomes are minimized or dismissed from discussion, has remained unchanged. It is the mechanisms underlying the interrogation process and practices that may be putting youth at disproportionate risk, for providing false confession. One such potential mechanism is temporal discounting.

\section{Interrogations and Temporal Discounting}

Psychology and law researchers have long speculated that suspects' tendency to prioritize short-term over long-term consequences and outcomes could increase suspects' risk for confession and subsequent conviction. In fact, many interrogation tactics are associated with proximal consequences that encourage suspects to confess. For example, the primary method utilized for police interrogation (i.e., the Reid Technique; Inbau et al., 2013) instructs that suspects should be isolated in a small room and seated in uncomfortable, straight-backed chairs. Furthermore, suspects are to be subjected to accusatorial and confrontational questioning. This is all by design. Suspects may confess because they believe that doing so will conclude the interrogation thus allowing them to escape this aversive and uncomfortable situation. Subsequently, distal consequences associated with confessing (e.g., possible conviction, incarceration, or even execution) encourage suspects to deny guilt and are often purposely minimized in most 
interrogations. However, should suspects fall prey to the natural tendency to value immediate rather than future outcomes, they are simultaneously putting themselves at risk for experiencing more severe distal consequences.

Drawing on this principle, Madon and colleagues $(2012,2013)$ developed an experimental mock interrogation paradigm to investigate the influence of temporal discounting on decision making in interrogation. The proposed research will utilize Madon and colleagues' novel paradigm as outlined below.

The tendency for individual's behavior to be influenced more strongly by proximal than distal factors is known as temporal discounting (Berns, Laibson, \& Loewenstein, 2007; Critchfield \& Kollins, 2001). The principle of temporal discounting is a well-established theory across disciplines (e.g., decision making, learning) within the psychological literature. However, for the purposes of the current study, its application in cognitive psychology, particularly in the realm of decision making, is most applicable. For example, decision theory indicates that people perceive immediate consequences to be more important than distal consequences (Björkman, 1984). That is, humans' cognition for distal events and consequences is limited in that their main focus is on the 'here and now' - if there is no benefit to be gained from waiting, individuals will prefer immediate versus delayed gratification. For instance, if money is placed into a savings account but there is no interest accrued on the money, then there is no benefit to leaving the money in the account and waiting to spend it later. Thus, individuals may choose to withdraw the money and spend it on immediate expenses. However, if interest will be accrued on the money, thus resulting in an increase in the total balance over time, 
individuals will gain more money by leaving the money in the bank and saving it for future expenses.

Similarly, research examining decision making strategies indicates that people judge proximal outcomes as more certain than distal outcomes (Kalenscher \& Pennartz, 2008; Rachlin, Logue, Gibbon, \& Frankel, 1986). Furthermore, according to prospect theory, people tend to give greater weight to outcomes that are certain rather than probabilistic, and, thus are more influenced by the proximal consequences associated with their decisions than distal ones (Kahneman \& Tversky, 1979). Perceiving proximal consequences as more certain may explain why immediate consequences are judged to be more important than distal consequences. Specifically, individuals may be more willing to incur, in some circumstances, an immediate consequence because it is a 'sure thing' over the possibility of unknown or potentially changing distal consequences. For example, suspects may be more willing to take a plea deal guaranteeing them 6 years in prison instead of opting to go to trial, of which the resulting consequences are uncertain (e.g., going to trial could result in the suspect being found not guilty and avoiding punishment altogether or could result in the suspect being found guilty and sentenced to a more severe sentence than that offered in the plea deal).

In sum, a body of extant research supports the phenomenon of temporal discounting and its influence on human decision making and behavior. These theories may be applicable in understanding suspect decision making in interrogation, particularly the decision to falsely confess. 


\section{False Confessions}

Police interrogation is a guilt presumptive process in which the primary goal is to obtain incriminating information from guilty suspects (Drizin \& Leo, 2004). While police interrogation usually elicits true confessions from guilty suspects, over the last decade, there has been a growing concern that the methods used during interrogation to obtain true confessions also put innocent suspects in danger of falsely confessing (OwenKostelnik, Reppucci, \& Meyer, 2006).

It is impossible to determine the precise prevalence of false confessions. However, we can look to real-world exoneration cases and field research to inform our understanding. Over 340 convictions have been overturned as a result of DNA evidence (Innocence Project, n.d.). Of those DNA exoneration cases, at least $28 \%$ have cited the proffering of self-incriminating statements, often in the form of false confession or false guilty plea, from innocent suspects as a contributing factor leading to the wrongful conviction (Innocence Project, n.d.). In light of such evidence, it is imperative to construct methods that elicit true confessions from guilty suspects while reducing or eliminating the likelihood of eliciting false confessions from innocent suspects.

One method for assessing the prevalence of false confession is to rely on selfreport data. Self-report studies use individuals' own reports of whether they have or have not falsely confessed to a past crime. Reports of alleged false confessions gathered from over 35,000 Icelandic youth, revealed that between $7 \%-14 \%$ of students who had been questioned by police as suspects claimed to have falsely confessed (Gudjonsson, Sigurdsson, Asgeirsdottir, \& Sigfusdottir, 2006; Gudjonsson, Sigurdsson, \& Sigfusdottir, 2009). Similar findings emerged for a sample of Danish youth with $7 \%$ claiming to have 
falsely confessed to police in the past (Steingrimsdottir, Hreinsdottir, Gudjonsson, Sigurdsson, \& Nielsen, 2007).

Researchers have also investigated reports of self-reported false confessions amongst incarcerated adult and adolescent offenders. Twelve percent of adult offenders in one Icelandic prison claimed to have falsely confessed to police with female offenders claiming higher rates of false confession than males (Gudjonsson \& Sigurdsson, 1994). Recently, research has begun to examine the prevalence of false confessions among incarcerated adolescent offenders. Two recent studies revealed that between $6 \%$ (Viljoen, Klaver, \& Roesch, 2005) and 17\% (Malloy et al., 2014) of serious adolescent offenders had reported past false confessions to police. While self-report studies are accompanied by certain limitations (e.g., ground truth is unknown, claims of both true and false confessions often cannot be verified), this research provides some insight into the prevalence of real-world false confessions.

As highlighted next, confession evidence, even if false, is accorded extraordinary weight at trial. Even more alarming is the fact that true and false confessions are often virtually indistinguishable (Kassin, Appleby, \& Perillo, 2010; Kassin, Meissner, \& Norwick, 2005) meaning that jurors cannot simply siphon out false confessions themselves. It is precisely for these reasons that it is paramount to acquire a better understanding of confession evidence.

\section{Impact of Confession Evidence}

Confession evidence is amongst the most damning evidence presented at criminal trial (Kassin et al., 2010; Drizin \& Leo, 2004), having greater impact on juror decision making than eyewitness and character testimony (Kassin \& Neumann, 1997). Even the 
United States Supreme Court has deemed confessions to be one of the most persuasive and condemning forms of evidence presented at criminal trials (Miranda v. Arizona, 1966). All the more striking is the fact that jurors fail to discount confession evidence even when they have concluded that the confession was coerced or given involuntarily (i.e., the confession was likely a false self-incriminating admission of guilt; Kassin \& Sukel, 1997; Kassin \& Wrightsman, 1980).

There are two primary reasons concerning why jurors are unable or unwilling to discount confession evidence when making verdict decisions even after recognizing that the confession was given as a result of coercion or duress. First, humans (including experienced police officers and interrogators) are poor detectors of deception with only chance levels of accuracy when judging the veracity of true and false admissions of guilt (Bond \& DePaul, 2006; Honts, Kassin, \& Craig, 2014; Kassin et al., 2005; Vrij, 2008). Second, humans have difficulty understanding why someone would confess to often quite heinous criminal acts if they had not committed the act. In other words, individuals tend to quickly and automatically make dispositional inferences for others' behavior (e.g., he confessed because he is guilty) but have difficulties considering and accounting for situational factors influencing that same behavior (e.g., he confessed because the police officer was threatening him with severe consequences). In social psychological terms, individuals make the fundamental attribution error (i.e., the tendency for individuals to overestimate the influence of dispositional factors and underestimate the influence of situational factors on others behavior; also known as correspondence inference theory; Jones \& Harris, 1967) when judging claims of suspects having made a false confession. 
Confessions are not only powerful in their own right but also have the power to corrupt perceptions and taint interpretations of other evidence. A handful of studies have shown that knowledge that a suspect has confessed influences experts and laypeople alike. In one study, participants were exposed to a mock crime and were later asked to identify a suspect from a photo lineup array. Participant witnesses returned to the laboratory one week later and were told that the person they had identified had either denied guilt, confessed, or that another lineup member, one that they had not identified, had confessed. Witnesses were then exposed to the photo lineup array again. A significant portion of witnesses changed their original identification decision to select the individual they were told had confessed and did so with high levels of confidence (Hasel \& Kassin, 2009). In two studies, researchers discovered that confession evidence could taint participants' perceptions of handwriting evidence (Kukucka \& Kassin, 2014). Participants who were told that a suspect had confessed were more likely to erroneously conclude that two handwriting samples were authored by the same individual (all handwriting samples used for comparison were authored by different individuals) even when the samples were rated as dissimilar.

Unfortunately, even professional forensic evidence experts are not immune to the influential power of confessions. In one study fingerprint experts were given a pair of fingerprints that they had previously accurately ruled as a match or exclusion years earlier. Unknowingly, experts were presented with these same prints, and, when told that the suspect had confessed, this misinformation produced a change in $17 \%$ of experts' original previously correct judgments (Dror \& Charlton, 2006). Because confession evidence is heavily weighted and because false confessions are associated with negative 
consequences for the alleged suspect, numerous research studies have highlighted the conditions - situational and dispositional - putting suspects at increased risk of confessing and incurring the negative consequences associated with doing so.

\section{Risk Factors Associated with False Confessions}

Previous literature on interrogations and confessions has largely focused on and revealed the specific techniques that are likely to elicit confessions. For example, research has revealed lengthy interrogations (Drizin \& Leo, 2004; Madon, Yang, Smalarz, Guyll, \& Scherr, 2013), the presentation of false evidence (Kassin \& Kiechel, 1996), physical isolation of the suspect (Drizin \& Leo, 2004), the offering of a deal (Russano, Meissner, Narchet, \& Kassin, 2005), the use of minimization tactics (e.g., minimizing the severity of the crime, using face saving techniques; Russano et al., 2005), among others, to increase the likelihood of eliciting a false confession (Kassin et al., 2010). While it is important to be aware of the specific tactics that enhance the risk of eliciting false confessions, a paucity of research has focused on the processes underlying the elicitation of confessions, and, thus, little is known about the general mechanisms underlying individuals' confession decisions.

Dispositional risk factors. A dispositional risk factor is something inherent in the individual being interrogated that makes him or her vulnerable to providing a false confession (Perillo \& Kassin, 2011). Three broad categories encompass dispositional risk factors for false confession: age, cognitive and intellectual disabilities, and personality and psychopathology (Kassin et al., 2010). The current study will primarily focus on youth as a dispositional risk factor for false confession. 
Youth is a dispositional risk factor for false confession. Multiple methodologies reveal a consistent finding: Youth is a dispositional risk factor for false confession (Drizin \& Leo, 2004; Redlich \& Goodman, 2003; Goldstein, Condie, Kalbeitzer, Osman, \& Geier, 2003; Malloy et al., 2014). For example, adolescents comprised 1/3 of the first 125 proven false confessions (Drizin \& Leo, 2004). Furthermore, in the National Registry of Exonerations (Gross \& Shaffer, 2012), adolescents were over five times $(42 \%)$ more likely to have provided a false confession than adults $(8 \%)$. While it is impossible to determine the precise prevalence of false confessions, a recent study found that $17 \%$ of 14 - to 17 -year-olds incarcerated in the U.S. reported having falsely confessed to police (Malloy et al., 2014).

Multiple experimental laboratory interrogation studies involving minor incidents of wrongdoing have been conducted with youth (Pimentel, Arndorfer, \& Malloy, 2015; Redlich \& Goodman, 2003). Unfortunately, knowledge of age as a risk factor for providing false confession does not reveal specifically why youth are more likely to falsely confess. General developmental research has revealed a number of cognitive (e.g., lack of future orientation, poor impulse control) and social (e.g., deference to authority, increased peer orientation) characteristics of youth that may contribute to youths' increased propensity to falsely confess. However, to date, no known research has been conducted to determine precisely what factor or factors influence youths' increased interrogative vulnerability.

Why are youth susceptible to providing false information? Developmental psychologists have identified various factors differentiating youth from adults which appear to put youth at increased risk in legal contexts, including when questioned by 
police as suspects (Steinberg, 2009, 2014). Only one known study has examined possible factors underlying youths' increased willingness to provide false information (Redlich \& Goodman, 2003). In this study, researchers examined the influence of suggestibility on internalized false confessions (i.e., when suspects actually come to believe they committed the crime in question; Kassin et al., 2010) of a laboratory wrongdoing (i.e., pressing a forbidden key $\mathrm{n}$ a computer task). Developmental characteristics like impulse control, future orientation, and sensation seeking, which are investigated in the current study, constitute more hallmark characteristics of adolescence. Furthermore, it is possible that impulse control, future orientation, and sensation seeking, rather than suggestibility, may better explain police induced false confessions (i.e., when suspects, due to the pressures of interrogation, are induced to confess to a crime they did not commit; Kassin et al., 2010). The focus of the current study was, in part, to identify factors contributing to interrogative vulnerability in police interrogation. Thus, in contrast to Redlich and Goodman, this study addressed police induced rather than internalized confession decisions.

Future orientation. One potentially crucial factor for adolescents' behavior and decision making in interrogation contexts is their documented lack of future orientation. Research indicates that adolescents weigh rewards differently than adults. Specifically, behavioral and neuroscience research has revealed that, compared to adults, adolescents' decisions are largely driven by gaining potential rewards as opposed to avoiding potential risks (Furby \& Beyth-Marom, 1992; Steinberg, 2009). Furthermore, compared to adults, adolescents are prone to making more short-sighted, risky decisions without adequate consideration for future consequences. For example, when adolescents' perceptions of 
the short- and long-term pros and cons of engaging in various risky behaviors were assessed (e.g., risks associated with unprotected sex; Steinberg \& Scott, 2003), adolescents tended to discount the future consequences (e.g., pregnancy) more than adults and put more weight on the short-term consequences (e.g., pleasure) of their decisions. Also, 10- to 15-year-olds demonstrate weaker future orientation than adolescents 16 and older (Steinberg, 2009). Deficits in future orientation may, in part, be due to underdevelopment of adolescents' brains in regions associated with impulse control and risk-taking (Steinberg, 2008; 2009). Research has shown that the ability to evaluate future outcomes increases with age (Cauffman \& Steinberg, 2000) with adolescents giving more weight to immediate, rather than delayed, outcomes (Steinberg, 2009).

The orientation to immediate outcomes may put young suspects at increased risk in the interrogation room. Consistent with the temporal discounting principle, compared to adults, adolescents may make self-incriminating statements simply because they overvalue the proximal consequence of escaping an aversive, stressful situation more than the distal consequences associated with continued denials (Drizin \& Leo, 2004; Owen-Kostelnik et al., 2006). This likely does not occur because adolescents blatantly disregard distal consequences, but because there are cognitive limitations on adolescents' abilities to realistically consider events that might occur sometime in the future.

The nature of police interrogation, whereby admissions are rewarded in the shortterm (i.e., escaping the stressful interrogation) and denials are continually punished (i.e., remaining in the stressful interrogation), may disproportionately affect youth. As discussed, Madon and colleagues $(2012,2013)$ developed an interrogation paradigm to investigate the possibility that temporal discounting serves as a mechanism underlying 
the elicitation of false information in interrogation. Their findings supported this supposition: When questioned about their engagement in a variety of criminal and unethical behaviors, young adults altered their responses so as to avoid the proximal consequence even though doing so put them at increased risk of incurring a more severe distal consequence (Madon et al., 2012, 2013). Adolescents, because of developmental deficits in future orientation, may be even more likely to avoid incurring undesirable proximal consequences in favor of potentially more severe distal consequences.

Impulse control. Another influential factor may be impulse control. Adolescents' diminished capacity to self-regulate and suppress their impulses may become exacerbated during police questioning. Compared to adults, adolescents may be at an increased propensity to make false self-incriminating statements due to the taxing nature of interrogation and the continual weakening of their already limited impulse control. As questioning continues, adolescents may be less able to persistently deny and override the impulse to provide the response police desire from them (i.e., an admission of guilt). Consequently, this process may result in the provision of false information. No known research has specifically investigated impulse control as it relates to decision making in interrogation.

Suspects who are both young and experience deficits in impulse control may be especially vulnerable to providing false information in the interrogation room. Research on one population of adolescents known to experience substantial reductions in impulse control as a core deficit of their disorder (i.e., those with Attention Deficit Hyperactivity Disorder; ADHD) has revealed that these youth engage in higher rates of criminal behavior (Sibley et al., 2012), substance use (Molina, Pelham, Gnagy, Thompson, \& 
Marshal, 2007), school drop-out (Kent et al., 2011), and early sexual behavior (Flory, Molina, Pelham, Gnagy, \& Smith, 2006). Research has shown that individuals with ADHD self-report having falsely confessed more than individuals without ADHD (Gudjonsson, Sigurdsson, Bragason, Newton, \& Einarsson, 2008; Gudjonsson, Sigurdsson, Sigfusdottir, \& Young, 2012). The current study sought to advance our understanding of factors characteristic of youth development with typically developing youth. Should findings emerge with the typically developing adolescents used in this study, one could only imagine that the effect would be even stronger with populations at increased risk of becoming involved with and over-represented in the criminal justice system (e.g., individuals with ADHD, intellectual disabilities, and mental illness). In fact, even justice involved youth without a clinical diagnosis of ADHD, have been found to exhibit poor impulse control (DeLisi \& Vaughn, 2007).

How can deficits in impulse control and future orientation in adolescents be explained? Numerous studies concerning adolescent development have involved behavioral research; however, more recent work has been grounded in developmental neuroscience in the hopes of revealing the neurological underpinnings of development across the life stages (Steinberg, 2009). Although the present research will not focus on adolescent brain development, neuroscientific and neurobiological evidence are discussed to provide explanations for how deficits in impulse control, future orientation, and sensation seeking may contribute to adolescents' increased interrogative vulnerability compared to adults.

Two main processes occur in adolescents' brains which likely influence adolescents' decision-making and their subsequent likelihood of engaging in deviant 
behaviors. First, around the onset of puberty, a rapid increase in dopaminergic activity occurs which is thought to increase reward seeking behavior (Steinberg, 2009). When coupled with deficits in areas of the brain that are thought to serve self-regulatory and impulse control functions, the rapid increase of dopaminergic activity leads to an increased likelihood of risk taking, particularly during the period of middle adolescence (Steinberg, 2009). Second, changes in brain structure and functioning occur during adolescence which are not complete until early adulthood. Specifically, improved connectivity across brain regions and maturation of the frontal lobes result in improved thinking abilities (Steinberg, 2009). However, the maturation of self-regulatory and impulse control functions and of the frontal lobes occur at different periods during adolescence, and, thus, have different implications for cognitive development (Steinberg, 2009).

The interaction of these two brain development processes, often result in an increase in sensation seeking in early to mid-adolescence. Concomitant self-regulatory processes needed to combat this drive do not reach full development until late adolescence or early adulthood (Steinberg, 2009). Because these processes develop asynchronously, adolescence may be a particularly vulnerable time period. For example, adolescents in interrogation may desire a lengthy, psychologically manipulative interrogation to end due to increased activation of areas associated with reward sensitivity. Because the brain regions associated with cognitive control are not fully developed in adolescents, young suspects may be unable to override impulses seeking reward fulfillment to end the interrogation by providing police with the desired response - a confession. Hence, this combination of developmental factors may result in 
adolescence being a developmental period characterized by immature judgment and decision-making, which may contribute, in part, to adolescents' heightened interrogative vulnerability.

The rate at which these two systems - those associated with increased sensation seeking, risk taking, and cognitive regulatory mechanisms - develop, specifically the gap that exists between the onset of one and the maturation and initiation of the other, continues to influence individuals into adulthood (Steinberg et al., 2008). One study examining self-reported and behavioral risk taking, sensation seeking, and impulsivity in individuals between the ages of 10 and 30, found increases in sensation seeking were more prominent in individuals between the ages of 12 and 15. However, increases in the ability to control those impulses was still undergoing development throughout adolescence and into young adulthood (Steinberg et al., 2008). Consequently, in order to detect differences in the influence of future orientation and impulse control on the decision to confess, research employing experimental laboratory methods with youth and both young and older adults is needed to provide insight into the influence of these deficits on confession decisions. Unfortunately, current interrogation and confession research has sampled from a rather limited age range.

\section{Experimental Laboratory Paradigms for Investigating Confession Decisions}

Because ground truth cannot be verified in self-report studies, nor can researchers attempt to induce suspects of actual crimes to falsely confess for experimental purposes, it is imperative to study the phenomenon of false confessions using experimental laboratory analogue paradigms. Accordingly, multiple standardized mock interrogation

paradigms have been designed to investigate and assess the prevalence of and the factors 
contributing to false confessions of wrongdoing (Kassin \& Kiechel, 1996; Russano et al., 2005). Currently, there are three experimental paradigms for investigating false confessions behaviorally in the laboratory.

The Alt key paradigm. Kassin and Kiechel (1996) provided the first experimental evidence that individuals could be induced to confess to an act of wrongdoing that they did not commit with their well-known "Alt key paradigm." In this study, adult participants were paired with a confederate for the purposes of completing a typing experience task. All participants were explicitly warned prior to beginning the typing task that they were not to hit the Alt key as doing so would result in the computer crashing and all data being lost. Although none of the participants actually pressed the Alt key, the computer was designed to automatically crash during the typing task. All participants were then accused of failing to heed to the experimenter's warning and causing the computer to crash. Sixty-nine percent of participants eventually falsely confessed to pressing the Alt key and causing the computer to crash. A later derivation of this study, conducted with both adult and adolescent participants, observed a similar overall confession rate (69\%) across all participants (Redlich \& Goodman, 2003). Moreover, this study revealed that youth were in fact more vulnerable to providing false admissions of guilt than adult participants. Specifically, approximately $75 \%$ of youth (78\% of 12 - to 13 -year-olds and $72 \%$ of 15 - to 16 -year-olds) falsely admitted guilt compared to $59 \%$ of adults.

While the Alt key paradigm generally represents an important first step in the experimental investigation of interrogation proceedings and outcomes, the paradigm has several limitations and fails to adequately portray real-world interrogation and confession 
situations. First, all participants were factually innocent which prohibited the assessment of diagnosticity through the comparison of true and false confessions, as all confessions elicited were false confessions. Second, participants were unsure as to whether they were innocent or guilty due to "accidentally" committing a highly plausible "crime." This is not reflective of real-world commission of crimes. Suspects in the real world are typically accused of intentionally committing a crime and are aware of their culpability. Another issue is that ground truth was unknown. That is, researchers had no way of knowing whether some participants did, in fact, hit the Alt key and were providing true confessions as researchers gathered no evidence of the keystrokes made during the typing task. Finally, there were no consequences associated with providing a confession (but see Redlich \& Goodman, 2003). In other words, in direct contrast to real world interrogations (in which serious consequences exist for those who admit to their involvement in a crime), participants in this study had nothing to lose by providing a confession. While Alt key paradigm provided a significant advance in the field and the first model for evaluating false confessions in the laboratory, it was evident that a more ecologically valid experimental paradigm was needed.

The “cheating" paradigm (Russano et al., 2005). Almost a decade later, a novel paradigm for examining true and false confessions in the laboratory was developed. This paradigm was designed to improve upon the limitations of the Alt key paradigm (Kassin \& Kiechel, 1996). First, this paradigm created a situation whereby participants could be randomly assigned to guilt or innocence, which allowed for the assessment of confession diagnosticity. Second, participants committed an intentional act of wrongdoing and thus were aware of their guilt status (i.e., whether they were guilty or 
innocent of the act of wrongdoing). Finally, participants were led to believe that severe consequences would result from providing a confession. Specifically, engaging in and confessing to this act had the potential to result in expulsion from the university, which is a very serious consequence for college students. This experimental mock interrogation paradigm provided the first empirical evidence that true and false confessions to an intentional act of wrongdoing could be elicited in the scientific laboratory.

In the cheating paradigm, participants arrived to the lab with a confederate under the guise of completing a logic problem task. An experimenter instructed the participants that some of the logic problems were designated as individual problems to be completed alone and others were designated as group problems to be solved together. During the problem solving phase of the experiment, confederates asked participants randomly assigned to be guilty for help on one of the problems that was to be solved individually, thereby violating a major experimental rule. Confederates never asked participants randomly assigned to be innocent for help on any of the individual problems (therefore the rules of the experiment were not violated). This manipulation induced some, but not all, participants to intentionally commit a "crime." All participants were later accused of "cheating" on one of the logic problems that was designated to be solved individually. Using a variety of interrogation tactics (some legal and others illegal for use in real-world police interrogations), all participants (regardless of guilt or innocence) were accused of having the same wrong answer on a problem that was to be solved individually, were told the violation of study procedures could result in expulsion, and were asked to sign a statement admitting to their involvement in the "cheating" incident. Nearly $20 \%$ of innocent participants falsely confessed to breaking the experimental rules. The rate of 
both true and false confessions increased when legal (e.g., minimizing the seriousness of the crime) and illegal (e.g., making explicit promises of leniency) interrogation tactics were used in combination. Diagnosticity was highest when neither legal nor illegal interrogation tactics were used and lowest when both were used in combination.

The cheating paradigm (Russano et al., 2005) has many advantages over its predecessor. However, this paradigm is not particularly well-suited for examining the possible influence of temporal discounting on confession decisions in interrogation, which is the primary goal of the proposed study.

The repetitive question paradigm (Madon et al., 2012). Drawing on the principle of temporal discounting (i.e., that proximal consequences influence behavior more than distal consequences), researchers (Madon et al., 2012) developed a novel experimental mock interrogation paradigm specifically to investigate the influence of temporal discounting on decision making in interrogation. In this paradigm, participants were questioned about their engagement in various criminal and unethical behaviors. Depending on experimental condition, denials or admissions were punished with the proximal (immediate) consequence of answering a set of repetitive questions. The distal (future) consequence was an increased likelihood of meeting with a police officer to discuss responses in depth at a later point in time. Consistent with the temporal discounting principle, adult participants altered their responses so as to avoid the proximal (immediate) consequence even though doing so put them at increased risk of incurring a more severe distal (future) consequence. Similar to real world interrogation, these findings simulate dogged persistence in the face of continued denials, and, when that was the case, adults provided more admissions to criminal and unethical behaviors. 
The proposed research will utilize Madon and colleagues' interrogation paradigm as it is particularly well-suited to address the main research questions posed.

\section{Expected Practical and Theoretical Contributions}

Because youth is a known risk factor for false confession, recommendations (e.g., mandatory provision of a lawyer or appropriate adult, special training for law enforcement personnel, electronic recording of interrogation, the use of developmentally appropriate interrogation practices) have been made with the intent to safeguard youth during interrogation (Kassin et al., 2010; Owen-Kostelnik et al., 2006; Tepfer, Nirider, \& Tricarico, 2010). However, these reforms were recommended without an informed empirical understanding of the factors underlying youths' increased vulnerability in interrogation. It is paramount that recommended reforms are grounded in empirical research, in order to ensure that reforms are effective and appropriately designed to address the tactics employed in interrogation that put suspects at increased risk of false confession. Because known research has largely bypassed this important step, current recommendations for reform may be misguided or even ineffective. To date, no study has systematically examined why young suspects are more susceptible to providing false information during questioning with police or other authority figures. The current study was the first to do so.

Theoretically, the current study contributes to our basic understanding of youths' susceptibility to provide false information when questioned as suspects. Results will advance scientific knowledge of possible mechanisms underlying the elicitation of false information in interrogation from youth. An understanding of the factors underlying youths' increased propensity to provide false information (e.g., poor impulse control) will 
allow the research community to design and implement informed and effectively targeted interrogation reforms while contributing to a better understanding of individual differences in confession decisions.

\section{The Current Study}

The overarching purpose of the current study was to examine, for the first time experimentally, the factors - youths' inability to appropriately consider future consequences, diminished impulse control, and increased sensation seeking - possibly underlying youths' disclosure of false information in interrogation settings. Another key goal was to examine the influence of temporal discounting on youths' and adults' interrogation decisions. Research suggests that, compared to adults, adolescents are prone to making short-sighted, risky decisions without adequate consideration for future consequences. Thus, suspects who are both young and experience deficits in impulse control may be in "double jeopardy" for providing false information during interrogation. In fact, extant research has produced evidence showing that impulsive youth specifically, those with low self-control - are more likely to engage in delinquency (DeLisi \& Vaughn, 2007).

I focused on examining potential factors that may underlie the increased elicitation of false information during interrogation. The key objectives were to: (1) compare admission rates of engagement in criminal and unethical behaviors among age groups (adolescents vs. young adults vs. older adults); (2) determine the influence of temporal discounting on admission decisions and whether the tendency to engage in this behavior in interrogation is more pronounced among youth; and (3) investigate the 
influence of impulse control, future orientation, and sensation seeking on the willingness of adults and adolescents to provide both true and false information.

The current study sought to assess developmental differences in the tendency to provide true and false admissions among adolescents (ages 12 to 17), young adults (ages 18 to 24 ), and older adults (age 25 and above). The reasoning behind these three age groups is twofold. First, extant interrogation research exploring developmental differences in the tendency to provide true and false admissions has used a fairly restrictive age range (e.g., Pimentel et al., 2015; Redlich \& Goodman, 2003). I wanted to expand the age range in an attempt to assess developmental differences across the age range of the populations most likely to commit crime (Moffitt, 1993). Research has shown that: 1) the majority of offenders are adolescents, 2) almost $50 \%$ of these offenders desist from offending by their early 20 s, and 3 ) by the late 20 s, almost $85 \%$ of previous teenage offenders have desisted from offending (Moffitt, 1993). Second, developmental research has shown that key cognitive areas associated with decision making, consequence consideration, and impulse control, do not fully develop until young adulthood (e.g., age 20-25; Steinberg, 2007, 2008).

A randomized experimental design comprised of adolescent and both young and older adult participants. All participants were questioned about their engagement in various criminal and unethical behaviors. Participants were told responding "yes" or "no" to these questions had either immediate (e.g., answering burdensome, repetitive questions) or future consequences (e.g., meeting with the police to discuss interview responses at a later date). Future orientation, impulse control, and sensation seeking were also measured. Experiential factors may also influence individuals' willingness to admit 
involvement in criminal and unethical behaviors. For that reason, participants were also asked to provide information on their past legal system involvement and understanding of Miranda rights. Self-reported legal system involvement and Miranda comprehension scores were used as a control in some of the subsequent analyses.

\section{Hypotheses}

Extant research findings and proposed underlying theoretical mechanisms discussed above, were used to formulate hypotheses for the current study. Overall, I predicted that temporal discounting would influence participants' rates of admission to having engaged in criminal and unethical behaviors and that the tendency to provide admissions would be stronger for (a) adolescents than adults, (b) individuals with lower impulse control (c) individuals with less future orientation, and (d) individuals with higher levels of self-reported sensation seeking. For all hypotheses, no specific predictions were made regarding the two adult groups (i.e., older vs. young adults). Differences were not predicted between these two age groups because the expected presence of cognitive differences is likely dependent on the mean age of each sample of adults. The following key predictions were made:

Hypothesis 1. A main effect of age group was expected. Specifically, I hypothesized that youth would provide more admissions than adults. Also, a main effect of consequences condition was expected. That is, I expected that more admissions would be provided when proximal consequences were associated with denials rather than when proximal consequences were associated with admissions. An interaction was expected between age group and consequences condition such that youth would provide more admissions than adults when denials were associated with proximal consequences 
compared to when admissions were associated with proximal consequences. Thus, it was expected that youth would succumb more than adults to the phenomenon of temporal discounting (i.e., the tendency for behavior to be influenced more strongly by proximal than distal factors; Berns et al., 2007; Critchfield \& Kollins, 2001), particularly when denials, rather than admissions, were associated with proximal consequences.

Hypothesis 2. A main effect of age group on impulse control was expected. Specifically, I hypothesized that youth would have lower levels of impulse control than adults. The main effect was expected to be qualified by a 3-way interaction between age group, consequences condition, and impulse control. Specifically, the interaction between age group and consequences condition was expected to vary based on impulse control. It was expected that impulse control would influence youths' admission decisions such that youth with lower levels of impulse control would provide more admissions than youth with higher levels of impulse control when denials were associated with proximal consequences but not when admissions were associated with proximal consequences. Impulse control was expected to have a less robust effect on adults' admission decisions.

Hypothesis 3. A main effect of age group on future orientation was expected such that youth were expected to be less future oriented than adults. I predicted that the main effect would be qualified by a 3-way interaction between age group, consequences condition, and future orientation. Specifically, the interaction between age group and consequences condition was expected to vary based on future orientation. That is, it was expected that future orientation would influence youths' admissions decisions such that youth with lower levels of future orientation were expected to succumb more to the 
proximal consequences of the interrogation situation than youth with higher levels of future orientation when denials, rather than admissions, were associated with proximal consequences. Because adults are less likely to experience deficits in future orientation, it was expected that future orientation would have a less robust effect on adults' admission decisions.

Hypothesis 4. A main effect of age group on sensation seeking was expected. That is, I expected youth to exhibit higher levels of sensation seeking than adults. I hypothesized that this main effect would be qualified by a 3-way interaction between age group, consequences condition, and sensation seeking. Specifically, the interaction between age group and consequences condition was expected to vary based on sensation seeking. Thus, it was expected that sensation seeking would influence youths' admissions decisions such that youth with lower levels of sensation seeking would provide more admissions than youth with higher levels of sensation seeking when denials were associated with proximal consequences but not when admissions were associated with proximal consequences. Sensation seeking was expected to have a less robust effect on adults' admission decisions.

Hypothesis 5: Impulse control, future orientation, and sensation seeking were hypothesized to mediate and completely account for the observed relationship between age group and number of admissions made during the interview (Figure 1). 


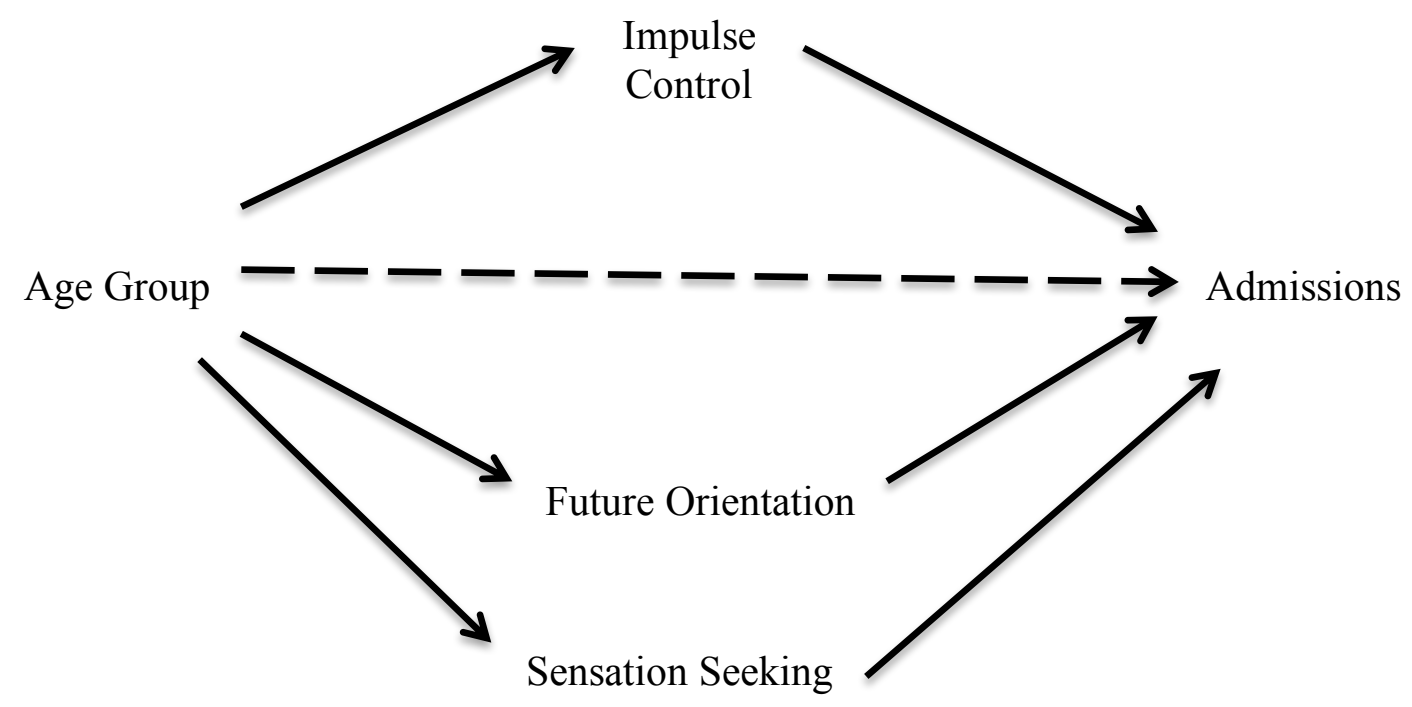

Figure 1. Proposed Model of Mediation. 


\section{METHOD}

\section{Design}

The study conformed to a 3 (Age Group) X 2 (Consequences Condition) between subjects factorial design. Adults and adolescents (Age Group: adolescent vs. young adult vs. older adult) were randomly assigned to one of two consequences conditions (Consequences Condition: proximal consequence for denials-distal consequence for admissions [PCD-DCA] vs. proximal consequence for admissions-distal consequence for denials [PCA-DCD]). Participants' admissions and denials to the criminal and unethical behavior (CUB) interview questions was the primary dependent measure of interest. Secondary dependent measures were participants' future orientation, impulsivity, and sensation seeking scores.

\section{Sample}

Power analysis. A power analysis indicated that a sample of 190 participants (approximately 32 participants per condition with 64 older adult, 64 young adult, and 64 adolescent participants) would provide $80 \%$ power to detect group mean differences of a relatively small (0.3) effect size, using an F test with a .05 significance level.

Characteristics. Two groups of adult participants were recruited for the current study. In an attempt to assess developmental differences across a wider age range than has been studied in previous research, I expanded the adult population of interest in the current study. Thus, data was collected from both young and older adults. For the purpose of the present study, young adults were classified as individuals age 18 to 24 and older adults were classified as individuals age 25 and above. 
The final sample comprised 205 participants ( 78 older adults, 74 young adults, and 53 adolescents). Older adults were college undergraduate students (59\% female) ages 25 years and older $\left(M_{\mathrm{age}}=28.68, S D=4.55\right)$ who identified as Hispanic $(70 \%)$, African American (14\%), Caucasian (8\%), or Other (8\%). Two older adults with ages more than three standard deviations above the mean were excluded from analyses. Young adults were college undergraduate students ( $76 \%$ female) ages 18 to 24 years $\left(M_{\text {age }}=20.51, S D=1.63\right)$ who identified as Hispanic (55\%), African American (19\%), Caucasian (11\%), and Other (15\%). Adolescents were middle and high school students $(60 \%$ female $)$ ages 12 to 17 years $\left(M_{\text {age }}=14.75, S D=1.65\right)$ who identified as Hispanic (74\%), African American (2\%), Caucasian (17\%), or Other (7\%).

Recruitment. All adult participants were recruited via SONA systems, an electronic research management and participant recruitment system, at a large urban university in exchange for extra credit. Adolescent participants were recruited from local middle and high schools, other youth-oriented programs, and via announcements made to faculty and undergraduate students in departments across the university. In exchange for their participation, adolescents received community service hours, which are a requirement for many local schools (Pimentel et al., 2015). Adolescent participants also received a \$25 Target gift card to compensate them for their time and travel to the university laboratory.

Informed consent/assent. The informed consent/assent process was similar across all three age groups, with the exception that simpler language was used with adolescent participants and that adolescents' parent(s) or legal guardian(s) had to provide informed consent in order for them to participate. 
Young and older adult participants were provided with a consent form with the study details to read on their own. RAs were close by during this time to answer participants' questions.

In order for adolescents to participate in the study, informed consent had to be received from their parent(s) or legal guardian(s). I conversed with all of the adolescents' parents or legal guardians (either by phone and/or email), prior to adolescents' study appointment. Also, all parent(s) or legal guardian(s) of interested participants received an email explaining the true purpose of the study, study procedures, instructions not to share this information with the adolescent, and specific information for what to say to their child or guardian if $\mathrm{s} / \mathrm{he}$ had questions prior to participating in the study. The informed consent form was attached to the email for parents and or legal guardians to review prior to the scheduled appointment. All parents and legal guardians were encouraged to reach out with questions at any time.

Parents or legal guardians were not required to accompany adolescents to the study. Those who chose not to accompany the adolescent, were instructed to send the completed consent form in a sealed envelope with the adolescent to the study. I engaged all parents and legal guardians who chose to accompany the adolescent to the study in an in-person informed consent process. During this process, the true purpose and procedures of the study were disclosed and background information on the significance of the research question was provided. Additionally, parent(s) and legal guardian(s) were apprised as to how the findings of the study were intended to be used (e.g., published in peer reviewed journals, disseminated to law enforcement, potentially to inform police interrogation policies). All parents and legal guardians were then given ample time to 
ask me questions about the study before choosing whether or not to consent to their child's participation in the study. During this process, adolescent participants were in a separate room with a RA.

After receiving informed consent from adolescents' parent(s) or legal guardian(s), assent procedures ensued with adolescent participants. Specifically, adolescent participants were informed how long the study would take (i.e., 3-4 hours), what they would be doing (i.e., answering some questionnaires on paper, on the computer, and faceto-face with a RA), what they would receive for participating (i.e., volunteer hours and a \$25 gift card), and that they could discontinue their participation in the study at any time without consequence. I also wanted to ensure that adolescents did not feel pressured to participate simply because their parent or legal guardian had consented. That is, I wanted to ensure that adolescent participants were aware they could choose not to participate or to stop participating at any time even though their parent or legal guardian had provided consent. To ensure participation was voluntary, adolescent participants were told that, even though their parents had consented, adolescents did not have to participate in the study if they did not want to. And, if they chose not to participate there would be no negative consequences or costs to them or their parent(s) or legal guardian(s).

Adolescents were then provided with a paper copy of the assent form to read. RAs were close by to answer adolescents' questions.

\section{Procedure}

Because of the nature and complexity of the research design, RAs underwent extensive training (i.e., 6 to 8 weeks) regarding the study procedures and administration of questionnaires prior to conducting experimental sessions with eligible research 
participants. All RAs had to submit to and pass memorization testing of key components of the study protocol and administration of the MRCI-II measures before being allowed to collect data with participants. To account for drift over time, all RAs were periodically (i.e., every three to four months) retested. Also, I observed multiple practice sessions with each RA supplying them with detailed feedback about their performance with real participants. Data collected during practice sessions was not included as part of the final data set. All RAs were required to successfully complete these practice sessions before collecting the data that contributed to this dissertation.

Participants arrived to the laboratory with the belief that s/he would be participating in a study examining student behaviors. After obtaining informed consent and providing the cover story, participants were asked to provide their name, email address, cell phone number, and student identification number (Appendix A). Contact information was collected in order to bolster belief that the police officer would be able to reach her/him to schedule a meeting in the future if necessary. Participants then completed the CUB interview and impulse control, future orientation, and sensation seeking measures. The order of the CUB interview and impulse control, future orientation, and sensation seeking measures was counterbalanced and presented in a random order across participants so as not to affect performance on other relevant measures. Specifically, following random assignment, half of the participants completed the measures before and half completed the measures after the CUB interview. Following the interview, participants completed self-report questionnaires to assess demographic information, suspicion, and their understanding of the Consequences experimental manipulation. Finally, participants' comprehension of Miranda rights was 
assessed before they were debriefed, completed a second, self-administered CUB interview, thanked for their participation, and dismissed. 


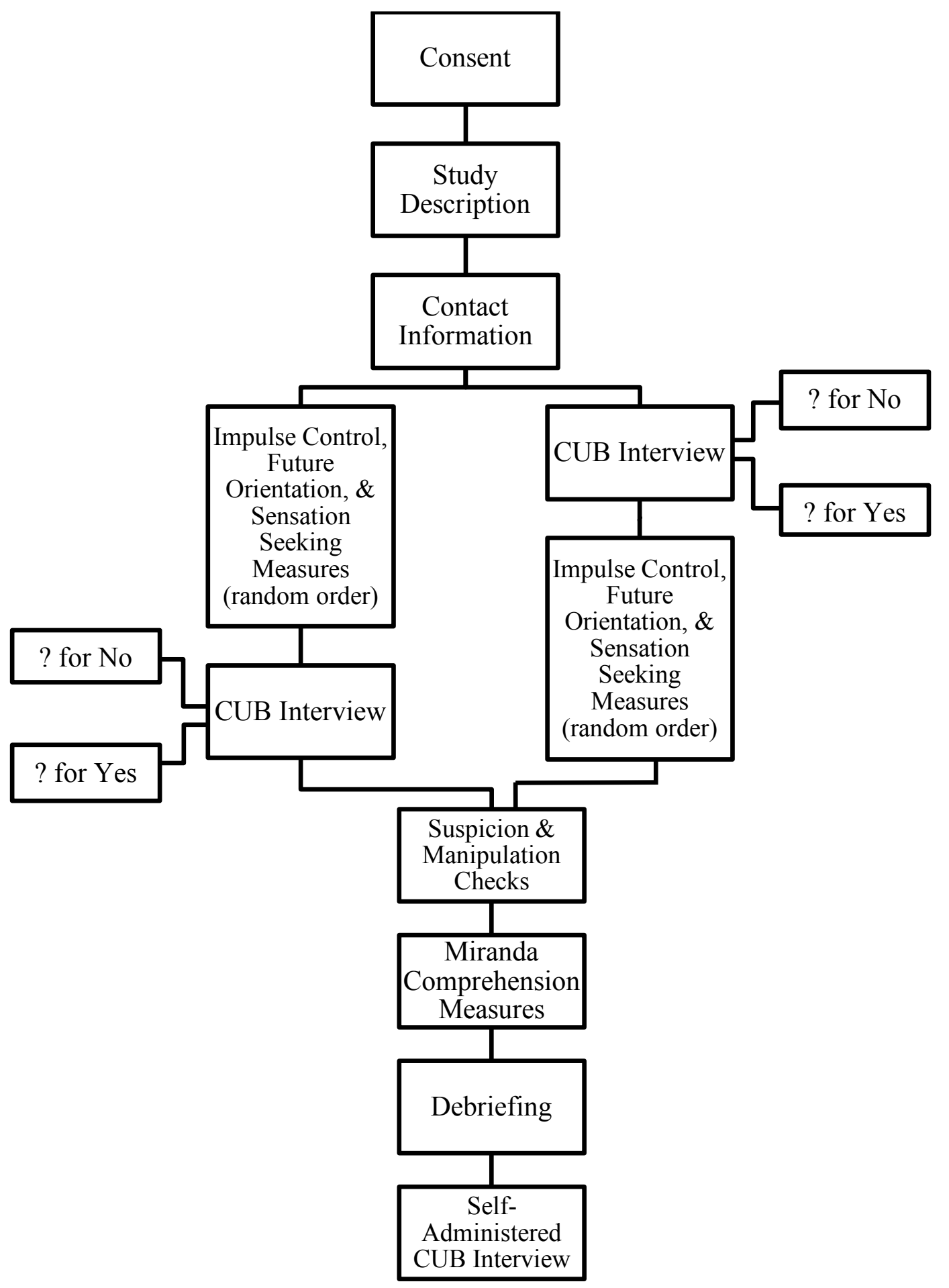

Figure 2. Flow Chart of the Experimental Procedure. 


\section{Materials, Measures, and Coding}

Cover story and interview room. Upon arrival to the laboratory, participants were told that they would be participating in a study examining the amount and types of criminal and unethical behaviors college/middle and high school students (depending on Age Group condition) have engaged in. To assess this, participants were told they would be interviewed by a research assistant (RA) involved in the study in which s/he would be asked a series of yes-no questions regarding his/her engagement in a variety of criminal and unethical behaviors (Appendix B). Furthermore, participants were told the study was a collaboration between professors in the Psychology Department and police officers within the Miami-Dade police department.

A number of props were used to support the cover story (Appendices A, C, D). All participants were individually interviewed in a small, brightly lit, white walled room containing only a small desk/table, two chairs (one for the participant and the other for the RA), and a laptop computer. Two colored flyers were obtained from the Miami-Dade Police Department website and were affixed to the wall directly above the laptop computer. The flyers offered safety tips for conducting internet sales transactions (Appendix D) and information about the local juvenile curfew ordinance (Appendix D). Both flyers clearly displayed the Miami-Dade Police Department emblem. In addition, a pencil cup placed next to the laptop computer contained multiple pens which were each engraved with the words "Miami-Dade Police Department." No other writing utensils were made available to participants during the study. Finally, RAs were clothed in white lab coats and wore lanyards printed with the words "Miami-Dade Police." 
Consequences scripts. Prior to completing the face-to-face interview with the RA, participants were given different instructions based on consequence condition. Participants in both experimental consequence conditions were told that their responses (i.e., whether they admit or deny engaging in the behaviors) to the criminal and unethical behavior interview questions would constitute immediate (proximal) or future (distal) consequences. The immediate (proximal) consequence involved answering a series of 32 burdensome and repetitive questions during the study session. The future (distal) consequence was potentially having to meet with a police officer at the police station in several weeks to discuss their responses. The precise number of admissions/denials that would require participants to have this meeting was never specified.

By design, the type and severity of the consequence is confounded with its proximity. Thus, any observed differences may not reflect a tendency for individuals to admit criminal and unethical behaviors to avoid the immediate (proximal) consequences rather than the future (distal) consequences, but, instead, to avoid the repetitive questions rather than meet with the police officer. However, past research (see Madon et al., 2012), which has reversed the consequences (i.e., the immediate [proximal] consequence was the meeting with the police officer and the future [distal] consequence was responding to the repetitive questions) indicates this is of little concern in the current study. When the consequences were reversed, this research continued to support the temporal discounting theory with participants' responses reflecting a tendency to avoid the proximal consequences, regardless of what the proximal consequence entailed (i.e., meeting with a police officer or answering additional questions; Madon et al., 2012). Since the publication of the initial studies, researchers employing this paradigm have used only the 
standard consequence contingency pairing (i.e., the proximal consequence is always answering the set of 32 repetitive questions and the distal consequence is always the potential meeting with the police officer; Madon et al., 2013; Scherr, Miller, \& Kassin, 2014; Yang, Madon, \& Guyll, 2015).

Proximal consequence: Repetitive questions. Repetitive questions (Appendix E) were adapted from Madon and colleagues $(2012,2013)$. Depending on condition, participants received the immediate (proximal) consequence of answering a set of 32 repetitive questions assessing participants' perceptions of how the "average Floridian" and "average American" would feel (e.g., hostile, jealous, happy-go-lucky) while engaging in the criminal or unethical behavior they just admitted or denied engaging in. Participants answered the repetitive questions on a computer with a 4-s delay between each question. In total, the entire set of 32 repetitive questions required approximately seven minutes to complete. These questions were, by design, burdensome and repetitive. The sole purpose of the repetitive questions was to serve as a consequence for admitting or denying having engaged in the behavior in question. Thus, we were not interested in analyzing the actual responses to these questions.

To ensure all participants experienced the tedious nature of the repetitive questions, each interview began with a "practice question" supposedly designed to familiarize participants with the interview procedures. In reality, practice questions were designed to elicit a response from participants that would require them to answer the repetitive questions. For example, participants assigned to answer the repetitive questions for each admission ("yes" response) to the CUB interview questions were asked whether s/he had ever littered (any material, biodegradable or otherwise, either on 
purpose or on accident). Participants assigned to answer the repetitive questions for each denial ("no" response) to the CUB interview questions were asked whether s/he had ever faked a high school diploma.

If participants failed to give the desired response, the RA feigned a computer malfunction. That is, the computer program was designed to display an error message and to fail to advance to the real CUB interview questions when the desired response (i.e., responses requiring that participants answer the repetitive questions) was not given. The RA then left the room to allegedly call a graduate supervisor for advice on handling the situation. Upon returning to the room, the RA stated that there was a problem with the computer program for that question but that the graduate supervisor was currently unable to fix it. The RA then indicated that the graduate supervisor had instructed $\mathrm{him} / \mathrm{her}$ to try selecting the other answer option (i.e., the response requiring that the participant answer the repetitive questions) to advance the program. Upon selecting the alternative answer option, the computer would advance to the repetitive questions. RAs then informed the participant that they would need to answer the repetitive questions to advance to the real CUB interview questions, despite the fact that their original response did not necessitate answering these questions. All participants were informed that there appeared to be a computer glitch only for this question. Finally, RAs reminded all participants that during the real CUB interview s/he would only have to answer the repetitive questions, depending on Consequence condition, for each admission or denial. Again, the computer malfunction occurred only for those participants that failed to give the desired response to the practice question. Participants who gave the desired response 
were not informed of a computer malfunction. The purpose of the computer malfunction was to ensure all participants had experience with the repetitive questions at least once.

Distal consequence: Meeting with police officer. Depending on condition, responses to the CUB interview questions increased the likelihood that participants received the future (distal) consequence of meeting with the police officer. Participants were told that the tendency to admit (answer "yes" to the interview questions) or deny (answer "no" to the interview questions) engaging in these behaviors would result in them having to meet with one of the police officers involved in the study at the police station in a few weeks. All participants were told that the purpose of this meeting would be to discuss their interview responses in depth with a police officer.

Proximal consequence for admissions-distal consequence for denials (PCADCD). Participants in the PCA-DCD condition were told that they had to answer additional follow-up questions on a computer during their session every time they responded "yes" to one of the CUB interview questions. Participants were told that this was necessary in order for researchers to obtain additional information about the behavior in question. However, participants were told they would be signed up to meet with a police officer involved in the research at a later date if they tended to answer "no" to the CUB interview questions. All participants were told that the purpose of the meeting was for law enforcement personnel to obtain more detailed information about their engagement in criminal and unethical behaviors. Furthermore, participants were told police officers would contact them directly to schedule this meeting.

Proximal consequence for denials-distal consequence for admissions (PCD-

DCA). Participants in the PCD-DCA condition were told the reverse of participants in 
the PCA-DCD condition. That is, these participants were told that they would have to answer additional follow-up questions on the computer during their session every time they gave a "no" response to one of the CUB interview questions. However, participants expected to meet with a police officer to discuss their responses in depth if they tended to answer "yes" to these CUB interview questions.

Interview questions. Interview questions (Appendix B) were adapted from Madon and colleagues $(2012,2013)$ and the Centers for Disease Control and Prevention's Youth Risk Behavior Surveillance System (2014). Questions assessed whether participants had ever engaged in 20 criminal (e.g., engaged in underage drinking, illegally downloading music, movies, or software) and unethical (e.g., reading another's text messages or emails without permission, starting or spreading a rumor about someone) behaviors. To ensure participants felt comfortable providing answers to questions of a personal nature, participants were told that none of the members of the research team would judge them for or share the responses they provided during their session. Participants were required to admit or deny having engaged in each behavior during an interview aloud by responding "yes" (coded as 1) or "no" (coded as 0 ) to each question. Coded responses were summed to create total admission and denial scores for each participant.

In this well-established paradigm, participants' responses to the interview questions are classified as admissions or denials. However, it is important to note that it is not possible to determine ground truth of any particular response. In an attempt to address this limitation, participants in the present study were also asked to provide honest responses to the interview questions after the true purpose of the study had been revealed. 
Measures. A variety of measures were administered to assess participant's level of impulse control, future orientation, sensation seeking, comprehension of rights during police questioning, and experiences with the legal system. Impulse control was assessed via both self-report and behavioral measures. The rest of the measures relied solely on self-report.

Counterbalancing. The order of these measures and the CUB interview were counterbalanced. That is, some participants were randomly assigned to complete the impulse control, future orientation, and sensation seeking measures before the CUB interview, whereas others completed them afterwards. Counterbalancing was done to ensure the order of the presentation of the measures did not affect other relevant study measures. Furthermore, impulse control and future orientation measures were presented in random order to each participant.

Barratt Impulsiveness Scale-11 (BIS-11; Patton, Stanford, \& Barratt, 1995; Appendix F). The BIS-11 is the most commonly administered measure for assessing impulsiveness in research and clinical settings (Stanford et al., 2009). This measure is comprised of 30-items assessed on a four-point (rarely/never to almost always/always) Likert scale. Sample items include the following: "I do things without thinking."; "I plan tasks carefully." Several items were reverse coded for analysis. Responses to the 30items were summed to create a total impulsivity score with higher scores indicating greater susceptibility to impulsivity and, thus, lower impulse control.

Circle tracing task (Bachorowski \& Newman, 1985). Behavioral impulse control was assessed with a circle tracing task (Appendix G). This task (or similar tracing/drawing tasks) has been used to assess behavioral impulse control with children 
(Avila, Cuenca, Felix, Parcet, \& Miranda, 2004; Homatidis \& Kostantareas, 1981), juvenile delinquents (Siegman, 1961; White et al., 1994), and adults (Bachorowski \& Newman, 1985, 1990; Stuart \& Holtzworth-Munroe, 2005). Participants were asked to trace a 9" diameter circle as slowly as possible. Tracing time (in seconds) was the main measure of interest. To ensure timely study completion, a maximum time limit of 8 minutes was set for this task. Experimenters stopped participants who were still completing the task after 8 minutes to move on to the next task. Only three participants ( 1 older adult, 1 young adult, and 1 adolescent) used the full 8 minutes to complete this task.

Future orientation. The tendency to consider future consequences, outcomes, and rewards was assessed with a 15-item self-report measure (Steinberg et al., 2009; Appendix $\mathrm{H}$ ) that has been used with both adolescents and adults. This measure consists of pairs of statements from which participants were instructed to choose the statement that best described them. Participants then indicated whether the description was really true or sort of true of them. Sample item pairs include the following: "Some people would rather be happy today than take their chances on what might happen in the future BUT Other people will give up their happiness now so that they can get what they want in the future"; "Some people like to think about all of the possible good and bad things that can happen before making a decision BUT Other people don't think it's necessary to think about every little possibility before making a decision." Using this format (i.e., presenting participants with pairs of statements separated by the word "but" and asking participants to choose the statement that best describes them) has been used in previous research and is thought to reduce social desirability in responding (Harter, 1982; 
Steinberg et al., 2009). Responses were coded on a 4-point scale, ranging from really true for one descriptor to really true for the other. Scores were then averaged to create an overall future orientation score with higher scores indicating greater future orientation.

Sensation seeking. Participant's level of sensation seeking was assessed with a self-report measure (Harden \& Tucker-Drob, 2011; Appendix I). Sensation seeking was measured based on participant's responses to the following three items: "I enjoy taking risks"; "I enjoy new and exciting experiences, even if they are a little frightening or unusual"; "Life with no danger in it would be too dull for me." Participants responded to all items on a 4-point Likert scale ranging from 1 (strongly disagree) to 4 (strongly agree). Scores were then averaged to create a mean sensation seeking score with higher scores indicating greater sensation seeking.

\section{Miranda Rights Comprehension Instruments - II (MRCI-II). Prior to}

undergoing custodial interrogation, police must inform suspects of their Miranda rights (e.g., rights to silence and legal counsel). Individuals may choose to either waive which many choose to do (three out of every four real-world criminal suspects waived their rights in one study; Leo, 1996b) - or invoke these Miranda rights. The same risk factors hypothesized in the current study as putting youth at increased risk of falsely confessing, also may make youth less capable of voluntarily and knowingly waiving the legal rights afforded to them as suspects undergoing custodial interrogation. In fact, comprehension deficits tend to be most pronounced among justice involved youth and adults (Grisso et al., 2003). Thus, to control for this possibility in subsequent analyses, two Miranda comprehension measures were employed. Miranda comprehension scores were used as a control in some of the subsequent analyses. 
Participants' comprehension of their Miranda rights was assessed with the MRCIII (Goldstein, Zelle, \& Grisso, 2014). This measure consists of four instruments that were each designed to assess a different aspect of individuals' understanding of their Miranda rights. Specifically, the instruments were designed to assess an individual's understanding of the meaning of their Miranda rights and appreciation for and consequences associated with waiving those rights. The instruments do not allow for the assessment of an individual's competency to waive his or her Miranda rights.

The MRCI-II was created for use with both adolescents and adults. Measurement norms were developed with data collected from samples of juvenile justice involved youth (i.e., youth housed in a residential post-adjudication facility, detention center, or short-term holding facility), middle to upper-middle SES community youth, and adult offenders (Goldstein et al., 2014). For the purposes of this study, time only allowed for the administration of two of the four instruments: Comprehension of Miranda RightsRecognition-II (CMR-R-II) and Function of Rights in Interrogation (FRI).

Comprehension of Miranda Rights - Recognition - II (CMR-R-II). The CMR-R-II was designed to assess comprehension of the five Miranda warnings (e.g., right to silence, right to counsel, etc.). However, instead of relying on verbal expressive skills, the CMR-R-II assesses Miranda comprehension through recognition. The CMR-R-II presents three pre-constructed sentences for each of the five Miranda warnings (see Appendix J). Participants are instructed to report whether each sentence is or is not identical in meaning to the original Miranda warning to which it is paired. Scoring for the CMR-R-II is dichotomous, with incorrect responses receiving 0 points and correct responses receiving 1 point. Thus, summed total scores on this measure can range from 0 
(i.e., incorrect recognition of each of the 15 pre-constructed sentences) to 15 (i.e., correct recognition of each of the 15 pre-constructed sentences).

Function of Rights in Interrogation (FRI). The FRI was designed to assess individuals' ability to appreciate and apply Miranda rights in various legal proceedings (Appendix K). While individuals may understand that they have the "right to remain silent," they may fail to appreciate its significance in the context of an interrogation or in court. For this instrument, experimenters read four scenarios aloud to participants. Each scenario was accompanied by a picture related to and depicting a legal proceeding (e.g., a suspect being questioned by police, a suspect meeting with an attorney, a defendant in court). Participants' appreciation of the significance of and the ability to apply their rights was assessed via 15 standardized questions. RAs followed up with standardized queries as necessary. The questions were designed to assess whether individuals recognized the adverse nature of interrogation and grasped both the significance of the right to counsel and the right to silence. Responses are considered inadequate, questionable, or adequate, and scored 0,1 , or 2 , respectively (see Table 1 for sample scoring of this measure). Total scores on this measure can range from 0 (i.e., inadequate responses to all 15 questions) to 30 (i.e., adequate responses to all 15 questions). 
Table 1

Sample Scoring Scheme for Function of Rights in Interrogation (FRI).

\begin{tabular}{llll}
\hline & & \multicolumn{1}{c}{ Response Type } & \\
\hline FRI Sample Items & Adequate Response & Questionable Response & Inadequate Response \\
$\begin{array}{l}\text { What is it that the policemen will want Joe } \\
\text { to do? }\end{array}$ & $\begin{array}{l}\text { Tell them where he } \\
\text { was at the time of the } \\
\text { crime. }\end{array}$ & Talk about something. & $\begin{array}{l}\text { Act with good } \\
\text { manners. }\end{array}$ \\
$\begin{array}{l}\text { While he is with his lawyer, what is Tim } \\
\text { supposed to do? }\end{array}$ & $\begin{array}{l}\text { Trust him and do what } \\
\text { the lawyer thinks is } \\
\text { best. }\end{array}$ & $\begin{array}{l}\text { Listen to what the } \\
\text { lawyer's saying. }\end{array}$ & Plead the fifth. \\
$\begin{array}{l}\text { Finish this sentence. If Greg decides to tell } \\
\text { the police about what he did, then the } \\
\text { things that Greg says }\end{array}$ & $\begin{array}{l}\text { Can be used against } \\
\text { him in court. }\end{array}$ & $\begin{array}{l}\text { Can get him into } \\
\text { trouble. }\end{array}$ & Won't matter anyway. \\
$\begin{array}{l}\text { If the judge finds out that Greg wouldn't } \\
\text { talk to the police, then what should } \\
\text { happen? }\end{array}$ & $\begin{array}{l}\text { The judge will listen } \\
\text { to what everybody } \\
\text { else has to say. }\end{array}$ & $\begin{array}{l}\text { Ask Greg why he } \\
\text { wouldn't talk. }\end{array}$ & Make him talk now. \\
\hline
\end{tabular}


MRCI-II scoring. All MRCI-II assessment sessions were audio recorded and transcribed verbatim. Because the CMR-R-II is scored in a purely objective manner, I independently scored all participant responses for this measure. Using standardized scoring procedures (Goldstein et al., 2014), two scorers independently scored participants' transcribed responses to the FRI. A primary scorer, blind to both Age Group and Consequences condition, scored all FRI responses. Fifteen percent of the data was randomly selected to be independently co-scored by a second scorer to establish inter-rater reliability. Prior to scoring for reliability, both scorers underwent intensive training according to standardized scoring rules. Kappa coefficients were calculated for each item in the measure to account for/represent variability within each item. Inter-rater agreement was examined with intra-class correlation coefficients (ICC; Suen \& Ary, 1989) for each subscale and the total FRI score, representing total score variability. An average ICC of 0.95 and an average Kappa coefficient of 0.88 were observed. These ICC values represent "almost perfect" agreement; Kappa values represent "substantial" to "almost perfect" agreement (McHugh, 2012). The Kappa coefficients for the individual items ranged from 0.70 to 1.00 . See Table 2 for all inter-rater reliability statistics for this measure. Miranda Comprehension scores were used as a control in most of the primary analyses. 
Table 2

Inter-rater Reliability Estimates for the Function of Rights in Interrogation (FRI).

\begin{tabular}{|c|c|c|}
\hline & $\underline{\mathrm{ICC}}$ & $\underline{\text { Kappa }}$ \\
\hline FRI Total & $.93 * * *$ & - \\
\hline NI Subscale & $.96 * * *$ & - \\
\hline NI-1 & - & $1.0 * * *$ \\
\hline NI-2 & - & $1.0 * * *$ \\
\hline NI-3 & - & ${ }^{\mathrm{a}}$ \\
\hline NI-4 & - & $.73 * * *$ \\
\hline NI-5 & - & $.70 * * *$ \\
\hline RC Subscale & $.97 * * *$ & - \\
\hline $\mathrm{RC}-1$ & - & $1.0 * * *$ \\
\hline $\mathrm{RC}-2$ & - & $-^{\mathrm{a}}$ \\
\hline $\mathrm{RC}-3$ & - & $1.0 * * *$ \\
\hline $\mathrm{RC}-4$ & - & $.84 * * *$ \\
\hline $\mathrm{RC}-5$ & - & $.79 * * *$ \\
\hline RS Subscale & $.94 * * *$ & - \\
\hline RS-1 & - & $.81 * * *$ \\
\hline RS-2 & - & $.91 * * *$ \\
\hline RS-3 & - & $-^{\mathrm{a}}$ \\
\hline $\mathrm{RS}-4$ & - & $.84 * * *$ \\
\hline RS-5 & - & $.93 * * *$ \\
\hline
\end{tabular}

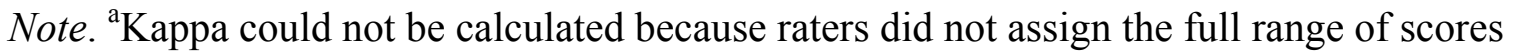
$(0-2)$ for these items. ${ }^{*} p<.05, * * p<.01, * * * p<.001$. 
Familiarity with the legal system. Extant research has demonstrated that prior experience with the law and/or legal system can influence individuals' knowledge and appreciation of Miranda rights (Leo, 1996a; Scherr, 2011; Softley, 1980). To control for this potential influence, all participants were asked to indicate whether they had ever been arrested, questioned by police, placed in juvenile detention or jail, and/or gone to court or been placed on probation (Appendix L). Participants who reported having these experiences, also answered questions about the number of times this had occurred and the timing of the most recent occurrence (e.g., 2-3 months ago, one year ago, 5 years ago). From this data, a dichotomous justice system involvement variable was created $(0=$ never had prior justice system involvement, $1=$ ever had prior justice system involvement). Those participants who self-reported having been arrested, questioned by police as a suspect, experience in court or on probation, or served time in juvenile detention or jail, were coded as 1 (ever had prior justice system involvement). Participants who did not report having any of these experiences, were coded as 0 (never had prior justice system involvement). Self-reported prior justice system involvement was used as a control in all of the primary analyses involving the Miranda measures.

Manipulation check items. Comprehension of the consequence manipulation was assessed both before and after the interview. Prior to the interview, RAs asked participants to explain what would happen when s/he responded "yes" and "no" to the interview questions. For participants who failed to adequately grasp their experimental Consequences condition, experimenters repeated an abbreviated version of the consequence script and assessed comprehension a second time. This process was repeated until participants demonstrated adequate comprehension of their Consequences 
condition. All participants were able to adequately demonstrate comprehension prior to the interview.

After completing the CUB interview, participants completed questionnaires (Appendix M) containing Consequences condition manipulation check items. Specifically, participants were asked whether they answered the repetitive questions when they (1) gave a "yes" response, (2) gave a "no" response, or (3) sometimes when they gave a "no" response and sometimes when they gave a "yes" response.

\section{Perceived aversiveness of the repetitive questions (proximal consequence).}

Participants were also asked several questions to assess the perceived aversiveness of the repetitive questions (Appendix M). Specifically, participants were asked eight questions about their perceptions of the repetitive questions. Five of these items were bipolar adjective scales participants used to rate the degree to which the repetitive questions were, (1) soothing - irritating; (2) varied - repetitive; (3) interesting - boring; (4) pleasant-unpleasant; and (5) enjoyable-annoying. Scores were then averaged for these five items to create an overall question aversion scale. The sixth item asked participants, "If you could, how much would you have liked to have skipped the additional questions about Floridians and Americans altogether?" Participants provided their response using a 5-point Likert scale ranging from 1 (not at all) to 5 (a lot). The seventh item assessed how tempted participants were to change their answers to avoid answering the additional questions ("Overall, how tempted were you to give a particular answer on the criminal and unethical behaviors survey just to avoid having to answer the additional questions about Floridians and Americans again?) on a 1 (not at all tempted) to 5 (very tempted) scale. Finally, participants were asked, "How glad were you when the 
additional questions about Floridians and Americans were completely done?" using a 1 (not at all glad) to 5 (very glad) scale. Thus, a total of four dependent variables were used to assess question aversiveness: (1) the question aversion scale, (2) the desire to skip the repetitive questions, (3) the temptation to change answers to avoid the repetitive questions, and (4) feeling glad when the repetitive questions were finished. Higher scores were indicative of greater perceived aversiveness to the repetitive questions for all resulting dependent variables.

\section{Perceived aversiveness of the meeting with a police officer (distal}

consequence). Similarly, six items were also included to assess participants' perceptions of the aversiveness of meeting with a police officer (Appendix M). The first five items were bipolar adjective scales. Participants were asked to rate their feelings about the possible meeting with the police officer using the following adjective pairs: (1) nervous calm; (2) reluctant-eager; (3) unenthused - enthused; (4) concerned-unconcerned; and (5) not looking forward to - looking forward to. Items were reverse coded so that higher scores were indicative of greater perceived aversiveness regarding meeting with a police officer. Scores were then averaged for these five items to create an overall police aversion scale. Finally, participants used a Likert scale ranging from 1 (not at all) to 5 (a lot) to indicate how much they hoped they would not have to meet with a police officer to discuss their responses to the CUB interview. Thus, a total of two dependent variables were used to assess police aversiveness: (1) the police aversion scale and (2) the hope that the participant would not have to meet with a police officer. Higher scores were indicative of greater perceived aversiveness to the police for all resulting dependent variables. 
Suspicion check items. Two approaches were used to determine whether participants were suspicious about any aspect of the study, particularly the potential meeting with the police officer. Following the CUB interview, participants completed a questionnaire specifically inquiring as to whether s/he believed the researchers were examining a research question other than the one stated at the beginning of the experiment (Appendix N). Participants responding in the affirmative were asked to specifically indicate what research question(s) s/he believed were under investigation. RAs further probed for suspicion during the debriefing (Appendix O). Specifically, RAs asked participants: (1) what s/he thought about the study; (2) if anything about the study was unusual; and (3) whether s/he believed s/he had been misled. RAs instructed participants to elaborate on their original responses as necessary.

Demographics. All participants were asked to provide demographic information regarding their race/ethnicity, age, gender, grade point average, highest level of academic achievement, and native language (Appendix L). Additionally, participants were asked whether they had taken or were currently taking courses relevant to the current study (e.g., Legal Psychology, Cognitive Processes, Juvenile Justice, The Criminal Justice System).

Debriefing. At the conclusion of the study, an extensive debriefing process ensued (Appendix O). During the debriefing session, participants were asked a series of questions to probe for suspicion (discussed above) and to acquire information about participant's experiences in the study. Immediately following this questioning, the true purpose of the study was revealed. Importantly, all participants were informed of the following: 
1. No police officers were involved in the study;

2. There would be no legal or any other consequences for participants based on their responses to the CUB interview questions;

3. Only de-identified, anonymous information provided during the study session would be reported and presented to the public.

After learning the true purpose of the study, all participants were informed of the importance of not sharing this information with other people who might participate in the study in the future. After providing verbal consent not to share the true purpose of the study with others, all participants were then asked to sign a confidentiality agreement (Appendix P).

In an attempt to measure ground truth of participants' actual engagement in these criminal and unethical behaviors all participants, now knowledgeable of the true purpose of the study, were asked to provide truthful responses to the CUB interview questions. All participants then completed the CUB interview again (Appendix Q). However, this time participants were fully aware that there would be no consequences based on their responses and were encouraged to provide only truthful responses. Participants completed the measure alone (i.e., without the RA or any members of the research team present in the testing room). 


\section{RESULTS}

The primary dependent variable of interest in the current study is the number of admissions provided during the CUB interview. The primary independent variables of interest are Age group, Consequences condition, impulse control, future orientation, and sensation seeking scores.

\section{Analysis Plan}

First, I present a series of preliminary analyses. Second, I describe the primary analyses testing the hypotheses concerning the effects of age group, consequences condition, and future orientation, impulse control, and sensation seeking on admissions decisions. Finally, I present exploratory analyses in an attempt to explain the lack of support for predicted age group differences on temporal discounting, impulse control, future orientation, and sensation seeking in the primary analyses.

\section{Preliminary Analyses}

Preliminary analyses were conducted to assess the presence of outliers and a normal distribution of the primary dependent measure. The influence of counterbalancing the measures and possible gender differences in the measures of interest were assessed. Additionally, manipulation check and suspicion checks were conducted. This included an assessment of the perceived level of aversiveness to answering repetitive questions and the possible meeting with a police officer. Analysis of manipulation checks is to ensure that all participants correctly understood the consequences associated with their interview responses. Participants who incorrectly classified their Consequences condition or who noted elevated levels of suspicion regarding relevant study procedures were excluded from subsequent analyses. 
Testing normality of the dependent variable. The primary dependent measure of interest in all analyses was the admissions rate, or the sum of the number of times participants said "yes" in response to questions asked about their involvement in various criminal and unethical behaviors (Table 3). The distribution of the primary dependent variable was assessed both visually, by examining histograms, Q-Q plots, and P-P plots, and statistically, by examining skewness and kurtosis values and conducting statistical tests (e.g., Kolmogorov-Smirnov and Shapiro-Wilks tests). Visual analysis revealed that the dependent variable appeared to be positively skewed. A Shapiro-Wilks test confirmed visual evidence of a non-normally distributed dependent variable, $W=.96, p$ $=.001$. Because the admissions rate was positively skewed, I attempted to normalize the distribution of the data by performing a square root transformation. After performing the transformation, visual and statistical examination revealed that the admissions rate continued to reveal non-normality, $W=.97, p<.01$. Thus, the square root transformation did not improve the distribution of the data. Because several of the statistical tests (e.g., Analysis of Variance) used for analyses are robust to non-normality (Schmider, Ziegler, Danay, Beyer, \& Bühner, 2010), the raw score for number of admissions was used in all subsequent analyses. 
Table 3

Number (and Percent) of Participant Admissions to the Criminal and Unethical Behavior Interview Questions as a Function of Age Group.

\section{Number of Admissions (\%)}

\section{Older Adults $\quad$ Young Adults $\quad$ Adolescents}

Have you ever...

1. Drank (even just one sip), bought, or tried to buy alcohol before you were 21 ?

2. Tried, used, or experimented with any illegal drugs such as marijuana, cocaine, crack, LSD, or any other kind of drug even just one time?

3. Cheated on an exam, paper, homework assignment, or school project by taking credit for someone else's work, ideas, or answers as your own (plagiarism) or helped another person cheat?

4. Used something that belonged to somebody else without permission, such as something that belonged to a family member, friend, roommate, or acquaintance?

5. Made a harassing, threatening, or prank phone call, text message, or social media post or private message?

6. Failed to wear a seat belt?

7. Knowingly kept something of value that you received in error, such as extra change given to you by a cashier or extra merchandise from a store or from an internet purchase?

8. Vandalized property, like keying a car, slashing a tire, spraying graffiti, or egging a house or car?

9. Invaded another's privacy such as by reading another's diary, text messages, or emails without permission?

$\begin{array}{llc}40(76 \%) & 37(82 \%) & 19(44 \%) \\ 24(45 \%) & 18(40 \%) & 3(7 \%) \\ 29(55 \%) & 26(58 \%) & 20(47 \%) \\ & & \\ 37(70 \%) & 26(58 \%) & 26(61 \%) \\ 17(32 \%) & 11(24 \%) & 8(19 \%) \\ 33(62 \%) & 30(67 \%) & 29(67 \%) \\ 24(45 \%) & 12(27 \%) & 3(7 \%) \\ 11(21 \%) & 1(2 \%) & 3(7 \%) \\ 34(64 \%) & 24(53 \%) & 16(37 \%)\end{array}$


10. Jumped or cut in line such as at the dining hall, movie theater or grocery store?

11. Purposefully not returned something that you borrowed like a book, clothing, or money?

12. Engaged in a nonviolent sex offense such as by exposing yourself to someone by mooning or flashing them or engaged in voyeurism, which is being a peeping Tom?

13. Started or spread a rumor about someone?

14. Assaulted someone with the intent of harming him or her, either with your bare hands or with any kind of object or weapon? In other words, have you ever been in a physical fight for the purposes of harming someone else?

15. Smoked (even just one puff), bought, or tried to buy cigarettes before you were 18 ?

16. Trespassed or broken into a building for fun or to look around?

17. Lied to your parents about where you were, who you were with, or how much money you spent on something?

18. Carried an illegal or concealed weapon, like a gun, knife, or club?

19. Shoplifted something such as makeup products, clothing, office supplies, food, or electronics?

20. Illegally downloaded music, movies, software, or anything else?

$\begin{array}{ccc}27(51 \%) & 23(51 \%) & 20(47 \%) \\ 18(34 \%) & 12(27 \%) & 9(21 \%) \\ 4(8 \%) & 3(7 \%) & 3(7 \%) \\ & & \\ 14(26 \%) & 12(27 \%) & 9(21 \%) \\ 16(30 \%) & 8(18 \%) & 5(12 \%) \\ & & \\ 16(30 \%) & 5(11 \%) & 3(7 \%) \\ 17(32 \%) & 10(22 \%) & 7(16 \%) \\ 46(87 \%) & 36(80 \%) & 25(58 \%) \\ 6(11 \%) & 5(11 \%) & 2(5 \%) \\ 18(34 \%) & 7(16 \%) & 9(21 \%) \\ 38(72 \%) & 32(71 \%) & 15(35 \%)\end{array}$

Note. Participants responded "yes" (coded as 1) or "no" (coded as 0 ) aloud to an RA for each interview question. The questions were adapted from Madon and colleagues $(2012,2013)$ and the Centers for Disease Control and Prevention's Youth Risk Behavior Surveillance System (2014). Coded responses were summed to create total admission and denial scores for each participant. 
Assessment and removal of outliers. The primary dependent and independent variables of interest were inspected for extreme outliers (i.e., values more than three standard deviations above the mean). Preliminary analyses did not reveal any extreme outliers for the primary dependent measure (number of admissions). Several independent variables (i.e., self-reported impulsivity [the BIS-11], behavioral impulsivity [the circle tracing task], future orientation, sensation seeking, and age) contained extreme outliers. These participants will be excluded from all analyses conducted in which these independent variables are included.

Counterbalancing. The presentation of the CUB interview questions and future orientation, impulse control, and sensation seeking measures were counterbalanced. That is, some participants were randomly assigned to complete the future orientation, impulse control, and sensation seeking measures before the CUB interview and others completed them after the CUB interview. This was done in order to ensure the order of presentation did not affect other relevant measure of interest. A series of Independent t-tests were conducted to examine the influence of order on the number of admissions provided to the CUB interview, future orientation scores, self-reported impulse control, behavioral impulse control, sensation seeking, and CMR-R-II and FRI scores. Order of presentation did not affect scores on any of these measures, all $p s>.14$. Thus the order in which study measures were administered was not considered further.

Gender. To determine whether gender needed to be included as a control in all analyses, a series of Independent t-tests were conducted to examine the influence of gender on the primary dependent measure of interest (i.e., the number of admissions to the CUB interview), impulse control, future orientation, sensation seeking, Miranda 
comprehension, and perceived aversiveness of the repetitive questions and the meeting with a police officer. Only one statistically significant difference emerged. Males ( $M=$ 2.64, $S D=1.59)$ indicated that they were more tempted than females $(M=2.10, S D=$ 1.19) to provide a particular answer in response to the CUB interview questions in order to avoid answering the repetitive questions, $t(139)=2.29, p=.02,95 \% \mathrm{CI}[0.73,1.01], d$ $=0.38$. All other comparisons were nonsignificant, all $p \mathrm{~s}>.07$. Thus gender was not considered further.

\section{Perceived aversiveness of the repetitive questions (proximal consequence).}

To examine participants' perceptions of the aversiveness of answering the repetitive questions, all participants were asked to provide Likert-type ratings of the questions. Of the 205 individuals who participated in the study, 141 participant responses were used in the subsequent analyses (due to suspicion and missing data points). A 3 (Age Group: older adult vs. young adult vs. adolescent) X 2 (Consequences: PCD-DCA vs. PCADCD) Multivariate Analysis of Variance (MANOVA) was conducted on (1) the five-item question aversion scale, (2) how much participants would have liked to skip the additional questions, (3) how tempted participants were to give a particular answer to the CUB survey to avoid the additional questions, and (4) how glad participants were when the additional questions were finished. There was a statistically significant age group difference on the combined dependent variables $F(8,264)=2.20, p=.03$, Wilks'

Lambda $=.88, \eta_{\mathrm{p}}{ }^{2}=.06$. When the results for the dependent variables were considered separately, only two differences reached statistical significance: the desire to skip the additional questions, $F(2,135)=2.16, p<.01, \eta_{\mathrm{p}}{ }^{2}=.09$, and being tempted to give a particular answer to avoid answering the additional questions, $F(2,135)=5.02, p<.01$, 
$\eta_{\mathrm{p}}{ }^{2}=.07$. Post hoc comparisons showed that young adults $(M=4.19)$ were more likely than older adults $(M=3.71)$ and adolescents $(M=3.36)$ to want to skip the additional questions. Furthermore, young adults $(M=2.78)$ were more likely than adolescents $(M=$ 1.90) to indicate that they were tempted to give a particular answer to avoid answering the additional questions. There were no other main effects or interactions. See Table 4 for mean and standard deviations and Table 5 for inferential statistics.

One-way ANOVAs were conducted separately to examine whether perceived question aversiveness varied by Consequences condition. No significant differences emerged for any of the items (i.e., question aversion scale, desire to skip questions, tempted to change answers to avoid questions, feeling glad when done answering questions) used to assess aversion to the questions, all $p \mathrm{~s}>.09$. 
Table 4

Means and Standard Deviations for Question Aversion Responses as a Function of Age Group and Consequences Condition.

\begin{tabular}{|c|c|c|c|c|c|}
\hline \multirow[t]{2}{*}{$\begin{array}{l}\text { Question Aversion } \\
\text { Item }\end{array}$} & \multirow[t]{2}{*}{ Age Group } & \multicolumn{2}{|c|}{$\begin{array}{c}\text { PCD-DCA } \\
\text { Condition }\end{array}$} & \multicolumn{2}{|c|}{$\begin{array}{l}\text { PCA-DCD } \\
\text { Condition }\end{array}$} \\
\hline & & Mean & $\underline{\mathrm{SD}}$ & Mean & $\underline{\mathrm{SD}}$ \\
\hline \multirow{3}{*}{$\begin{array}{l}\text { Like to skip additional } \\
\text { questions }\end{array}$} & Older Adults & 3.91 & 1.27 & 3.47 & 1.25 \\
\hline & Young Adult & 4.43 & 0.87 & 3.96 & 1.04 \\
\hline & Adolescent & 3.26 & 1.18 & 3.45 & 0.83 \\
\hline \multirow[t]{3}{*}{$\begin{array}{l}\text { Tempted to give } \\
\text { particular answer }\end{array}$} & Older Adults & 2.64 & 1.53 & 1.90 & 1.30 \\
\hline & Young Adults & 3.14 & 1.46 & 2.42 & 1.25 \\
\hline & Adolescents & 1.65 & 1.07 & 2.15 & 1.18 \\
\hline \multirow[t]{3}{*}{$\begin{array}{l}\text { Glad questions were } \\
\text { finished }\end{array}$} & Older Adults & 4.55 & 0.86 & 4.03 & 1.07 \\
\hline & Young Adults & 4.38 & 0.92 & 4.33 & 0.87 \\
\hline & Adolescents & 4.17 & 0.98 & 3.85 & 0.99 \\
\hline \multirow[t]{3}{*}{$\begin{array}{l}\text { Question Aversion } \\
\text { Scale }\end{array}$} & Older Adults & 3.89 & 0.60 & 3.47 & 0.99 \\
\hline & Young Adults & 3.94 & 0.87 & 3.82 & 0.72 \\
\hline & Adolescents & 3.57 & 0.72 & 3.48 & 0.72 \\
\hline \multirow[t]{3}{*}{ Irritating $^{\mathrm{a}}$} & Older Adults & 3.55 & 0.96 & 3.27 & 1.08 \\
\hline & Young Adults & 3.81 & 0.75 & 3.71 & 0.91 \\
\hline & Adolescents & 3.57 & 0.95 & 3.15 & 0.88 \\
\hline \multirow[t]{3}{*}{ Repetitive $^{\mathrm{a}}$} & Older Adults & 4.73 & 0.55 & 3.87 & 1.57 \\
\hline & Young Adults & 4.33 & 1.07 & 4.33 & 1.05 \\
\hline & Adolescents & 4.30 & 1.02 & 4.65 & 0.59 \\
\hline \multirow[t]{3}{*}{ Boring $^{\mathrm{a}}$} & Older Adults & 3.77 & 1.07 & 3.33 & 1.37 \\
\hline & Young Adults & 3.90 & 1.18 & 3.71 & 1.16 \\
\hline & Adolescents & 3.30 & 1.30 & 3.35 & 1.04 \\
\hline \multirow[t]{2}{*}{ Unpleasant $^{\mathrm{a}}$} & Older Adults & 3.55 & 0.86 & 3.33 & 1.09 \\
\hline & Young Adults & 3.62 & 1.12 & 3.38 & 1.06 \\
\hline
\end{tabular}




\begin{tabular}{cccccc} 
& Adolescents & 3.17 & 0.83 & 3.00 & 0.92 \\
Annoying $^{\mathrm{a}}$ & Older Adults & 3.86 & 0.89 & 3.53 & 1.04 \\
& Young Adults & 4.05 & 1.07 & 3.96 & 0.69 \\
& Adolescents & 3.48 & 1.04 & 3.25 & 1.07 \\
\hline
\end{tabular}

Note. ${ }^{\text {a }}$ denotes items included in the Question Aversion Scale.

Table 5

F Values, p Values, and Effect Sizes for Question Aversion Responses.

Dependent Variables

\begin{tabular}{lccc}
\hline & $\mathrm{F}$ & $p$ & $\eta_{\mathrm{p}}{ }^{2}$ \\
Age Group & 2.20 & $.03 *$ & .06 \\
Consequence Condition & 1.01 & .41 & .03 \\
Age Group x Consequence Condition & 1.39 & .20 & .04 \\
\hline
\end{tabular}

Note. ${ }^{*}$ Denotes a significant effect at $p<.05$.

\section{Perceived aversiveness of the meeting with a police officer (distal}

consequence). To examine participants' perceptions of the aversiveness of meeting with a police officer in a few weeks, all participants were asked to provide Likert-type ratings of several questions. In line with the question aversiveness analyses, 141 participant responses were used in the subsequent analyses (due to suspicion and missing data points). A 3 (Age Group: older adult vs. young adult vs. adolescent) X 2 (Consequences: PCD-DCA vs. PCA-DCD) MANOVA was conducted on (1) the five-item police aversion scale and (2) how much participants' hoped they would not have to meet with 
the police officer in a few weeks to discuss their responses to the CUB interview. There was a statistically significant interaction on the combined dependent variables $F(4,266)$ $=2.94, p=.02$, Wilks' Lambda $=.92, \eta_{\mathrm{p}}{ }^{2}=.04$. When the results for the dependent variables were considered separately, the interaction reached statistical significance for both dependent variables.

Simple effects analyses were conducted separately for each dependent variable. These analyses revealed that police aversion ratings were similar for older $\left(M_{P C D-D C A}=\right.$ 2.65; $\left.M_{P C A-D C D}=2.81\right)$ and young adults $\left(M_{P C D-D C A}=2.70 ; M_{P C A-D C D}=2.83\right)$ regardless of the consequences associated with their CUB interview responses. However, adolescents experienced greater self-reported aversion to the police when proximal consequences (i.e., answering a set of 32 repetitive questions, $M_{P C D-D C A}=3.24$ ) were associated with denials and distal consequences (i.e., meeting with a police officer in a few weeks) were associated with admissions than when proximal consequences were associated with admissions and distal consequences were associated with denials $\left(M_{\mathrm{PCA}-}\right.$ $\mathrm{DCD}=2.53)$

Simple effects analyses were also conducted regarding how much participants' hoped they would not have to meet with the police officer in a few weeks to discuss their responses to the CUB interview. Young adults provided similar ratings regardless of the consequences associated with their CUB interview responses $\left(M_{P C D-D C A}=3.60 ; M_{P C A-D C D}\right.$ =3.46). However, older adults experienced less self-reported aversion to the meeting with police when proximal consequences were associated with denials and distal consequences were associated with admissions $\left(M_{P C D-D C A}=3.09\right)$ than when proximal consequences were associated with admissions and distal consequences were associated 
with denials $\left(M_{\mathrm{PCA}-\mathrm{DCD}}=3.81\right)$. In contrast, adolescents experienced greater aversion to the meeting with police when proximal consequences were associated with denials and distal consequence were associated with admissions $\left(M_{P C D-D C A}=3.57\right)$ than when proximal consequences were associated with admissions and distal consequences were associated with denials $\left(M_{\mathrm{PCA}-\mathrm{DCD}}=2.80\right)$. Thus, it appears older adults were more averse to the possibility of speaking with the police about criminal and unethical behaviors they had not engaged in, whereas adolescents were more concerned about meeting with the police to discuss behaviors in which they had engaged. See Table 6 for mean and standard deviations and Table 7 for inferential statistics.

One-way ANOVAs were conducted separately to examine whether the perceived aversiveness of the meeting with a police officer varied by consequences condition. No significant differences emerged for any of the items (i.e., police averse scale and the hope that one would not have to meet with the police) used to assess aversion to the questions, all $p \mathrm{~s}>.39$. 
Table 6

Means and Standard Deviations for Police Aversion Responses as a Function of Age Group and Consequences Condition.

\begin{tabular}{|c|c|c|c|c|c|}
\hline \multirow[t]{2}{*}{ Police Aversion Item } & \multirow[t]{2}{*}{ Age Group } & \multicolumn{2}{|c|}{$\begin{array}{c}\text { PCD-DCA } \\
\text { Condition }\end{array}$} & \multicolumn{2}{|c|}{$\begin{array}{l}\text { PCA-DCD } \\
\text { Condition }\end{array}$} \\
\hline & & Mean & $\underline{\mathrm{SD}}$ & Mean & $\underline{\mathrm{SD}}$ \\
\hline \multirow[t]{3}{*}{$\begin{array}{l}\text { Hope won't have to } \\
\text { meet with police }\end{array}$} & Older Adults & 3.09 & 1.44 & 3.81 & 1.25 \\
\hline & Young Adult & 3.60 & 1.14 & 3.46 & 1.32 \\
\hline & Adolescent & 3.57 & 1.16 & 2.80 & 0.95 \\
\hline \multirow[t]{3}{*}{ Police Aversion Scale } & Older Adults & 2.65 & 0.82 & 2.77 & 1.00 \\
\hline & Young Adults & 2.70 & 0.97 & 2.83 & 0.90 \\
\hline & Adolescents & 3.24 & 0.96 & 2.53 & 0.64 \\
\hline \multirow[t]{3}{*}{ Nervous ${ }^{\mathrm{a}}$} & Older Adults & 1.91 & 1.27 & 2.03 & 1.54 \\
\hline & Young Adults & 2.10 & 1.12 & 2.21 & 1.32 \\
\hline & Adolescents & 2.78 & 1.59 & 2.05 & 1.10 \\
\hline \multirow[t]{3}{*}{ Reluctant $^{\mathrm{a}}$} & Older Adults & 3.14 & 0.89 & 3.23 & 1.22 \\
\hline & Young Adults & 3.05 & 1.15 & 3.04 & 1.08 \\
\hline & Adolescents & 3.48 & 1.08 & 2.70 & 1.03 \\
\hline \multirow[t]{3}{*}{ Unenthused $^{\mathrm{a}}$} & Older Adults & 3.27 & 1.03 & 3.37 & 1.10 \\
\hline & Young Adults & 2.95 & 1.10 & 3.38 & 1.17 \\
\hline & Adolescents & 3.74 & 0.96 & 2.80 & 0.77 \\
\hline \multirow[t]{3}{*}{ Concerned $^{\mathrm{a}}$} & Older Adults & 1.73 & 1.12 & 1.67 & 1.18 \\
\hline & Young Adults & 2.30 & 1.38 & 2.00 & 1.18 \\
\hline & Adolescents & 2.61 & 1.62 & 2.15 & 0.93 \\
\hline \multirow[t]{3}{*}{ Not looking forward to ${ }^{\mathrm{a}}$} & Older Adults & 3.18 & 1.05 & 3.57 & 1.36 \\
\hline & Young Adults & 3.10 & 1.17 & 3.50 & 1.10 \\
\hline & Adolescents & 3.61 & 1.03 & 2.95 & 0.89 \\
\hline
\end{tabular}

Note. ${ }^{a}$ denotes items included in the Police Aversion Scale. 
Table 7

F Values, $p$ Values, and Effect Sizes for Police Aversion Responses as a Function of Age Group and Consequences Condition.

Dependent Variables

\begin{tabular}{lccc}
\hline & $\mathrm{F}$ & $p$ & $\eta_{\mathrm{p}}{ }^{2}$ \\
Age Group & 1.31 & .27 & .02 \\
Consequences Condition & 0.43 & .65 & .01 \\
Age Group x Consequences Condition & 2.94 & $.02 *$ & .04 \\
\hline
\end{tabular}

Note. * Denotes a significant effect at $p<.05$.

Suspicion check. I examined participants' written and oral responses to the suspicion check questions to identify participants who doubted the veracity of the meeting with the police officer. I also examined participants' written responses regarding the purpose of or prior knowledge about the study to identify participants who appeared to determine the true purpose of the study. Overall, 42 participants (16 older adults, 24 young adults, and 2 adolescents) were identified and excluded from the primary analyses. Of these participants, 16 ( 8 older adults, 8 young adults) were excluded because they expressed strong suspicion about the police (i.e., doubt about the veracity of the collaboration with or veracity of the meeting with police) and 13 participants ( 4 older adults, 9 young adults) because they made mention of "the police" in response to the suspicion check question. An additional 11 participants ( 4 older adults, 7 young adults) were excluded because they were suspicious of or figured out the true purpose of the study. Despite expressly instructing parents not to share the true purpose of the study or 
the parental consent form with their child prior to his/her participation, one adolescent participant disclosed having read the parental consent form (which contained the true purpose of the study) prior to participating, and, thus, was excluded from the primary analyses. Finally, one adolescent participant was excluded because s/he was unable to complete the main study measure during the allotted study appointment. Procedures were in place to deal with participants who became unduly stressed during the study (Appendix R). However, no participants had to be excluded from analyses for this reason.

Consequences condition manipulation check. Frequency analyses were conducted to assess participants' understanding of the consequence condition to which they had been assigned. Twenty-two participants incorrectly identified their consequence condition, one of whom was also identified as suspicious of the veracity of the meeting with the police officer. Of these participants, twelve (including the individual who was previously excluded for suspicion) said they did not answer any repetitive questions. By design, all participants answered the repetitive questions at least once. This particular subset of participants answered the repetitive questions an average of 11 times (including the additional questions following the practice question; minimum $=4$, maximum $=21$ ). Anecdotally, some participants were confused with the terminology of the question and believed that the "additional questions" referenced something other than the repetitive computer-based questions. Also, nine participants indicated that they had answered the repetitive questions sometimes when giving a "yes" response and sometimes when giving a "no" response. All participants only answered the additional questions for all yes or all no responses. However, in order to ensure that all participants experienced answering the 
additional questions, a practice question was asked. The practice question was designed to evoke the response that would require participants to answer the additional questions. Participants who did not provide the desired response were led to believe that a computer malfunction had occurred that required them to complete the additional questions even though they had not given the response they were told led to answering the additional questions. Only one of these nine participants did not give the desired response to the practice question requiring the induction of the computer malfunction hoax. A final participant indicated that s/he was in the opposite consequence condition than the one to which $\mathrm{s} / \mathrm{he}$ had been assigned. An investigation of the data indicated that this was not the case. Even so, all participants $(n=22)$ who incorrectly identified their assigned Consequences condition were excluded from analyses.

Testing for differences between participants who were and were not excluded based on suspicion and a failed manipulation check. Thirty percent of the sample $(\mathrm{n}=$ 63) was excluded from analyses due to suspicion and/or failure to correctly report the experimental consequences condition to which they had been assigned. The final sample thus consisted of 142 participants. Analyses were conducted in an attempt to determine whether there were differences in gender, age group, performance on the study measures, and perceptions of the aversiveness of the questions and the meeting with a police officer between individuals who were and were not excluded.

First, I examined participant gender and age group via chi square analyses. Participants' gender was unrelated to exclusion status, $\chi^{2}(1)=.07, p=.79, \varphi=.02$. A 2 (exclusion status) $\times 3$ (age group) $\chi^{2}$ test was conducted to test the equal distribution of adolescents, young adults, and older adults across exclusion status. This analysis was 
statistically significant, $\chi^{2}(2)=5.99, p=.05, \varphi=.17$. Overall, $31 \%$ of older adults, $39 \%$ of young adults, and 19\% of adolescents were excluded. Second, I used a series of t-tests to examine possible differences based on exclusion status in the number of admissions provided, scores on impulse control, future orientation, sensation seeking, and Miranda comprehension measures, and ratings of perceived aversiveness of the questions and meeting with a police officer. Significant differences only emerged for the question averse scale, $t(190)=3.07, p=.002,95 \%$ CI $[-0.67,-0.15], d=0.52$, and the other three question averse items regarding the desire to skip the repetitive questions, $t(190)=2.49$, $p=.01,95 \% \mathrm{CI}[-0.83,-0.10], d=0.41$, the temptation to give a particular response to avoid answering the repetitive questions, $t(190)=2.21, p=.03,95 \%$ CI $[-0.93,-0.05], d$ $=0.36$, and being glad when the repetitive questions were done, $t(190)=2.33, p=.02$, $95 \% \mathrm{CI}[-0.66,-0.05], d=0.39$. Examination of the means indicated that, as compared to those who were included in analyses, individuals who were excluded were more averse to the questions $\left(M_{\text {excluded }}=4.11, S D_{\text {excluded }}=0.78\right.$ vs. $\left.M_{\text {included }}=3.70, S D_{\text {included }}=0.81\right)$, possessed a greater desire to skip the repetitive questions $\left(M_{\text {excluded }}=4.20, S D_{\text {excluded }}=\right.$ 1.07 vs. $\left.M_{\text {included }}=3.74, S D_{\text {included }}=1.15\right)$, were more tempted to give a particular answer to avoid answering the repetitive questions $\left(M_{\text {excluded }}=2.78, S D_{\text {excluded }}=1.33\right.$ vs. $M_{\text {included }}$ $\left.=2.29, S D_{\text {included }}=1.36\right)$, and were happier when the questions were done $\left(M_{\text {excluded }}=\right.$ 4.58, $S D_{\text {excluded }}=0.81$ vs. $\left.M_{\text {included }}=4.23, S D_{\text {included }}=0.96\right)$. All other comparisons were non-significant, all $\mathrm{ps}>.18$.

\section{Primary Analyses}

The influence of consequences condition and age on admission decisions. To test the hypothesis that youth would provide more admissions than adults when denials 
were associated with proximal consequences, a 3 (Age group: older adult vs. young adult vs. adolescents) X 2 (Consequences condition: PCD-DCA vs. PCA-DCD) ANOVA was conducted. The sum of the number of admissions participants made in response to the CUB interview served as the dependent variable and consequences condition and age group served as the independent variables. There was no significant interaction between age group and consequences condition, $F(2,135)=.68, p=.51, \eta^{2}=0.08$ (see Figure 3 ). However, main effects of age group and consequences condition emerged.

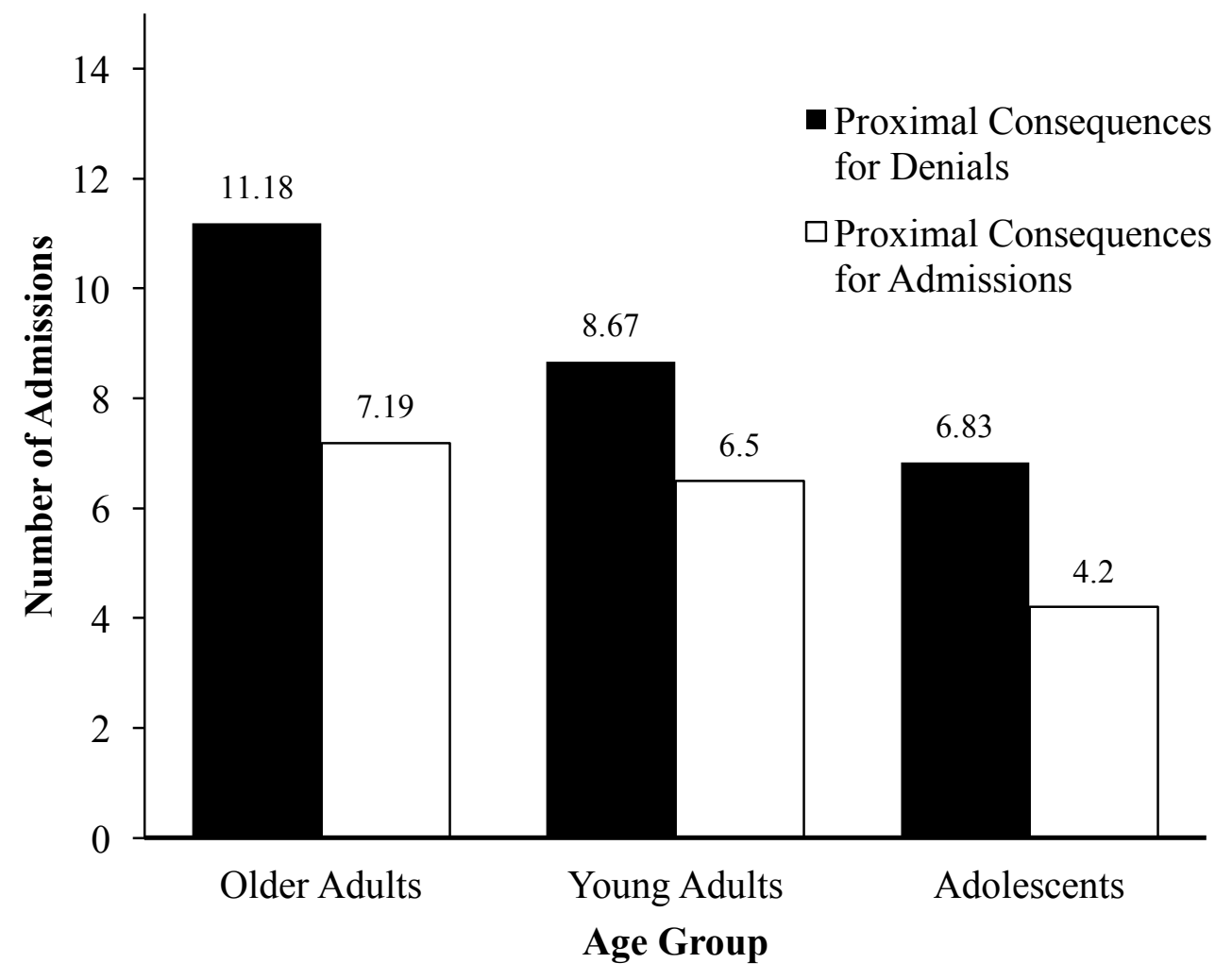

Figure 3. Mean Admissions as a Function of Consequences Condition and Age Group.

Main effects analysis showed that significantly more admissions were provided when denials were punished $(M=8.89)$ than when admissions $(M=5.97)$ were punished, 
$F(1,135)=18.54, p<.001, \eta^{2}=0.11$ (Figure 4$)$. There was also a significant main effect of age group on the number of admissions provided, $F(2,135)=9.89, p<.001, \eta^{2}$ $=0.11$ (Figure 5). Examination of the means showed that the admissions rate was similar for older adults $(M=9.19)$ and young adults $(M=7.58), p=.23,95 \%$ CI $[-0.58,3.26]$, and for young adults and adolescents $(M=5.51), p=.07,95 \%$ CI $[-0.11,3.93]$. However, older adults provided significantly more admissions than adolescents, $p<.001$, $95 \%$ CI $[1.30,5.19]$.

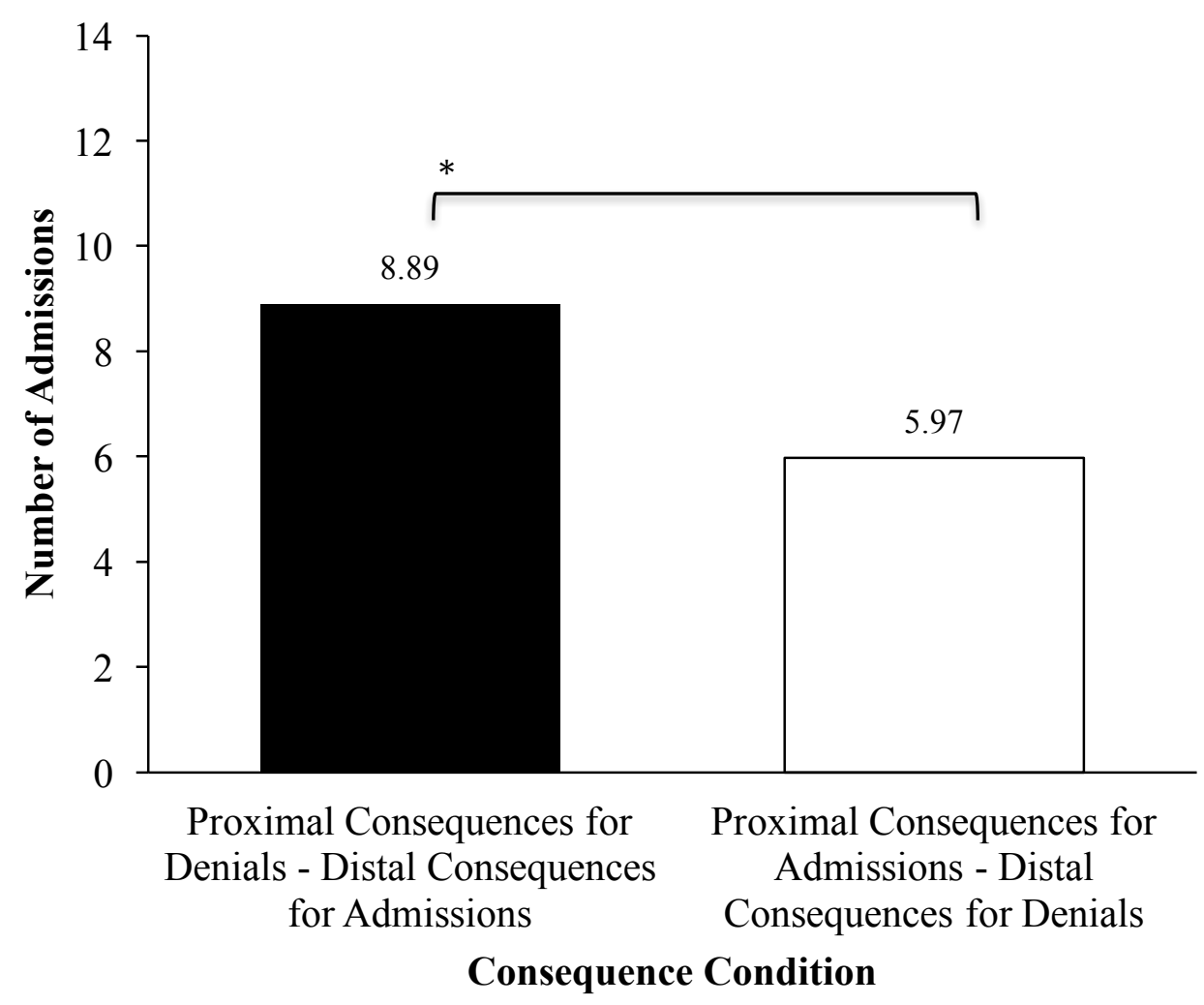

Figure 4. Main Effect of Consequences Condition. Values indicate the admissions rate of participants in each consequence condition. The proximal consequence of answering the additional questions resulted in more admissions than the distal consequence of meeting with a police officer involved in the study in a few weeks. Note. * Denotes a significant difference at $p<.001$. 


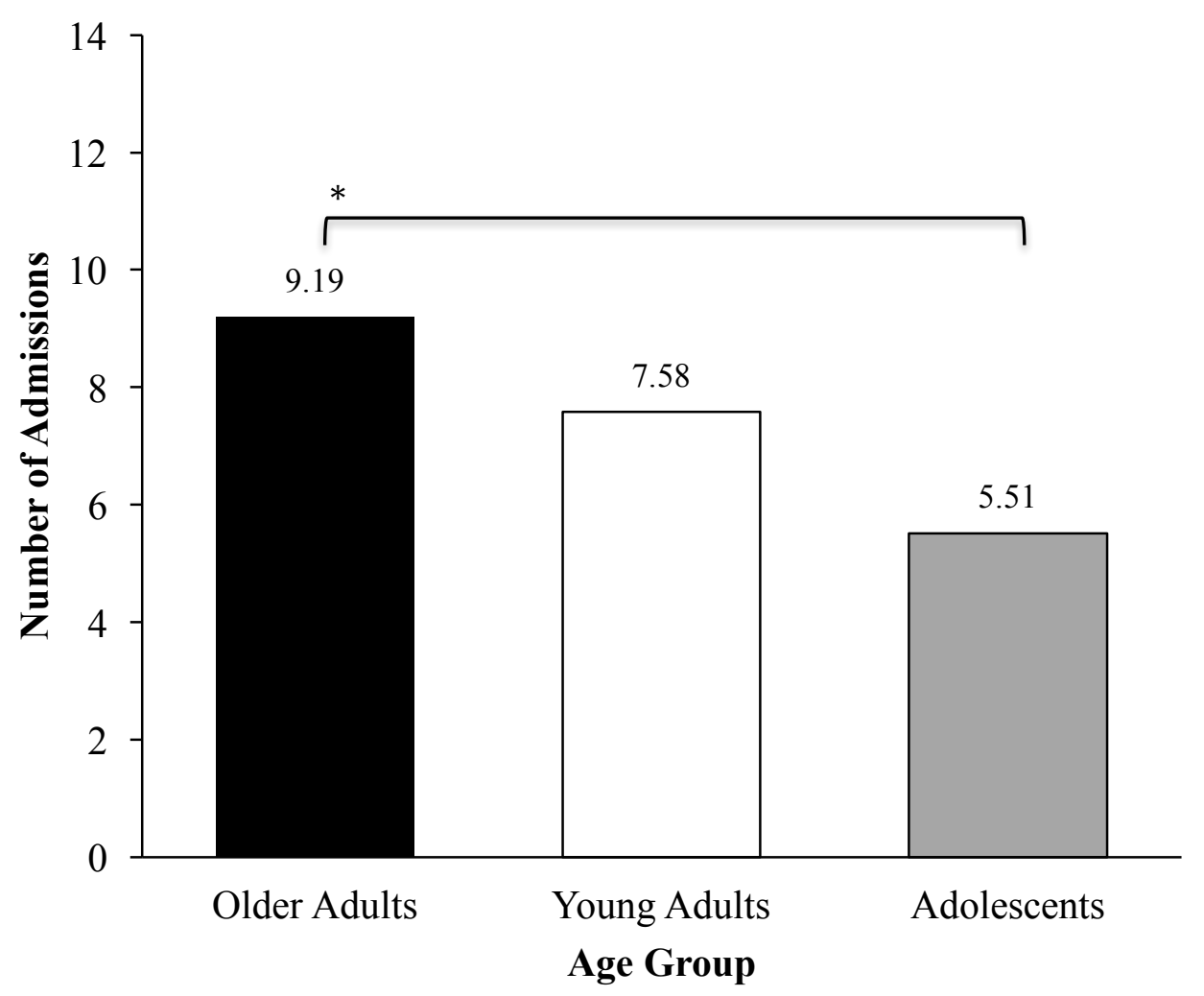

Figure 5. Main Effect of Age Group. Values indicate the admissions rate of participants in each age group. Older adults provided more admissions during the CUB interview than adolescents. Differences between all other age group comparisons were not statistically significant. Note. * Denotes a significant difference at $p<.001$.

Four linear regression analyses tested the influence of self-reported impulse control, behavioral impulse control, future orientation, and sensation seeking on the number of admissions provided during the CUB interview. Specifically, the number of admissions given was regressed on four primary outcome variables: (a) self-reported impulse control scores on the BIS-11, (b) the time taken (in seconds) to complete the circle tracing task (i.e., the measure of behavioral impulsivity, (c) self-reported future orientation, and (d) sensation seeking scores. To control for prior involvement in and/or knowledge of the legal system, self-reported legal involvement $(0=$ never had prior 
justice system involvement, 1 = ever had justice system involvement) and Miranda comprehension scores were entered in the first step of the model. The continuous age variable, consequence condition, impulse control, future orientation, or sensation seeking score, and all two- and three-way interactions were entered into the second step of the model.

\section{The influence of consequences condition, age, and self-reported impulse} control on admission decisions. Contrary to hypotheses, linear regression analyses revealed that neither age, consequences condition, self-reported impulse control, or any of the two- or three-way interactions were associated with admission decisions (Table 8).

Table 8

The Influence of Age, Consequences Condition, and Self-Reported Impulse Control on Total Admission Decisions

\begin{tabular}{|c|c|c|c|c|}
\hline Predictor & $B(S E)$ & $\beta$ & $95 \% C I$ & $p$ \\
\hline \multicolumn{5}{|l|}{ Step 1} \\
\hline Legal system involvement & $1.21(.89)$ & .11 & $-0.55-2.97$ & .18 \\
\hline FRI score* & $0.30(.14)$ & .16 & $0.02-0.58$ & .04 \\
\hline CMR-R-II score & $0.25(.20)$ & .10 & $-0.15-0.65$ & .22 \\
\hline \multicolumn{5}{|l|}{ Step $2^{\mathrm{a}}$} \\
\hline Age & $-0.25(.64)$ & -.34 & $-1.51-1.02$ & .70 \\
\hline Consequences condition & $-5.15(18.15)$ & -.58 & $-41.09-30.78$ & .78 \\
\hline $\begin{array}{l}\text { Self-reported impulse } \\
\text { control }\end{array}$ & $-0.01(.25)$ & -.02 & $-0.50-0.48$ & .96 \\
\hline Age $\mathrm{x}$ Consequences condition & $.39(.78)$ & 1.09 & $-1.15-1.93$ & .61 \\
\hline $\begin{array}{l}\text { Age x Self-reported impulse } \\
\text { control }\end{array}$ & $.01(.01)$ & .74 & $-0.01-0.03$ & .46 \\
\hline $\begin{array}{l}\text { Consequences condition x Self- } \\
\text { reported impulse control }\end{array}$ & $.07(.31)$ & .44 & $-0.54-0.67$ & .83 \\
\hline $\begin{array}{l}\text { Age x Consequences condition } \\
\text { x Self-reported impulse control }\end{array}$ & $-.002(.002)$ & -.37 & $-0.03-0.02$ & .20 \\
\hline
\end{tabular}

Note. Higher scores are indicative of more admissions provided during the CUB interview.

${ }^{\mathrm{a}} R^{2}=.31$ for Step 2. ${ }^{*} p<.05$. 


\section{The influence of consequences condition, age, and behavioral impulse control}

on admission decisions. Consistent with hypotheses, linear regression analyses revealed that age was associated with admission decisions (Table 9). Specifically, for each additional year of age, there was a .38 increase in the number of admissions provided during the CUB interview. However, contrary to hypotheses, neither consequences condition or behavioral impulsivity nor the two- or three-way interactions significantly predicted the number of admissions provided.

Table 9

The Influence of Age, Consequences Condition, and Behavioral Impulse Control on Total Admission Decisions

\begin{tabular}{lcccc}
\hline \multicolumn{1}{c}{ Predictor } & $B(S E)$ & $\beta$ & $95 \% C I$ & $p$ \\
\hline Step 1 & & & & \\
$\quad$ Legal system involvement & $1.32(.92)$ & .13 & $-0.49-3.14$ & .15 \\
FRI score* & $0.31(.16)$ & .16 & $0.00-0.62$ & .05 \\
CMR-R-II score & $0.13(.21)$ & .05 & $-0.29-0.55$ & .54 \\
Step 2 & & & & \\
$\quad$ Age* & $0.38(.17)$ & .53 & $0.04-0.72$ & .03 \\
Consequences condition & $3.25(5.10)$ & .38 & $-6.85-13.36$ & .53 \\
$\quad$ Behavioral impulse control & $0.03(.03)$ & .42 & $-0.04-0.09$ & .39 \\
$\quad$ Age x Consequences condition & $-0.33(.21)$ & -.91 & $-0.75-0.09$ & .13 \\
Age x Behavioral impulse & $-.002(.001)$ & -.54 & $-0.01-0.001$ & .24 \\
control & & & & \\
$\quad$ Consequences condition x & $-0.04(.04)$ & -.70 & $-0.12-0.04$ & .31 \\
$\quad$ Behavioral impulse control & & & & \\
$\quad$ Age x Consequences condition & $.003(.002)$ & .93 & $0.00-0.002$ & .15 \\
$\quad$ x Behavioral impulse control & & & & \\
\hline
\end{tabular}

Note. Higher scores are indicative of more admissions provided during the CUB interview.

${ }^{\mathrm{a}} R^{2}=.26$ for Step 2. ${ }^{*} p \leq .05$. 


\section{The influence of consequences condition, age, and future orientation on}

admission decisions. Again, contrary to hypotheses, linear regression analyses revealed that neither age, consequences condition, future orientation, or any of the two- or threeway interactions were associated with the number of admissions provided during the CUB interview (Table 10).

Table 10

The Influence of Age, Consequences Condition, and Future Orientation on Total Admission Decisions

\begin{tabular}{lcccc}
\hline \multicolumn{1}{c}{ Predictor } & $B(S E)$ & $\beta$ & $95 \% C I$ & $p$ \\
\hline Step 1 & & & & \\
$\quad$ Legal system involvement & $1.44(.88)$ & .13 & $-0.31-3.18$ & .12 \\
$\quad$ FRI score & $0.26(.15)$ & .14 & $-0.04-0.56$ & .09 \\
$\quad$ CMR-R-II score & $0.25(.21)$ & .10 & $-0.16-0.65$ & .23 \\
Step 2 & & & & \\
$\quad$ Age & $0.71(.86)$ & 1.00 & $-0.99-2.41$ & .41 \\
$\quad$ Consequences condition & $20.79(28.10)$ & 2.34 & $-34.82-76.40$ & .46 \\
$\quad$ Future orientation & $4.66(6.41)$ & .27 & $-8.01-17.34$ & .47 \\
$\quad$ Age x Consequences condition & $-0.77(1.23)$ & -2.11 & $-3.21-1.67$ & .53 \\
$\quad$ Age x Future orientation & $-0.17(.30)$ & -0.73 & $-0.76-0.42$ & .57 \\
$\quad$ Consequences condition x & $-7.45(9.61)$ & -2.50 & $-26.46-11.56$ & .44 \\
$\quad$ Future orientation & & & & \\
$\quad$ Age x Consequences condition & $.23(.42)$ & 1.91 & $-0.61-1.07$ & .58 \\
$\quad$ x Future orientation & & & & \\
\hline Note. Higher scores are indicative of more admissions provided during the CUB & \\
interview. & & & & \\
${ }^{2} R^{2}=.26$ for Step 2. &
\end{tabular}




\section{The influence of consequences condition, age, and sensation seeking on}

admission decisions. A final linear regression analysis was conducted to examine the influence of age, consequences condition, and sensation seeking on admission decisions. Analyses revealed that neither age, consequences condition, self-reported sensation seeking, nor the two- or three-way interactions were significant predictors of admission decisions during the CUB interview (Table 11).

Table 11

The Influence of Age, Consequences Condition, and Sensation Seeking on Total Admission Decisions

\begin{tabular}{lcccc}
\hline \multicolumn{1}{c}{ Predictor } & $B(S E)$ & $\beta$ & $95 \% C I$ & $p$ \\
\hline Step 1 & & & & \\
$\quad$ Legal system involvement & $0.90(.85)$ & .08 & $0.44-3.90$ & .29 \\
FRI score* & $0.30(.14)$ & .16 & $0.03-0.64$ & .03 \\
$\quad$ CMR-R-II score & $0.22(.20)$ & .09 & $-0.07-0.78$ & .26 \\
Step 2 & & & & \\
$\quad$ Age & $-0.24(.34)$ & -.33 & $0.05-0.36$ & .48 \\
Consequences condition & $1.96(9.34)$ & .22 & $-7.53-0.31$ & .84 \\
Sensation seeking & $-3.04(2.84)$ & -.46 & $-0.24-2.58$ & .29 \\
Age x Consequences condition & $-0.13(.41)$ & -.37 & & .75 \\
$\quad$ Age x Sensation seeking & $0.23(.14)$ & .93 & & .11 \\
Consequences condition x & $-0.62(3.55)$ & -.20 & & .86 \\
$\quad$ Sensation seeking & & & & .95 \\
$\quad$ Age x Consequences condition & $-0.01(.17)$ & -.08 & $-0.06-0.08$ & \\
$\quad$ x Sensation seeking & & & & \\
\hline
\end{tabular}

Note. Higher scores are indicative of more admissions provided during the CUB interview.

${ }^{\mathrm{a}} R^{2}=.32$ for Step $2 . * p<.05$. 
Proposed mediation analyses. Recall that a key objective of the current study was to examine why adolescents are more prone to providing false information during police questioning than adults. Furthermore, it was expected that, due to increased sensation seeking and deficits in impulse control and future orientation, adolescents would be even more likely than adults to provide false information when denials were associated with taxing proximal consequences. Because a significant interaction between age group and consequences condition did not emerge, mediation analyses to determine whether certain characteristics of adolescence (i.e., impulse control, future orientation, and sensation seeking) accounted for this relationship were not warranted.

\section{Exploratory Analyses}

In light of results from the primary analyses showing that the data did not support the study hypotheses, further analyses were conducted to examine 1) whether the consequences conditions were equivalent and 2) whether the predicted age group differences emerged for impulse control, future orientation, and sensation seeking scores.

Consequences condition. A series of Independent t-tests were conducted to examine whether the two consequences conditions were equivalent in terms of the number of admissions given, impulse control, future orientation, sensation seeking, Miranda comprehension, and perceived aversiveness of the repetitive questions and the meeting with a police officer. More admissions were provided when denials were associated with proximal consequence $(M=8.86, S D=4.80)$ than when admissions were associated with the proximal consequence $(M=6.17, S D=3.64), t(139)=3.77, p<.001$, 95\% CI $[1.28,4.10], d=0.63$. All other comparisons were nonsignificant, all $p \mathrm{~s}>.095$. 
Impulse control. Both self-reported and behavioral impulse control was assessed. Participants completed the BIS-11, a 30-item self-report measure, to assess impulse control. Analyses revealed one case with a score three standard deviations above the mean. This case was excluded from all subsequent analyses including BIS-11 scores. A One-Way ANOVA was conducted on BIS-11 total scores and revealed no significant differences in self-reported impulse control among the three age groups $\left(M_{\text {older adult }}=\right.$ $\left.57.14, M_{\text {young adult }}=57.77, M_{\text {adolescent }}=58.24\right), F(2,128)=.16, p=.85, \eta^{2}=0.002$.

Differences in behavioral impulse control were assessed using participants' time taken to trace a circle (measured in seconds). Analyses revealed thirteen cases in which individuals' times were three standard deviations above the mean time taken to complete the task. These scores were excluded from all analyses including the behavioral impulse control measure. A One-Way ANOVA conducted excluding the extreme outliers, revealed significant differences in behavioral impulse control among the three age groups, $F(2,128)=4.03, p=.02, \eta^{2}=0.06$. Specifically, adolescents $(M=118 \mathrm{~s})$ spent significantly more time on the tracing task than older adults $(M=79 \mathrm{~s}), p=.02$. There were no differences in tracing time between older adults and young adults $(M=103 \mathrm{~s}), p$ $=.20$, or between young adults and adolescents, $p=.53$. Thus, behavioral measures of impulse control showed that, contrary to hypotheses, adolescents exuded greater restraint than older adults.

Future orientation. Future orientation was assessed with a 15-item self-report measure. Responses were assigned values ranging from 1 to 4 . Mean scores were created to represent individuals' overall level of future orientation with higher scores indicative of higher future orientation. Examination of future orientation scores revealed 
three individuals with scores more than three standard deviations below the mean. These scores were excluded from all analyses involving future orientation scores.

It was predicted that adolescents would report lower future orientation than adults. As expected, a One-way ANOVA revealed significant age differences in future orientation scores, $F(2,135)=3.32, p=.04, \eta^{2}=0.05$. However, in post hoc analyses no significant differences emerged in the comparisons between any of the three age groups, all $p \mathrm{~s}>.05$.

Sensation seeking. Differences in sensation seeking were assessed using participant responses to three items on a self-report measure. Responses were assigned values ranging from 1 to 4 . Mean scores were calculated from these responses with higher scores indicative of greater sensation seeking. Examination of sensation seeking scores revealed no individuals with scores more than three standard deviations above or below the mean.

I predicted that adolescents would report greater sensation seeking than adults. A One-Way ANOVA was conducted to test this hypothesis. As expected, there were differences between the three age groups, $F(2,136)=7.10, p<.001, \eta^{2}=0.09$. Specifically, adolescents $(M=2.76)$ reported greater levels of sensation seeking than older adults $(M=2.29), p<.001$. Young adults $(M=2.63)$ also reported greater levels of sensation seeking than older adults, $p=.03$. There were no differences in self-reported sensation seeking between young adults and adolescents, $p=.60$.

MRCI-II measures. In an attempt to explain why adolescents in the current study were equally likely as adults to be susceptible to temporal discounting, exploratory 
analyses concerning the MRCI-II measures and self-administered CUB interview were conducted.

$C M R-R-I I$. A series of One-way ANOVAs was conducted to investigate possible age group differences in the comprehension of the five Miranda warnings (e.g., the right to silence, counsel, etc.) from the CMR-R-II measure. Results revealed significant age group differences in the overall comprehension score, $F(2,138)=4.52, p=.01, \eta^{2}=$ 0.06 , with adolescents $(M=11.84)$ demonstrating significantly worse comprehension scores than older adults $(M=12.87)$. All other age group comparisons were nonsignificant.

To specifically examine which concepts of their Miranda warnings youth struggled to grasp, further exploratory analyses examined the five subtotal scores that are used to compute a total CMR-R-II score. The subtotal scores pertain to the five elements of the Miranda warning:

1. You have the right to remain silent. (Subtotal A)

2. Anything you say can be used against you in court. (Subtotal B)

3. You have the right to talk to a lawyer before we ask you any questions and to have him or her with you during questioning. (Subtotal C)

4. If you cannot afford a lawyer, one will be appointed for you before questioning if you wish. (Subtotal D)

5. If you decide to answer questions now without a lawyer present, you still have the right to stop questioning at any time until you talk to a lawyer. (Subtotal E)

These analyses revealed age group differences in only two of the five Miranda warnings. Specifically, adolescents $(M=2.14 ; M=1.86)$ demonstrated significantly worse 
comprehension of the two components of the Miranda warnings, compared to older adults $(M=2.62 ; M=2.28)$, concerning the right to a lawyer during questioning $\left(\right.$ Subtotal C), $F(2,138)=7.47, p=.001, \eta^{2}=0.10$, and to have a lawyer appointed even if individuals cannot afford one (Subtotal D), $F(2,138)=4.36, p=.02, \eta^{2}=0.06$ respectively. See Table 12 for means and standard deviations across age group. 
Table 12

Means and Standard Deviations for the CMR-R-II Subtotals and Total Score as a Function of Age Group.

\begin{tabular}{|c|c|c|c|}
\hline$\underline{\text { CMR-R-II Item }}$ & Age Group & & \\
\hline & & Mean & $\underline{\mathrm{SD}}$ \\
\hline \multirow[t]{3}{*}{ Subtotal A } & Older Adults & 2.45 & 0.70 \\
\hline & Young Adults & 2.40 & 0.62 \\
\hline & Adolescents & 2.19 & 0.79 \\
\hline \multirow[t]{3}{*}{ Subtotal B } & Older Adults & 2.60 & 0.66 \\
\hline & Young Adults & 2.64 & 0.57 \\
\hline & Adolescents & 2.84 & 0.37 \\
\hline \multirow[t]{3}{*}{ Subtotal C*** } & Older Adults & 2.62 & 0.56 \\
\hline & Young Adults & 2.36 & 0.65 \\
\hline & Adolescents & 2.14 & 0.64 \\
\hline \multirow[t]{3}{*}{ Subtotal D* } & Older Adults & 2.28 & 0.69 \\
\hline & Young Adults & 2.18 & 0.78 \\
\hline & Adolescents & 1.86 & 0.68 \\
\hline \multirow[t]{3}{*}{ Subtotal E } & Older Adults & 2.91 & 0.30 \\
\hline & Young Adults & 2.76 & 0.48 \\
\hline & Adolescents & 2.81 & 0.39 \\
\hline \multirow[t]{3}{*}{ CMR-R-II Total } & Older Adults & 12.87 & 1.55 \\
\hline & Young Adults & 12.33 & 1.91 \\
\hline & Adolescents & 11.84 & 1.57 \\
\hline
\end{tabular}

Note. Higher scores are indicative of greater comprehension of Miranda rights. $* p<.05$. *** $p<.001$. 
FRI. The second Miranda rights measure administered (i.e., the FRI), assessed participants' ability to appreciate and apply their rights during various legal proceedings (i.e., during interrogation, during conferral with counsel, and in court). Analyses revealed only a marginally significant difference based on age group for the FRI overall score, $F(2,138)=2.76, p=.07, \eta^{2}=0.04$. Post hoc analyses indicated that young adults $(M=25.29)$ had marginally lower FRI scores than older adults $(M=26.38)$. Further analyses of the three subscales making up the measure revealed significant differences in participants' understanding of the nature of interrogation, $F(2,138)=5.39, p<.01, \eta^{2}=$ 0.07. Specifically, adolescents $(M=9.35)$ demonstrated better understanding than young adults for items designed to assess individuals understanding of the nature of interrogation $(M=8.47), p<.01$. Significant age differences also emerged for the subscale intended to assess the understanding of the right to silence in interrogation and in court, $F(2,138)=10.29, p=.04, \eta^{2}=0.04$. However, post hoc analyses revealed only marginally significant differences between older adults $(M=8.00)$ and adolescents $(M=$ 7.16), $p=.06$. This suggests there was inadequate power to detect differences for this subscale. All other subscales and comparisons revealed non-significant differences. See Table 13 for means and standard deviations by age group for the FRI. 
Table 13

Means and Standard Deviations for the FRI Subscales and Total Score as a Function of Age Group.

$\underline{\text { FRI Item }}$

\begin{tabular}{|c|c|c|c|}
\hline & & $\underline{\text { Mean }}$ & $\underline{\mathrm{SD}}$ \\
\hline \multirow[t]{3}{*}{ Nature of Interrogation } & Older Adults & 8.96 & 1.22 \\
\hline & Young Adults $^{\mathrm{a}}$ & 8.47 & 1.63 \\
\hline & Adolescents $^{\mathrm{a}}$ & 9.35 & 0.78 \\
\hline \multirow[t]{3}{*}{ Right to Counsel } & Older Adults & 9.42 & 0.95 \\
\hline & Young Adults & 9.56 & 0.87 \\
\hline & Adolescents & 9.53 & 0.88 \\
\hline \multirow[t]{3}{*}{ Right to Silence } & Older Adults $^{b}$ & 8.00 & 1.56 \\
\hline & Young Adults & 7.27 & 2.01 \\
\hline & Adolescents $^{\mathrm{b}}$ & 7.16 & 1.83 \\
\hline \multirow[t]{3}{*}{ FRI Total } & Older Adults & 26.38 & 2.33 \\
\hline & Young Adults & 25.29 & 2.65 \\
\hline & Adolescents & 26.05 & 1.89 \\
\hline
\end{tabular}

Note. Higher scores are indicative of greater comprehension of Miranda rights.

${ }^{\mathrm{a}}$ Denotes a significant difference between age groups at $p<.05 .{ }^{\mathrm{b}}$ Denotes a marginally significant difference between age groups at $p=.06$. 
Self-Administered CUB. The repetitive question paradigm assumes that the increased admissions given as a result of the influence of temporal discounting (i.e., when denials are associated with proximal consequences) are false. In an attempt to determine ground truth of individuals' actual engagement in the criminal and unethical behaviors in question, participants completed the CUB interview a second time after being debriefed of the true purposes of the study. It is possible that differences based on age group and temporal discounting in the number of admissions given to the CUB interview questions was masked in the current study. Because adults have had more life experiences, it is possible that they provided more truthful, and less false, admissions than adolescents. In contrast, adolescents have had less life experience, thus most or all of their responses may have been false. However, the number of false admissions made by adolescents may still have failed to exceed the number of truthful admissions provided by adults. The number of admissions provided during the face-to-face CUB interview were subtracted from the number of admissions provided on the self-administered CUB interview. The resulting score was indicative of the number of false admissions participants provided during the face-to-face interview.

A 3 (Age group: older adult vs. young adult vs. adolescents) X 2 (Consequences: PCD-DCA vs. PCA-DCD) ANOVA was conducted to examine the influence of age group and temporal discounting on the number of false admissions provided during the face-to-face CUB interview. Results revealed no significant interaction between age group and consequences condition, $F(2,121)=.15, p=.86, \eta^{2}=0.003$. There were also no differences between the three age groups, $F(2,121)=1.24, p=.29, \eta^{2}=0.02$. However, a main effect of consequences condition emerged, $F(1,121)=10.21, p=.002$, 
$\eta^{2}=0.08$. Contrary to hypotheses, temporal discounting did not appear to influence the number of false admissions provided in the expected direction. That is, fewer false admissions were provided when denials were associated with proximal consequences ( $M$ $=0.53, S D=0.87$ ) rather than when admissions were associated with proximal consequences $(M=1.34, S D=1.79)$. This indicates participants' admissions were influenced to a greater degree by the future meeting with a police officer than with the repetitive questions. 


\section{DISCUSSION}

The purpose of the current study was to examine the influence of temporal discounting and other developmental factors (i.e., impulse control, future orientation, and sensation seeking) possibly underlying youths' increased proclivity to provide false information during police questioning. The overarching goal was to contribute to research that could provide empirically based recommendations for the reform of interrogation procedures with young suspects.

Consistent with extant research, study findings showed that more admissions were provided when denials, rather than admissions, were associated with unpleasant proximal consequences, thereby supporting general hypotheses regarding temporal discounting. However, contrary to hypotheses, youth were no more likely to provide admissions than adults. That is, youths' admissions decisions were not influenced more by temporal discounting than adults - youth did not provide more admissions than adults when denials were associated with proximal consequences. Rather admission decisions were similar across all three age groups regardless of the consequences associated with denials. This finding is, at least in part, inconsistent with prior research showing that adolescents are more likely to provide false admissions in response to simulated police questioning (see Pimentel et al., 2015; Redlich \& Goodman, 2003). Because the basic premise on which the study was designed was not supported by the data, the conditions necessary for determining whether the developmental characteristics of interest (i.e., impulse control, future orientation, and sensation seeking) accounted for observed age group differences were not met. Consequently, mediation analyses were not conducted. 
Several possible explanations exist as to why the data did not support the current study hypotheses. Although, as predicted, adolescents reported greater sensation seeking than older adults, youth and adults were comparable in terms of impulse control and future orientation. In this study, impulse control was assessed via self-report with the BIS-11 and behaviorally with the circle tracing task. Both of these measures provided mixed findings regarding differences in impulse control between adolescents and adults. The BIS-11 revealed no significant differences among any of the three age groups in selfreported impulse control. In contrast, the circle tracing task showed that adolescents actually had better impulse control than older adults. Given these mixed findings, it is difficult to discern the role of impulse control in the current study.

The lack of age group differences in impulse control, particularly in the predicted direction, may have been an artifact of the sample of youth recruited for the current study. That is, perhaps there are inherent differences in impulse control between delinquent and non-delinquent youth. Particular focus was not given to recruiting at-risk or delinquent youth, a population known to experience deficits in impulse control (DeLisi \& Vaughn, 2007), for the current study. Had delinquent or at-risk youth made up all of or a substantial portion of our sample of youth, it is possible that differences in impulse control may have emerged.

An alternative explanation also exists. Research has shown that situational and emotional factors influence whether factors characteristic of adolescent development are sufficient to result in differences in decision making between adolescents and adults. It is specifically in high stakes situations or when decisions must be made in the "heat of the moment," that adolescent performance falters compared to adults (Casey \& Caudle, 
2013). In the absence of these conditions, adolescents can perform as well as, if not better than, adults. Thus, real-world interrogations, which are, by design, psychologically manipulative, stressful, and intimidating (see Kassin et al., 2010; Lassiter \& Meissner, 2010; Leo, 2008, for reviews), may produce differences in adolescent decision making, whereas the current study did not, possibly because the paradigm used was not designed to be a highly stressful situation.

It is important to note that participants completed the behavioral measure of impulse control while the RA was in the room. Thus, it is possible that adolescents, who tend to be more obedient to authority than adults (Grisso et al., 2003), spent longer on the behavioral measure - which resulted in greater impulse control - because adolescents had more difficulty than adults disobeying RAs' instructions to "take as much time as you need to trace the circle as slowly as possible." It is also possible that adults evinced lower impulse control on the behavioral measure due to the seemingly immature nature of the task. Anecdotally, numerous adults indicated during the debriefing that the circle tracing task seemed strange and inquired as to its purpose. Thus, it is possible that adults did not take the task as seriously as adolescents because it seemed irrelevant to the stated purpose of the study and/or appeared juvenile in nature. Regardless, findings regarding impulse control from the measures administered in the current study fail to provide clear evidence regarding differences in impulse control amongst the three age groups tested here.

The tendency to think about the future was assessed with a 15-item self-report measure. Consistent with past research, it was hypothesized that adolescents would exhibit diminished abilities to consider future consequences compared to both groups of adults. However, no statistically significant differences in degree of future orientation 
emerged between the three age groups studied. Surprisingly, adolescents in the current study did not exhibit diminished capabilities to adequately consider future consequences, at least according to this self-report measure, which has previously been used with both adolescents and adults and was designed to reduce socially desirable responding (Steinberg et al., 2009).

The composition of the adult and adolescent sample and the ways in which the two were recruited could account for the lack of observed differences in future orientation. That is, both adults and adolescents who are apt to consider the future, may have been more likely to select to participate in the research study. Adult participants sought to receive extra credit in their courses by taking part in the study. The drive to engage in activities at one point in time that will benefit one's final course grade several weeks or even months in the future, seems to be indicative of considerable future orientation. Furthermore, there may be something quite different about adults currently attending college as compared to similar age adults in the community who are not currently enrolled in or attending college that influences future orientation. For instance, adults attending college are likely doing so in order to achieve a particular degree or career in the future. Thus, these individuals must continually consider and plan how to best reach and prepare for that goal with their college education. Although, a sample of same age community adults likely also consider future goals and consequences, this tendency may not be as encouraged and emphasized as with adults who are attending college.

Similarly, adolescents sought to fulfill volunteer hour requirements mandated by their respective middle or high schools. Anecdotally, in my conversations with several of 
these individuals, multiple youth indicated that they were participating in order to fulfill their volunteering hours well in advance of the deadline. Additionally, many youth reported they had participated in the study to get a sense of the university campus and/or an idea of what they might like to major in at college in the future. These anecdotes suggest that youth who participated in the study may have been driven to participate because of careful consideration of their future life and educational goals. It is also possible that merely having to come to a university campus to participate in the study triggered thoughts about the future for youth.

Considering the impulse control and future orientation data in concert, findings suggest that adolescents in the current study possibly possessed more mature cognitive control and decision making capacities than youth in previous research and those involved in the justice system. Of course the reverse could also be true. That is, it could be that the adult participants in this study were exceptionally immature. Participants' Miranda comprehension scores were examined to determine which possibility was most likely. Youth in the current study performed more poorly than adults when completing the measure designed to assess their ability to recognize the rights (i.e., CMR-R-II) afforded to them in Miranda. Although mean scores on this measure were quite high for all age groups $\left(M_{\text {Older Adult }}=12.87, M_{\text {Young Adult }}=12.33, M_{\text {Adolescents }}=11.84\right.$ out of 15$)$. When tested on their ability to understand, appreciate, and apply Miranda rights in the context of arrest, interrogation, and in court (i.e., the FRI measure of Miranda), adolescents' performance did not differ significantly from that of older and young adults. Again, mean scores on this measure were quite high for all age groups $\left(M_{\text {Older Adult }}=\right.$ $26.38, M_{\text {Young Adult }}=25.29, M_{\text {Adolescents }}=26.05$ out of 30$)$. These results suggest that 
cognitive and decision making capacities among youth in this study were similar to adults. Moreover, results provide evidence to support the idea that adolescents in the current study possessed advanced cognitive and decision making capacities, which may be responsible, in part, for the lack of support for the hypothesized findings.

Mock interrogation paradigms have been developed (e.g., Kassin \& Kiechel, 1996; Russano et al., 2005) to mimic real world interrogation processes and procedures in the lab. These interrogation paradigms involve direct accusations of "guilt" and incorporate various social pressures and psychological techniques designed to induce participants to confess. Because the overarching research question for the current study involved investigating the underlying processes of interrogation and the influence of temporal discounting, I opted to use a paradigm that did not involve direct accusations of guilt or social psychological pressures to elicit confessions. Instead, the study procedures were modeled after previous research designed to investigate a key underlying principle of interrogations - that denials are punished with continued questioning and admissions are rewarded with questioning coming to an end (Madon et al., 2012; 2013).

Using a mock interrogation paradigm that did not include social pressures to confess could account for the lack of evidence to support the hypothesized age group differences. That is, social pressures may be the key component inducing youth to provide false admissions. In the current study, youth reported greater perceived aversiveness to the police than adults. If direct accusations and social pressures to confess had come from police - or another real or perceived authority figure - it is possible that youths' ability to regulate impulse control and consider the future consequences of their behavior would have been weakened or taxed. Thus, the inclusion 
of social pressures to confess may exacerbate cognitive deficits in adolescent decision making in interrogation. Though youth in the current study had greater fear of the meeting with a police officer than adults, that did not appear to be enough to influence admission decisions.

It is also possible that adolescents took the study more seriously than adults, resulting in adolescents overriding the desire to provide false admissions for fear that they would get in trouble or ruin the integrity of the research. Adult participants likely also had more demands on their time (e.g., jobs, other appointments, children), incentivizing them to complete the study quickly, which may have resulted in the provision of more false admissions to avoid answering the repetitive questions for denials.

Furthermore, adult participants at the university are routinely required or incentivized to participate in psychological research, and may view research opportunities as an experience to quickly get through in order to obtain extra credit. Anecdotal evidence suggests youths' experiences were quite different. My first-hand discussion with youths' parents, revealed that most youth involved in the study were participating in research for the first time. I had contact (via email and/or phone) with all parents prior to their child's participation in the study, and provided parents with instructions for how to handle their child's questions about what s/he would be doing in the study. Upon discussion with parents during the in-person parental consent procedures, several parents indicated that their child/children were nervous about participating. Parents indicated that they attempted to assuage their child/children's nerves by telling him/her that the researchers would be nice to them. Furthermore, 
numerous parents specifically directed their child/children to be honest and truthful with researchers during the study. Adult participants, at least to my awareness, were not given the same admonition prior to study participation. Thus, it is possible that adolescents felt extra pressure not to provide false admissions to escape the proximal consequences associated with denials during the CUB interview. It is likely that this could be attributed to youths' fear of their parents being apprised of their study responses. However, it is important to note that all members of the research team were instructed to inform adolescent participants that their responses to any of the study measures would not be shared with his/her parent(s) unless required by the university.

A final explanation exists. Specifically, it is likely that adults, due to greater life experience, have actually engaged in more of the criminal and unethical behaviors in question than adolescents. This possibility was considered when choosing the interview questions to include for the current study. Interview questions were adapted from Madon and colleagues $(2012,2013)$ research using this paradigm with undergraduate students. Questions from the Centers for Disease Control and Prevention's Youth Risk Behavior Surveillance System (2014) were also included. Questions were adapted from both sources in order to ensure that the final set of interview questions contained behaviors both adolescents and adults had engaged in and to which they could provide truthful admissions. Thus, the resulting set of interview questions was designed to be appropriate for use with both adolescents and adults.

However, it could still be that adults truthfully responded to the interview questions by admitting having engaged in, for example, eight of the behaviors in question, only one or two of which were false admissions. In contrast, adolescents likely 
have engaged in less of the behaviors in question. During the interview, adolescents may have truthfully admitted to engaging in one or two of the behaviors but provided three or four false admissions. Thus, even though the mean admission rate is lower for adolescents than adults, a more fine-grained analysis may reveal that adolescents provided more false admissions than adults. Data were collected to assess this possible explanation (the self-administered CUB post debriefing), and, while both adolescents and adults provided false admissions, there were no differences between the three age groups in the tendency to do so. However, these results should be interpreted with caution, because it is impossible to determine ground truth of participants' face-to-face and selfadministered CUB interview responses.

\section{Limitations and Future Directions}

The present study represents an initial step in assessing the influence of temporal discounting, impulse control, and future orientation on individuals' potential willingness to provide false admissions during questioning with police and other authority figures. Several limitations are present which should be considered when evaluating the results of the current study.

First, a key limitation of the current study, as with many experimental studies, was the reliance on college students to form the young and older adult participant samples. Similarly, many adolescent participants were recruited within the university setting. That is, announcements were made to faculty in departments across campus and to undergraduate psychology students soliciting the participating of their children, siblings, and/or relatives. Neither college students nor youth from highly educated families are representative of the population of individuals typically questioned by police 
as suspects of crime. In fact, research shows that individuals with low IQ and mental illness are overrepresented among both adult and adolescent offenders (Lynam, Moffit \& Stouthamer-Loeber, 1993; Redlich, 2007). Deficits in impulse control and the ability to appropriately consider consequences are often identified as key deficits of mental illness and intellectual impairment (e.g., individuals with Attention Deficit Hyperactivity Disorder). Thus, while impulse control and future orientation did not differ based on age group nor did they appear to influence the decision to provide false admissions among participants in the current study, those deficits may play a role in high stakes, stressful interrogations. However, because the current study did not include a sample of representative justice involved adults and youth, the current study may have failed to fully capture the influence of the factors of interest that influence decision making in interrogation.

To account for these limitations, future research should recruit participants who have been or are currently involved with the justice system to adequately examine the possibility of the existence of the relationship between willingness to provide false information and deficits in impulse control and consideration of future consequences. Because this type of research may be difficult to conduct with actual offenders in prison or in juvenile detention facilities, researchers could also consider recruiting non-criminal adults and youth from the community known to have deficits in impulse control (e.g., the mentally ill, youth and adults with ADHD), or those who are at-risk of being involved with the justice system.

Second, the suspicion rate among participants in the present study (20\% overall) was higher than that observed in previous studies utilizing this paradigm. Specifically, 
previous research has reported either no suspicion (Madon et al., 2012, 2013), a suspicion rate of less than 1\% (Madon et al., 2013; Yang et al., 2015), or a maximum suspicion rate of approximately $3.5 \%$ (Madon et al., 2012). However, differences in suspicion rate may be due to the criteria used to exclude participants for suspicion. The current study utilized a liberal approach, excluding any participant who merely mentioned "the police/police officer" (with or without elaboration indicating clear suspicion of the veracity of the meeting with a police officer or police officer involvement in the study) in response to suspicion check items (e.g., "Do you think you were misled in any way during the study? [If yes] Can you explain to me how?"). It is possible that extant research employed a more conservative criterion for suspicion exclusion decisions (e.g., excluding only those participants who explicitly stated they believed the police officer was fake). Although, it should be noted that the suspicion rate observed in the current study is comparable to that of related research utilizing a more ecologically valid mockinterrogation paradigm (see Perillo \& Kassin, 2011; Pimentel et al., 2015).

Elevated suspicion could also be an artifact of the sample characteristics. That is, racial and/or ethnic minorities tend to hold less favorable attitudes of the police (Taylor, Turner, Esbensen, \& Winfree, 2001). The mere mention of police involvement in a university psychology study could have been enough to raise suspicion for the participants involved in the current study. The majority of participants in the present study $(74 \%)$ identified as a racial/ethnic minority (i.e., Hispanic or African American). Far fewer participants were racial and/or ethnic minorities in previous studies utilizing this paradigm ( $\sim 5 \%$ in Madon et al., 2012; 10\% in Madon et al., 2013; $\sim 6 \%$ in Yang et al., 2015). Regardless of the reason for elevated suspicion in the current study, the 
exclusion of a large portion of the sample was unexpected. The exclusion of these participants likely lowered power in the analyses and the ability to detect differences across all analyses.

Third, the interrogation paradigm used was chosen because it is designed to closely mimic one of the underlying processes of interrogation, whereby denials are punished with additional questions, accusations, and the inability to end the questioning process, and admissions are rewarded with individuals being able to move forward with the process. While this paradigm was particularly well-suited for the purpose and goals of the current study, it also lacks several realistic elements of the interrogation process. Ethical considerations make it impossible for real world interrogation practices to be fully utilized in the laboratory. However, as previously discussed, multiple mock interrogation paradigms have been developed for research purposes that incorporate some real world tactics and procedures, albeit in limited capacity and for short duration (e.g., Pimentel et al., 2015; Russano et al., 2005). For example, in more realistic laboratory mock interrogation paradigms, interrogators accuse participants of violating a lab rule and employ various interrogation techniques that have been used by real world interrogators to attempt to induce the participant to truly or falsely confess to the act of wrongdoing.

Participants in the current study were merely asked yes/no questions about their past involvement in criminal and unethical behaviors. The RAs asking these questions neither specifically accused participants of engaging in those activities nor were participants threatened with more severe consequences if they refused to admit having engaged in the behaviors in question. Thus, several of the key social psychological elements (e.g., developing rapport, pressure to obey authority, direct accusation of guilt, 
minimization techniques, the presentation of false evidence) of the typical interrogation process were missing from this study. Pressure from the interrogator, direct accusations of guilt, and minimization of the seriousness of the crime and/or the consequences associated with confessing, play a key role in the process of providing false information during questioning (see Kassin et al., 2010 for a review). It is likely that these social psychological elements interact with the interpersonal developmental characteristics of interest (e.g., impulse control and future orientation). Moreover, it may even be necessary for social psychological elements and pressures to be present to exacerbate differences between youth and adults in impulse control, future orientation, and the tendency to more readily value immediate over future consequences and rewards. The questioning process in the current study, in which participants answered a series of yes/no questions in the absence of pressure and accusations of being deceptive, was not designed to invoke stress or hurried decisions. Developmental research has shown that it is specifically in situations in which adolescents must make rash decisions, that their decision making capabilities tend to be inferior to adults (Steinberg, Cauffman, Woolard, Graham, \& Banich, 2009). In contrast, when the situation does not necessitate adolescents make hasty decisions, their decision making is comparable to adults (Steinberg et al., 2009). Future research should consider altering the questioning style participants are subjected to in an attempt to more closely examine the influence and interaction of situational and interpersonal factors on individuals' decisions to provide true and false admissions.

Finally, it is impossible to assess whether participants' admissions and denials to the CUB interview questions were in fact true or false. In an attempt to overcome this 
limitation, participants in the current study, after being informed of the true purpose of the study, were asked to complete the CUB interview questions a second time. However, this time, participants were aware that there were no consequences for their responses (i.e., there were no additional questions to answer based or the possibility of meeting with a police officer based on their responses), that there were no police officers actually involved in the study, that their responses would be anonymous, and that only authorized members of the research team would have access to their responses. Furthermore, participants were informed of the importance of telling the truth on the survey and were made to feel that it was normal for participants in their situation to previously have admitted (or denied) engaging in behaviors s/he had not (had) actually engaged in during the face-to-face interview, in order to avoid answering the additional questions.

In an attempt to establish ground truth, responses to the self-administered CUB interview were examined. Findings revealed that youth and adults provided false admissions during the face-to-face CUB interview, but there were no significant age group differences in the tendency to do so. Although numerous attempts were made to ensure that participants felt comfortable providing truthful responses on this second administration of the interview, it is possible that participants remained reluctant to disclose truthful responses. Anecdotally, several adult participants indicated that they did not feel it would be in their best interest to disclose truthful information to researchers about their engagement in criminal and unethical behaviors. Because it was not possible to verify interview responses with individuals' criminal records, the veracity of participants' interview responses cannot be determined. 


\section{Implications and Conclusions}

The United States Supreme Court has deemed custodial interrogation to be an inherently coercive process (Miranda v. Arizona, 1966). Interrogation is beneficial because questioning often results in the elicitation of incriminating information from guilty suspects (Drizin \& Leo, 2004). However, interrogation can be problematic if and when, due to the tactics used or characteristics of the suspect, false confessions are elicited from innocent suspects. Concern has arisen over the increased number of cases that have come to light in recent decades involving young suspects who have been compelled to falsely confess during police questioning (Owen-Kostelnik et al., 2006). The current study sought to provide an in-depth examination of characteristics of the interrogation situation (i.e., temporal discounting) and possible factors underlying youths' increased susceptibility to provide false information in interrogation. This was the first study to investigate this novel question experimentally in the laboratory (but see Gudjonsson, Sigurdsson, Bragason, Einarsson, \& Validmarsdottir, 2004; Gudjonsson, Sigurdsson, Einarsson, Bragason, \& Newton, 2010 for an examination of some of these factors in field research).

Study findings were intended to be particularly useful at the interface of psychology and the law. This research was designed to advance scientific understanding of the influence of the mechanisms underlying interrogation on the vulnerabilities of youth and subsequent elicitation of both true and false information. This is a critical

question because (1) the criminal justice system relies heavily on eliciting presumably truthful information, often in the form of confession, to solve crimes, and (2) recommendations for interrogation reforms to safeguard youth (e.g., mandatory provision 
of a lawyer, special training for law enforcement personnel, electronic recording of interrogation) have routinely been proffered without empirical support as to evidence of the underlying mechanisms they have been designed to address.

The importance of a systematic investigation of the incidence and impact of the vulnerability of youth in interrogation is twofold. This acquired understanding allows researchers to propose developmentally appropriate reforms which can then be relayed to practitioners for use when questioning young suspects. Study findings can be directly translated into guidelines on questioning young suspects (e.g., providing young suspects with breaks, imposing time limits when questioning young suspects) and have the potential to directly impact countless real crime suspects, investigators, and justice system officials. For example, interrogators may be encouraged to explicitly highlight and explain to young suspects the immediate and future consequences of confessing. For instance, in the short-term, a confession means that youth will no longer be interrogated but that they may still have to remain in police custody. In the long term, providing a confession may mean that youth could be charged with and possibly tried and convicted for this crime. Furthermore, interrogators can estimate the amount of time youth can expect to serve if convicted of committing a crime of this caliber. In court, jury instructions could be given regarding the science of this recommended procedure and how to differentially weigh confession evidence when the recommended procedures are not followed with young suspects undergoing police questioning. Relatedly, findings can be directly integrated into investigator trainings on how to best elicit truthful information from young suspects. 
Unfortunately, the data did not support the study predictions. Contrary to hypotheses and previous research, adolescents in the current study were less likely to provide admissions, and thereby less influenced by temporal discounting, compared to both older and young adults. Furthermore, adolescents did not show evidence of expected developmental deficits in impulse control and future orientation. Regardless of the reason, in order to determine the role of impulse control and future orientation on admission decision, the age groups sampled must first differ on these characteristics.

Three main reasons could exist to explain why the study hypotheses were not supported. First, the paradigm used does not employ - by design - key situational and social psychological elements shown to elicit both true and false confessions. Future research should examine the current study's research questioning using a more ecologically valid mock interrogation paradigm. Second, general measures of impulse control, future orientation, and sensation seeking were administered. Perhaps more specific measures designed precisely to capture impulse control, future orientation, and sensation seeking in an interrogation context are needed. Finally, lack of support for hypotheses may be due to the sample of adolescents who participated in the study. These youth were not characteristic of young suspects who have been involved in or who are at risk of being involved in the justice system.

The goal of future research should be to more thoroughly understand the problem of false confession among young suspects. To provide the most beneficial insight to the criminal justice system, this enhanced understanding can be used to develop empirically based recommendations for the reform of interrogation to safeguard young suspects. In order to achieve these goals, it is imperative that future research is conducted with youth 
who are representative of young suspects involved in the justice system in situations that most closely mimic custodial interrogation. Specifically, the basic science concerning interrogation needs to be extended to a sample of youth known to exhibit impulse control and future orientation deficits, that is at risk of committing crime, being questioned by police, and providing false information to police. While youth with these problems are overrepresented among justice involved youth, there has been no known experimental interrogation research with this population. Until or unless this research is conducted, the research community will be unable to (1) provide the criminal justice system with an informed evaluation of safeguards currently in place or (2) design and implement new empirically derived and tested interrogation reforms for use with young suspects. Without this research to inform interrogation reform, it is likely that some young suspects will continue to provide false information and be wrongfully convicted for crimes they did not commit. 


\section{LIST OF REFERENCES}

Avila, C., Cuenca, I., Felix, V., Parcet, M.- A., Miranda, A. (2004). Measuring impulsivity in school-aged boys and examining its relationship with ADHD and ODD ratings. Journal of Abnormal Child Psychology, 32, 295-304. doi: 10.1023/B:JACP.0000026143.70832.4b

Berns, G. S., Laibson, D., \& Loewenstein, G. (2007). Intertemporal choice - toward an integrative framework. TRENDS in Cognitive Sciences, 11, 482-488. doi: 10.1016/j.tics.2007.08.011

Bachorowski, J., \& Newman, J. P. (1985). Impulsivity in adults: Motor inhibition and time-interval estimation. Personality and Individual Differences, 6, 133-136. doi:10.1016/0191-8869(85)90041-8

Bachorowski, J., \& Newman, J. P. (1990). Impulsive motor behavior: Effects of personality and goal salience. Journal of Personality and Social Psychology, 58, 512-518. doi:10.1037/0022-3514.58.3.512

Björkman, M. (1984). Decision making, risk taking and psychological time: Review of empirical findings and psychological theory. Scandinavian Journal of Psychology, 25, 31-49.

Bond, C. F., \& DePaulo, B. M. (2006). Accuracy of deception judgments. Personality and Social Psychology Review, 10(3), 214-234.

Cauffman, E., \& Steinberg, L. (2000). (Im)maturity of judgment in adolescence: Why adolescents may be less culpable than adults. Behavioral Sciences \& the Law, 18, 741-760. doi: 10.1002/bsl.416

Centers for Disease Control and Prevention. (2014). Youth Risk Behavior Surveillance2013. Atlanta, GA.

Critchfield, T. S., \& Kollins, S. H. (2001). Temporal discounting: Basic research and the analysis of socially important behavior. Journal of Applied Behavior Analysis, 34, 101-122. doi: 10.1901/jaba.2001.34-101

Culombe v. Connecticut, 367 U.S. 568 (1961).

Davis v. North Carolina, 384 U.S. 737 (1966). 
DeLisi, M., \& Vaughn, M. G. (2007). The Gottfredson-Hirschi critiques revisited: Reconciling self-control theory, criminal careers, and career criminals. International Journal of Offender Therapy and Comparative Criminology, 52, doi: 10.1177/0306624X07308553

Drizin, S. A., \& Leo, R. (2004). The problem of false confessions in the post-DNA world. North Carolina Law Review, 82, 891-1008.

Dror, I. E., \& Charlton, D. (2006). Why experts make errors. Journal of Forensic Identification, 56, 600-616.

Flory, K., Molina, B., Pelham, W., Gnagy, E., \& Smith, B. (2006). Childhood ADHD predicts risky sexual behavior in young adulthood. Journal of Clinical Child and Adolescent Psychology, 35, 571-577. doi:10.1207/s15374424jccp3504_8

Furby, L., \& Beyth-Marom, R. (1992). Risk taking in adolescence: A decision-making perspective. Developmental Review, 12, 1-44. doi:10.1016/0273-2297(92)90002-J

Goldstein, N. E. S., Condie, L. O., Kalbeitzer, R., Osman, D., \& Geier, J. L. (2003). Juvenile offenders' Miranda rights comprehension and self-reported likelihood of offering false confessions. Assessment, 10, 359-369. doi: 10.1023/A:1024065015717

Goldstein, N. E. S., Zelle, H., \& Grisso, T. (2014). The Miranda Rights Comprehension Instruments: Manual for Juvenile and Adult Evaluations. Sarasota, FL: Professional Resource Press.

Grisso, T., Steinberg, L., Woolard, J., Cauffman, E., Scott, E., Graham, S., . . Schwartz, R. (2003). Juveniles' competence to stand trial: A comparison of adolescents' and adults' capacities as trial defendants. Law and Human Behavior, 27, 333-363. doi:10.1023/A:1024065015717

Gross, S. R., \& Shaffer, M. (2012). Exonerations in the United States, 1989 Through 2012: Report by the National Registry of Exonerations. University of Michigan Law School.

Gudjonsson, G. H., \& Sigurdsson, J. F. (1994). How frequently do false confessions occur? An empirical study among prison inmates. Psychology, Crime \& Law, 1(1), 21-26. doi:10.1080/10683169408411933

Gudjonsson, G. H., Sigurdsson, J. F., Asgeirsdottir, B. B., \& Sigfusdottir,I. D. (2006). Custodial interrogation, false confession and individual differences: A national study among Icelandic youth. Personality and Individual Differences, 41, 49-59. doi:10.1016/j.paid.2005.12.012 
Gudjonsson, G. H., Sigurdsson, J. F., Bragason, O. O., Einarsson, E., \& Valdimarsdottir, E. B. (2004). Confessions and Denials and the relationship with personality. Legal and Criminological Psychology, 9, 121-133. doi:10.1348/135532504322776898

Gudjonsson, G. H., Sigurdsson, J. F., Bragason, O. O., Newton, A. K., \& Einarsson, E. (2008). Interrogative suggestibility, compliance and false confessions among prisoners and their relationship with attention deficit hyperactivity (ADHD) symptoms. Psychological Medicine, 38, 1037-1044. doi:

$10.1017 / \mathrm{S} 0033291708002882$

Gudjonsson, G. H., Sigurdsson, J. F., Einarsson, E., Bragason, O. O., \& Newton, A. K. (2010). Inattention, hyperactivity/impulsivity and antisocial personality disorder: Which is the best predictor of false confessions? Personality and Individual Differences, 48, 720-724. doi:10.1016/j.paid.2010.01.012

Gudjonsson, G. H., Sigurdsson, J. F., \& Sigfusdottir, I. D. (2009). Interrogation and false confessions in seven European countries. What background and psychological variables best discriminate between false confessors and non-false confessors? Psychology, Crime, \& Law, 15,711-728. doi:10.1080/10683160802516257

Gudjonsson, G. H., Sigurdsson, J. F., Sigfusdottir, I. D., \& Young, S. (2012). False confessions to police and their relationship with conduct disorder, ADHD, and life adversity. Personality and Individual Differences, 52, 696-701. doi: 10.1016/j.paid.2011.12.025

Harter, S. (1982). The Perceived Competence Scale for Children. Child Development, 53, 87-97.

Hasel, L. E., \& Kassin, S. M. (2009). On the presumption of evidentiary independence: Can confessions corrupt eyewitness identifications? Psychological Science, 20(1), 122-126. doi: 10.1111/j.1467-9280.2008.02262.x

Honts, C. R., Kassin, S. M., \& Craig, R. A. (2014). 'I'd know a false confession if I saw one': A constructive replication with juveniles. Psychology, Crime \& Law, 20(7), 695-704. doi: 10.1080/1068316X.2013.854792

Homatidis, S., \& Konstantareas, M. M. (1981). Assessment of hyperactivity: Isolating measures of high discriminant ability. Journal of Consulting and Clinical Psychology, 49, 533-541. doi:10.1037/0022-006X.49.4.533

Inbau, F. E., Reid, J. E., Buckley, J. P., \& Jayne, B. C. (2013). Criminal interrogation and confessions $\left(5^{\text {th }}\right.$ ed.). Burlington, MA: Jones \& Bartlett.

Innocence Project. (n.d.). False confessions. Retrieved from http://www.innocenceproject.org/understand/False-Confessions.php 
Jones, E. E., \& Harris, V. A. (1967). The attribution of attitudes. Journal of Experimental Social Psychology, 3(1), 1-24. doi: 10.1016/0022-1031(67)90034-0

Kahneman, D., \& Tversky, A. (1979). Prospect theory: An analysis of decision under risk. Econometrics, 47(2), 263-292.

Kalenscher, T., \& Pennartz, C. M. A. (2008). Is a bird in the hand worth two in the future? The neuroeconomics of intertemporal decision-making. Progress in Neurobiology, 84(3), 1-32. doi:10.1016/j.pneurobio.2007.11.004

Kassin, S. M. (1997). The psychology of confession evidence. American Psychologist, 52(3), 221-233. doi:10.1037/0003-066X.52.3.221

Kassin, S. M. (2008). False confessions: Causes, consequences, and implications. Current Directions in Psychological Science, 17, 249-253.

Kassin, S. M., Appleby, S. C., \& Perillo, J. T. (2010). Interviewing suspects: Practice, science, and future directions. Legal and Criminological Psychology, 15, 39-55. doi:10.1348/135532509X449361

Kassin, S. M., Drizin, S. A., Grisso, T., Gudjonsson, G. H., Leo, R. A., \& Redlich, A. D. (2010). Police-induced confessions: Risk factors and recommendations. Law and Human Behavior, 34, 3-38. doi: 10.1007/s10979-009-9188-6

Kassin, S. M., \& Gudjonsson, G. H. (2004). The psychology of confessions: A review of the literature and issues. Psychological Science in the Public Interest, 2, 33-67. doi: $10.1111 / \mathrm{j} .1529-1006.2004 .00016 . x$

Kassin, S. M., \& Kiechel, K. L. (1996). The social psychology of false confessions: Compliance, internalization, and confabulation. Psychological Science, 7, 125128. doi:10.1111/j.1467-9280.1996.tb00344.x

Kassin, S. M., \& McNall, K. (1991). Police interrogations and confessions: Communicating promises and threats by pragmatic implication. Law and Human Behavior, 15, 233-251. doi:10.1007/BF01061711

Kassin, S. M., Meissner, C. A., \& Norwick, R. J. (2005). 'I'd know a false confession if I saw one": A comparative study of college students and police investigators. Law and Human Behavior, 29(2), 211-227.doi: 10.1007/s10979-005-2416-9

Kassin, S. M., \& Neumann, K. (1997). On the power of confession evidence: An experimental test of the fundamental difference hypothesis. Law and Human Behavior, 21(5), 469-484. doi:10.1023/A:1024871622490 
Kassin, S. M., \& Sukel, H. (1997). Coerced confessions and the jury: An experimental test of the "harmless error" rule. Law and Human Behavior, 21, 27-46. doi: 10.1023/A:1024814009769

Kassin, S.M., \& Wrightsman, L.S. (1980). Prior confessions and mock juror verdicts. Journal of Applied Social Psychology, 10(2), 133-146.

Kent, K. M., Pelham, W. E., Molina, B. S. G., Sibley, M. H., Waschbusch, D. A., Yu, J., $\&$ Karch, K. M. (2011). The academic experience of male high school students with ADHD. Journal of Abnormal Child Psychology, 39, 451-462. doi:10.1007/s10802-010-9472-4

Kukucka, J., \& Kassin, S. M. (2014). Do confessions taint perceptions of handwriting evidence? An empirical test of the forensic confirmation bias. Law and Human Behavior, 38, 256-270. doi: 10.1037/1hb0000066

Lassiter, G. D., \& Meissner, C. A. (Eds.). (2010). Police interrogations and false confessions: Current research, practice, and policy recommendations. Washington, DC: American Psychological Association. doi: 10.1037/12085-000

Leo, R. A. (1996a). Miranda's revenge: Police interrogation as a confidence game. Law and Society Review, 30, 259-288. doi:10.2307/3053960

Leo, R. A. (1996b). Inside the interrogation room. Journal of Criminal Law and Criminology, 86, 621-692. doi:10.2307/1144028

Leo, R. A. (2008). Police interrogation and American justice. Cambridge, MA: Harvard University Press.

Lynam, D., Moffitt, T., \& Stouthamer-Loeber, M. (1993). Explaining the relation between IQ and delinquency: Class, race, test motivation, school failure, or selfcontrol? Journal of Abnormal Psychology, 102, 187-196.

Madon, S., Guyll, M., Scherr, K. C., Greathouse, S., \& Wells, G. L. (2012). Temporal discounting: The differential effect of proximal and distal consequences on confession decisions. Law and Human Behavior, 36, 13-20. doi: $10.1037 / \mathrm{h} 0093962$

Madon, S., Yang, Y., Smalarz, L., Guyll, M., \& Scherr, K. C. (2013). How factors present during the immediate interrogation situation produce short-sighted confession decisions. Law and Human Behavior, 37, 60-74. doi: 10.1037/lhb0000011 
Malloy, L. C., Shulman, E. P., \& Cauffman, E. (2014). Interrogations, confessions, and guilty pleas among serious adolescent offenders. Law and Human Behavior, 38, 181-193. doi: 10.1037/lhb0000065

Miranda v. Arizona, 384 U.S. 436 (1966).

Molina, B. S. G., Pelham, W. E., Gnagy, E. M., Thompson, A. L., \& Marshal, M. P. (2007). Attention-deficit/hyperactivity disorder risk for heavy drinking and alcohol use disorder is age specific. Alcoholism: Clinical and Experimental Research, 31, 643-654. doi:10.1111/j.1530-0277.2007.00349.x

Moston, S., Stephenson, G.M., \& Williamson, T.M. (1992). The effects of case characteristics on suspect behavior during police questioning. British Journal of Criminology, 32(1), 23-40.

Office of Juvenile Justice and Delinquency Prevention Statistical Briefing Book. (n. d.). Retrieved March 24, 2015, from http://www.ojjdp.gov/ojstatbb/offenders/overview.html

Owen-Kostelnik, J., Reppucci, N. D., \& Meyer, J. R. (2006). Testimony and interrogation of minors: Assumptions about maturity and morality. American Psychologist, 61, 286-304. doi: 10.1037-0003-066X.61.4.286

Perillo, J. T., \& Kassin, S. M. (2011). Inside interrogation: The lie, the bluff, and false confessions. Law and Human Behavior, 35, 327-337. doi: 10.1007/s10979-0109244-2

Pimentel, P., Arndorfer, A., \& Malloy, L. C. (2015). Taking the blame for someone else's wrongdoing: The effects of age and reciprocity. Law and Human Behavior, 39, 219-231. doi:10.1037/lhb0000132

Rachlin, H., Logue. A. W., Gibbon, J., \& Frankel, M. (1986). Cognition and behavior in studies of choice. Psychological Review, 93(1), 33-45. doi:10.1037/0033295X.93.1.33

Reck v. Pate, 367 U.S. 433 (1961).

Redlich, A. D. (2007). Double jeopardy in the interrogation room for youths with mental illness. American Psychologist, 62, 609-611. doi: 10.1037/0003-066X62.6.609

Redlich, A. D., \& Goodman, G. S. (2003). Taking responsibility for an act not committed: The influence of age and suggestibility. Law and Human Behavior, 27, 141-156. doi: 10.1023/A:1022543012851 
Russano, M. B., Meissner, C. A., Narchet, F. M., \& Kassin, S. M. (2005). Investigating true and false confessions within a novel experimental paradigm. Psychological Science, 16(6), 481-486.

Scherr, K. C. (2011). An examination of factors that influence suspects'Miranda comprehension and willingness to offer a waiver (Doctoral dissertation). Retrieved from Graduate Theses and Dissertations. Paper 10147.

Scherr, K. C., Miller, J. C., \& Kassin, S. M. (2014). "Midnight confessions": The effect of chronotype asynchrony on admissions of wrongdoing. Basic and Applied Social Psychology, 36(4), 321-328. doi: 10.1080/01973533.2014.917974

Schmider, E., Ziegler, M., Danay, E., Beyer, L., \& Bühner, M. (2010). Is it really robust? Investigating the robustness of ANOVA against violations of the normal distribution assumption. Methodology, 6, 147-151. doi: 10.1027/16142241/a000016

Sibley, M. H., Pelham, W. E., Molina, B. S. G., Gnagy, E. M., Waschbusch, D. A., Garefino, A. C., Kuriyan, A. B., Babinski, D. E., \& Karch, K. M. (2012). Diagnosing ADHD in adolescence. Journal of Counseling and Clinical Psychology, 80, 139-150. doi: 10.1037/a0026577

Siegman, A. W. (1961). The relationship between future time perspective, time estimation, and impulse control in a group of young offenders and in a control group. Journal of Consulting Psychology, 25, 470-475. doi:10.1037/h0046829

Softley, P. (1980). Police interrogation: An observational study in four police stations. London: Home Office Research Study, Royal Commission on Criminal Procedure Research study.

Steinberg, L. (2008). A social neuroscience perspective on adolescent risk-taking. Developmental Review, 28, 78-106. doi: 10.1016/j.dr.2007.08.002

Steinberg, L. (2009). Adolescent development and juvenile justice. Annual Review of Clinical Psychology, 5, 459-485. doi: 10.1146/annurev.clinpsy.032408.153603

Steinberg, L. (2014). Age of opportunity: Lessons from the new science of adolescence. Boston: Eamon Dolan/Houghton Mifflin Harcourt.

Steinberg, L., Albert, D., Cauffman, E., Banich, M., Graham, S., \& Woolard, J. (2008). Age differences in sensation seeking and impulsivity as indexed by behavior and self-report: Evidence for a dual systems model. Developmental Psychology, 44, 1764-1778. doi: 10.1037/a0012955 
Steinberg, L., Cauffman, E., Woolard, J., Graham, S., \& Banich, M. (2009). Are adolescents less mature than adults? Minors' access to abortion, the juvenile death penalty, and the alleged APA "flip-flop." American Psychologist, 64, 583-594. doi: $10.1037 / \mathrm{a} 0014763$

Steinberg, L., Graham, S., O’Brien, L., Woolard, J., Cauffman, E., \& Banich, M. (2009). Age differences in future orientation and delay discounting. Child Development, 80, 28-44. doi: 10.1111/j.1467-8624.2008.01244.x

Steinberg, L., \& Scott, E. S. (2003). Less guilty by reason of adolescence: Developmental immaturity, diminished responsibility and the juvenile death penalty. American Psychologist, 58, 1009-1018. doi: 10.1037/003-066X.58.12.1009

Steingrimsdottir,G., Hreinsdottir, H., Gudjonsson, G. H., Sigurdsson, J. F., \& Nielsen, T. (2007). False confessions and the relationship with offending behaviour and personality among offending Danish adolescents. Legal \& Criminological Psychology, 12, 287-296. doi:10.1348/135532506X153380

Stuart, G. L., \& Holtzworth-Munroe, A. (2005). Testing a theoretical model of the relationship between impulsivity, mediating variables, and husband violence. Journal of Family Violence, 20, 291-303. doi: 10.1007/s10896-005-6605-6

Suen, H. K., \& Ary, D. (1989). Analyzing quantitative behavioral observation data. Hillsdale, NJ: Lawrence Earlbaum Associates.

Taylor, T. J., Turner, K. B., Esbensen, F., \& Winfree, L. T. (2001). Coppin' an attitude: Attitudinal differences among juveniles toward police. Journal of Criminal Justice, 29, 295-305. http://dx.doi.org/ 10.1016/S0047-2352(01)00089-7

Tepfer, J. A., Nirider, L. H., \& Tricarico, L. M. (2010). Arresting development: Convictions of innocent youth. Rutgers Law Review, 62, 888-941.

The International Association of Chiefs of Police. (2012). Reducing risks: An executives guide to effective juvenile interview and interrogation. Office of Juvenile Justice and Delinquency Prevention: U.S. Department of Justice.

Townsend v. Swain, 372 U.S. 293 (1963).

U.S. Department of Justice, Federal Bureau of Investigation. (2011). Crime in the United States, 2010. Retrieved from http://www.fbi.gov/about-us/cjis/ucr/crime-in-theu.s/2010/crime-in-the-u.s.-2010.

U.S. Department of Justice, Federal Bureau of Investigation. (2012). Crime in the United States, 2012. Retrieved from http://www.fbi.gov/about-us/cjis/ucr/crime-in-theu.s/2012/crime-in-the-u.s.-2012U.S. 
U.S. Department of Justice, Federal Bureau of Investigation. (2013). Crime in the United States, 2013. Retrieved from http://www.fbi.gov/about-us/cjis/ucr/crime-in-theu.s/2013/crime-in-the-u.s.-2013.

Viljoen, J. L., Klaver, J., \& Roesch, R. (2005). Legal decisions of preadolescent and adolescent defendants: Predictors of confessions, pleas, communication with attorneys, and appeals. Law and Human Behavior, 29, 253-277.

doi:10.1007/s10979-005-3613-2

Vrij, A. (2008). Detecting lies and deceit: Pitfalls and opportunities (2 ${ }^{\text {nd }}$ ed.). New York, NY: John Wiley \& Sons Ltd.

White, J. L., Moffitt, T. E., Caspi, A., Jeglum Bartusch, D., Needles, D. J., \& Stouthamer-Loeber, M. (1994). Measuring impulsivity and examining its relationship to delinquency. Journal of Abnormal Psychology, 103(2), 192-205. doi:10.1037/0021-843X.103.2.192

Yang, Y., Madon, S., \& Guyll, M. (2015). Short-sighted confession decisions: The role of uncertain and delayed consequences. Law and Human Behavior, 39(1), 44-52. doi: $10.1037 / 1 \mathrm{hb} 0000100$ 


\section{APPENDICES}

Appendix A

\section{Contact Information Sheet}

Contact Information Record

Department of Psychology $\bullet$ FLORIDA

INTERNATIONAL UNIVERSITY

\section{Part I. Participant Contact Information}

1. Participant's Name:

Last $\quad$ First $\quad$ Middle

2. Student ID \#:

3. Email:

4. Cell Phone \#:

\section{Part II. Appointment Information}

1. Date:

2. Time:

3. Location:

4. Officer:

5. Study Name: 
Appendix B

\section{Criminal and Unethical Behaviors Interview Questions (RA Administered)}

\section{Have you ever...}

$P Q:$ Faked a high school diploma? $\quad \square$ Yes $\square$ No

1. Drank (even just one sip), bought, or tried to buy alcohol $\quad \square$ Yes $\quad \square$ No before you were 21 ?

2. Tried, used, or experimented with any illegal drugs such as $\quad \square$ Yes $\quad \square$ No marijuana, cocaine, crack, LSD, or any other kind of drug even just one time?

3. Cheated on an exam, paper, homework assignment, or school project by taking credit for someone else's work, ideas, or answers as your own (plagiarism) or helped another person cheat?

4. Used something that belonged to somebody else without permission, such as something that belonged to a family member, friend, roommate, or acquaintance?

5. Made a harassing, threatening, or prank phone call, text $\quad \square$ Yes $\quad \square$ No message, or social media post or private message?

6. Failed to wear a seat belt?

7. Knowingly kept something of value that you received in error, such as extra change given to you by a cashier or extra merchandise from a store or from an internet purchase?

8. Vandalized property, like keying a car, slashing a tire, $\quad \square$ Yes $\quad \square$ No spraying graffiti, or egging a house or car?

9. Invaded another's privacy such as by reading another's $\quad \square$ Yes $\quad \square$ No diary, text messages, or emails without permission?

10. Jumped or cut in line such as at the dining hall, movie $\quad \square$ Yes $\quad \square$ No theater, or grocery store?

11. Purposefully not returned something that you borrowed like $\quad \square$ Yes $\quad \square$ No a book, clothing, or money? 
12. Engaged in a nonviolent sex offense such as exposing $\square$ Yes $\square$ No yourself to someone by mooning or flashing them or engaged in voyeurism, which is being a peeping Tom?

13. Started or spread a rumor about someone?

$\square$ Yes $\square$ No

14. Assaulted someone with the intent of harming him or her, $\square$ Yes $\quad \square$ No either with your bare hands or with any kind of object or weapon? In other words, have you ever been in a physical fight for the purposes of harming someone else?

15. Smoked (even just one puff), bought, or tried to buy $\square$ Yes $\quad \square$ No cigarettes before you were 18 ?

16. Trespassed or broken into a building for fun or to look $\quad \square$ Yes $\quad \square$ No around?

17. Lied to your parents about where you were, who you were $\quad \square$ Yes $\quad \square$ No with, or how much money you spent on something?

18. Carried an illegal or concealed weapon, like a gun, knife, or $\quad \square$ Yes $\quad \square$ No club?

19. Shoplifted something such as makeup products, clothing, $\quad \square$ Yes $\quad \square$ No office supplies, food, or electronics?

20. Illegally downloaded music, movies, software, or anything $\quad \square$ Yes $\quad \square$ No else? 
Appendix C

\section{Police Officer Availability Schedule}

\section{Miami Dade Police Availability Schedule}

\section{MIAMI-DADE} COUNTY

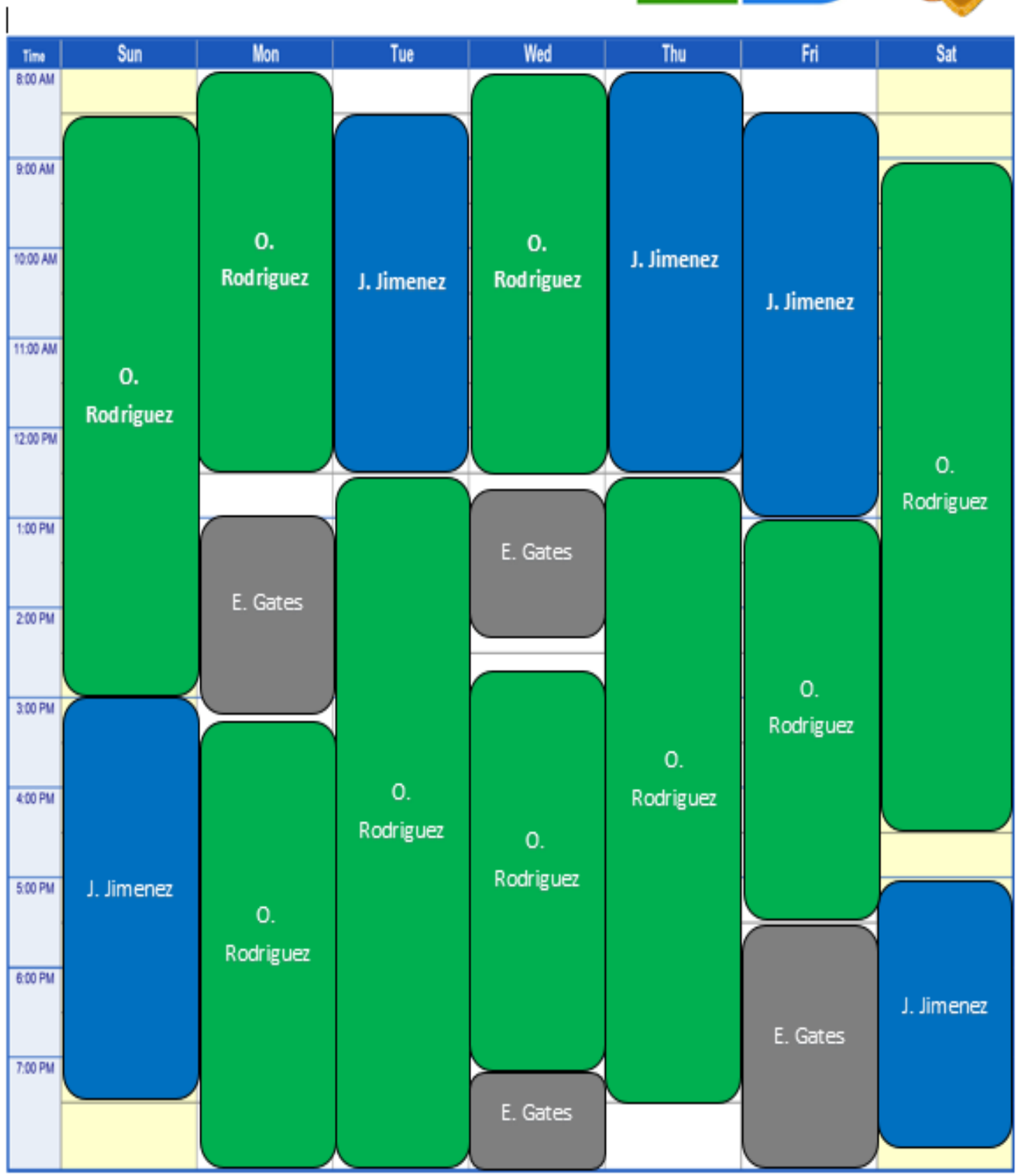




\section{Appendix D}

\section{Police Flyers}

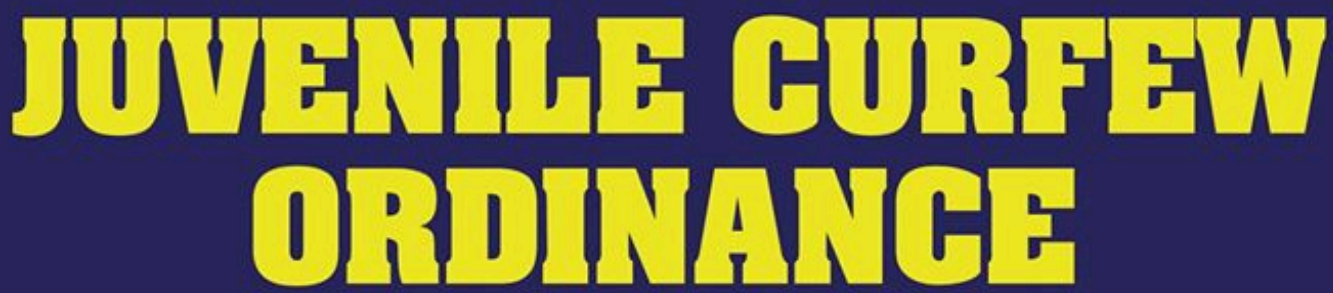

Miami-Dade County Code of Ordinances, Sec. 21-201 - 21-219

The Curfew Ordinance states that it is unlawful for any juvenile under the age of 17 to be in any public or quasi-public place, whether on foot or in a vehicle, during the curfew hours. The curfew hours are 11:00 p.m. to 6:00 a.m. Sunday through Thursday, and 12:00 midnight until 6:00 a.m. Friday and Saturday.

There are, however, numerous exceptions to the curfew which lawfully allow a juvenile to be out during the curfew hours. These exceptions are as follows:

- A juvenile accompanied by a parent or legal guardian.

- A juvenile who is with a person 21 years of age or older and that person has the permission of the juvenile's parent or legal guardian to be in charge of the juvenile.

- A juvenile who is working or traveling directly to or from work.

- A juvenile who is traveling interstate.

- A juvenile who is running an errand for a parent or legal guardian and has written permission from that parent or legal guardian to do so.

- A juvenile who is aiding or assisting in an emergency.

- A juvenile attending or traveling directly to or from a school, religious, or recreational event sponsored by Dade County, the Dade County School Board, a municipality, or a civic organization.

- A juvenile who has been emancipated either by marriage or by court order.

- A juvenile who is homeless.

- A juvenile who is exercising his or her First Amendment rights.

- A juvenile who is on the swale or sidewalk in front of the juvenile's residence or a next door neighbor's residence if the neighbor does not object.

- A juvenile with written permission from a parent or legal guardian who is attending or returning from a public event which is open to the general public and begins before 10:00 p.m.

- A juvenile who is authorized by the County Commission to be out in public during curfew hours.

RESPONSIBILITY OF BUSINESS OWNERS AND OPERATORS

It shall be unlawful for any operator. Owner or any employee managing or conducting any business or other establishment to knowingly permit a juvenile to linger, stay, congregate, move about, wander or stroll upon the premises of the establishment during curfew hours.

PENALTY OR REMEDY FOR VIOLATIONS

Any juvenile violating the Ordinance for the first and second time shall be taken into custody and transported immediately to the police station, substation, or other appropriate holding facility, or to the juvenile's home. With the third and any subsequent violation, a juvenile civil citation may be issued not to exceed $\$ 500.00$.

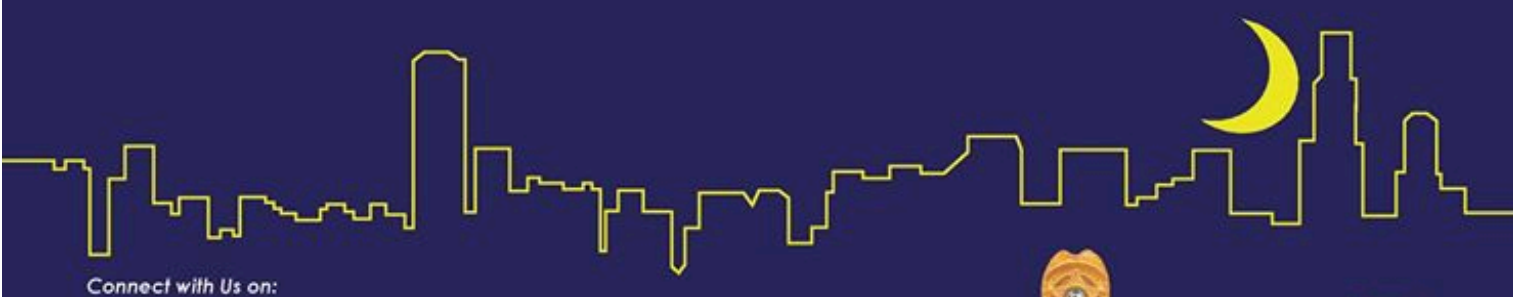

Connect with Us on: 


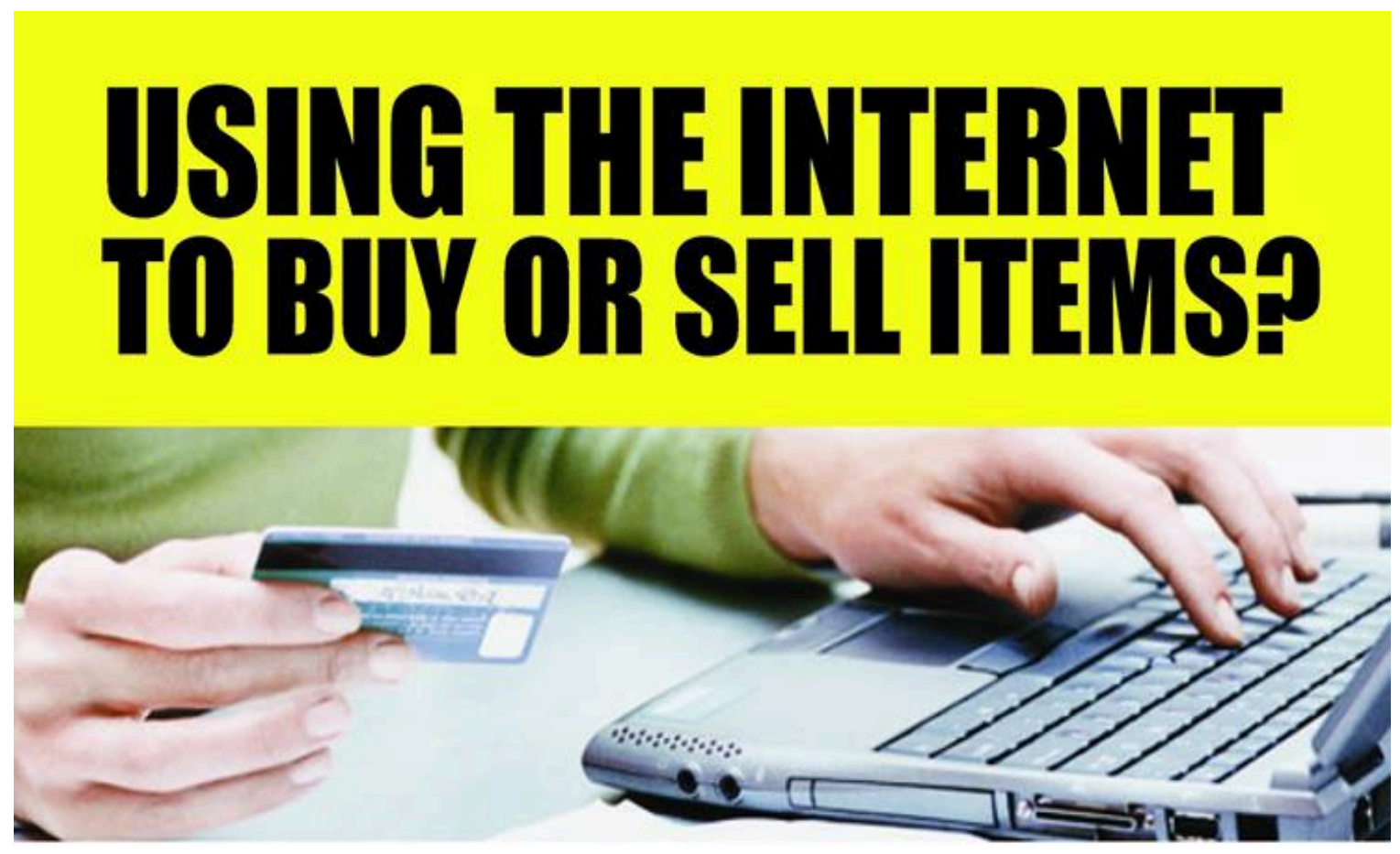

The Miami-Dade Police Department is committed to keeping residents and visitors safe by providing a SAFE HAVEN for exchanges from online transactions to take place at any Miami-Dade police station public parking area. Police stations are public places that deter crime, are well populated, operate $24 / 7$, and provide a safe location to conduct Internet sale transactions.

\section{SAFETY TIPS:}

- Meet in a public place.

- Do not meet in a secluded area, or invite strangers to your home.

- Tell a friend or family member where you are going.

- Take your cell phone with you.

- Consider having a friend accompany you.

- Protect yourself from fraud and identity theft.

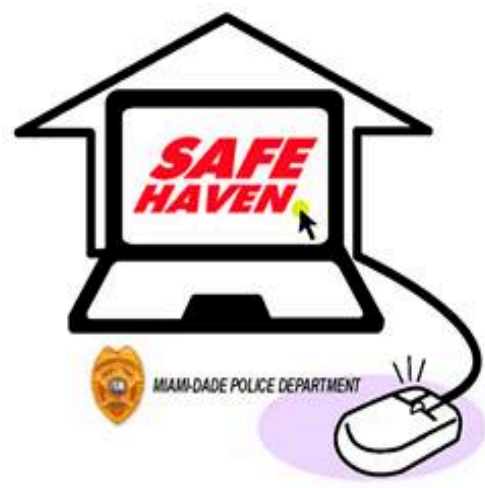

The following Miami-Dade police stations are SAFE HAVEN locations for conducting your transactions:

South Station
10800 SW 211 Street
Miami, FL 33189
Hammocks Station
10000 SW 142 Avenue
Miami, FL 33186
Northside Station
799 NW 81 Street
Miami, FL 33150

\section{Northwest Station 5975 Miami Lakes Drive East Miami Lakes, FL 33014}

Midwest Station

9101 NW 25 Street

Doral, FL 33172

Kendall Station

7707 SW 117 Avenue Miami, FL 33173

\section{Intracoastal Station \\ 15665 Biscayne Boulevard Miami, FL 33160}

\section{Connect with us on:}

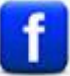

(6) YouTube 
Appendix E

\section{Repetitive Questions}

\section{Thinking about the average FLORIDIAN...}

How invulnerable do you think the average FLORIDIAN would be while engaging in the illegal or unethical behavior (e.g., drinking, buying, or trying to buy alcohol before the age of 21)?

\begin{tabular}{|c|c|c|c|c|}
\hline 1 & 2 & 3 & 4 & 5 \\
\hline Not at all & A little bit & Moderately & Quite a bit & Extremely \\
\hline
\end{tabular}

How self-important do you think the average FLORIDIAN would be while engaging in the illegal or unethical behavior (e.g., drinking, buying, or trying to buy alcohol before the age of 21)?

\begin{tabular}{|c|c|c|c|c|}
\hline 1 & 2 & 3 & 4 & 5 \\
\hline Not at all & A little bit & Moderately & Quite a bit & Extremely \\
\hline
\end{tabular}

How gratified do you think the average FLORIDIAN would be while engaging in the illegal or unethical behavior (e.g., drinking, buying, or trying to buy alcohol before the age of 21)?

\begin{tabular}{|c|c|c|c|c|}
\hline 1 & 2 & 3 & 4 & 5 \\
\hline Not at all & A little bit & Moderately & Quite a bit & Extremely \\
\hline
\end{tabular}

How resentful do you think the average FLORIDIAN would be while engaging in the illegal or unethical behavior (e.g., drinking, buying, or trying to buy alcohol before the age of 21)?

\begin{tabular}{|c|c|c|c|c|}
\hline 1 & 2 & 3 & 4 & 5 \\
\hline Not at all & A little bit & Moderately & Quite a bit & Extremely \\
\hline
\end{tabular}


How doubtful do you think the average FLORIDIAN would be while engaging in the illegal or unethical behavior (e.g., drinking, buying, or trying to buy alcohol before the age of 21)?

\begin{tabular}{|c|c|c|c|c|}
\hline 1 & 2 & 3 & 4 & 5 \\
\hline Not at all & A little bit & Moderately & Quite a bit & Extremely \\
\hline
\end{tabular}

How guilty do you think the average FLORIDIAN would be while engaging in the illegal or unethical behavior (e.g., drinking, buying, or trying to buy alcohol before the age of 21)?

\begin{tabular}{|c|c|c|c|c|}
\hline 1 & 2 & 3 & 4 & 5 \\
\hline Not at all & A little bit & Moderately & Quite a bit & Extremely \\
\hline
\end{tabular}

How self-righteous do you think the average FLORIDIAN would be while engaging in the illegal or unethical behavior (e.g., drinking, buying, or trying to buy alcohol before the age of 21)?

\begin{tabular}{|c|c|c|c|c|}
\hline 1 & 2 & 3 & 4 & 5 \\
\hline Not at all & A little bit & Moderately & Quite a bit & Extremely \\
\hline
\end{tabular}

How jealous do you think the average FLORIDIAN would be while engaging in the illegal or unethical behavior (e.g., drinking, buying, or trying to buy alcohol before the age of 21)?

\begin{tabular}{|c|c|c|c|c|}
\hline 1 & 2 & 3 & 4 & 5 \\
\hline Not at all & A little bit & Moderately & Quite a bit & Extremely \\
\hline
\end{tabular}

How disoriented do you think the average FLORIDIAN would be while engaging in the illegal or unethical behavior (e.g., drinking, buying, or trying to buy alcohol before the age of 21)?

\begin{tabular}{|c|c|c|c|c|}
\hline 1 & 2 & 3 & 4 & 5 \\
\hline Not at all & A little bit & Moderately & Quite a bit & Extremely \\
\hline
\end{tabular}


How worthless do you think the average FLORIDIAN would be while engaging in the illegal or unethical behavior (e.g., drinking, buying, or trying to buy alcohol before the age of 21)?

\begin{tabular}{|c|c|c|c|c|}
\hline 1 & 2 & 3 & 4 & 5 \\
\hline Not at all & A little bit & Moderately & Quite a bit & Extremely \\
\hline
\end{tabular}

How self-assured do you think the average FLORIDIAN would be while engaging in the illegal or unethical behavior (e.g., drinking, buying, or trying to buy alcohol before the age of 21)?

\begin{tabular}{|c|c|c|c|c|}
\hline 1 & 2 & 3 & 4 & 5 \\
\hline Not at all & A little bit & Moderately & Quite a bit & Extremely \\
\hline
\end{tabular}

How self-conscious do you think the average FLORIDIAN would be while engaging in the illegal or unethical behavior (e.g., drinking, buying, or trying to buy alcohol before the age of 21)?

\begin{tabular}{|c|c|c|c|c|}
\hline 1 & 2 & 3 & 4 & 5 \\
\hline Not at all & A little bit & Moderately & Quite a bit & Extremely \\
\hline
\end{tabular}

How happy-go-lucky do you think the average FLORIDIAN would be while engaging in the illegal or unethical behavior (e.g., drinking, buying, or trying to buy alcohol before the age of 21)?

\begin{tabular}{|c|c|c|c|c|}
\hline 1 & 2 & 3 & 4 & 5 \\
\hline Not at all & A little bit & Moderately & Quite a bit & Extremely \\
\hline
\end{tabular}

How surprised do you think the average FLORIDIAN would be while engaging in the illegal or unethical behavior (e.g., drinking, buying, or trying to buy alcohol before the age of 21)?

\begin{tabular}{|c|c|c|c|c|}
\hline 1 & 2 & 3 & 4 & 5 \\
\hline Not at all & A little bit & Moderately & Quite a bit & Extremely \\
\hline
\end{tabular}


How strong do you think the average FLORIDIAN would be while engaging in the illegal or unethical behavior (e.g., drinking, buying, or trying to buy alcohol before the age of 21)?

\begin{tabular}{|c|c|c|c|c|}
\hline 1 & 2 & 3 & 4 & 5 \\
\hline Not at all & A little bit & Moderately & Quite a bit & Extremely \\
\hline
\end{tabular}

How hostile do you think the average FLORIDIAN would be while engaging in the illegal or unethical behavior (e.g., drinking, buying, or trying to buy alcohol before the age of 21)?

\begin{tabular}{|c|c|c|c|c|}
\hline 1 & 2 & 3 & 4 & 5 \\
\hline Not at all & A little bit & Moderately & Quite a bit & Extremely \\
\hline
\end{tabular}

\section{Thinking about the average AMERICAN...}

How invulnerable do you think the average AMERICAN would be while engaging in the illegal or unethical behavior (e.g., drinking, buying, or trying to buy alcohol before the age of 21)?

\begin{tabular}{|c|c|c|c|c|}
\hline 1 & 2 & 3 & 4 & 5 \\
\hline Not at all & A little bit & Moderately & Quite a bit & Extremely \\
\hline
\end{tabular}

How self-important do you think the average AMERICAN would be while engaging in the illegal or unethical behavior (e.g., drinking, buying, or trying to buy alcohol before the age of 21)?

\begin{tabular}{|c|c|c|c|c|}
\hline 1 & 2 & 3 & 4 & 5 \\
\hline Not at all & A little bit & Moderately & Quite a bit & Extremely \\
\hline
\end{tabular}


How gratified do you think the average AMERICAN would be while engaging in the illegal or unethical behavior (e.g., drinking, buying, or trying to buy alcohol before the age of 21)?

\begin{tabular}{|c|c|c|c|c|}
\hline 1 & 2 & 3 & 4 & 5 \\
\hline Not at all & A little bit & Moderately & Quite a bit & Extremely \\
\hline
\end{tabular}

How resentful do you think the average AMERICAN would be while engaging in the illegal or unethical behavior (e.g., drinking, buying, or trying to buy alcohol before the age of 21)?

\begin{tabular}{|c|c|c|c|c|}
\hline 1 & 2 & 3 & 4 & 5 \\
\hline Not at all & A little bit & Moderately & Quite a bit & Extremely \\
\hline
\end{tabular}

How doubtful do you think the average AMERICAN would be while engaging in the illegal or unethical behavior (e.g., drinking, buying, or trying to buy alcohol before the age of 21)?

\begin{tabular}{|c|c|c|c|c|}
\hline 1 & 2 & 3 & 4 & 5 \\
\hline Not at all & A little bit & Moderately & Quite a bit & Extremely \\
\hline
\end{tabular}

How guilty do you think the average AMERICAN would be while engaging in the illegal or unethical behavior (e.g., drinking, buying, or trying to buy alcohol before the age of 21)?

\begin{tabular}{|c|c|c|c|c|}
\hline 1 & 2 & 3 & 4 & 5 \\
\hline Not at all & A little bit & Moderately & Quite a bit & Extremely \\
\hline
\end{tabular}

How self-righteous do you think the average AMERICAN would be while engaging in the illegal or unethical behavior (e.g., drinking, buying, or trying to buy alcohol before the age of 21)?

\begin{tabular}{|c|c|c|c|c|}
\hline 1 & 2 & 3 & 4 & 5 \\
\hline Not at all & A little bit & Moderately & Quite a bit & Extremely \\
\hline
\end{tabular}


How jealous do you think the average AMERICAN would be while engaging in the illegal or unethical behavior (e.g., drinking, buying, or trying to buy alcohol before the age of 21)?

\begin{tabular}{|c|c|c|c|c|}
\hline 1 & 2 & 3 & 4 & 5 \\
\hline Not at all & A little bit & Moderately & Quite a bit & Extremely \\
\hline
\end{tabular}

How disoriented do you think the average AMERICAN would be while engaging in the illegal or unethical behavior (e.g., drinking, buying, or trying to buy alcohol before the age of 21)?

\begin{tabular}{|c|c|c|c|c|}
\hline 1 & 2 & 3 & 4 & 5 \\
\hline Not at all & A little bit & Moderately & Quite a bit & Extremely \\
\hline
\end{tabular}

How worthless do you think the average AMERICAN would be while engaging in the illegal or unethical behavior (e.g., drinking, buying, or trying to buy alcohol before the age of 21)?

\begin{tabular}{|c|c|c|c|c|}
\hline 1 & 2 & 3 & 4 & 5 \\
\hline Not at all & A little bit & Moderately & Quite a bit & Extremely \\
\hline
\end{tabular}

How self-assured do you think the average AMERICAN would be while engaging in the illegal or unethical behavior (e.g., drinking, buying, or trying to buy alcohol before the age of 21)?

\begin{tabular}{|c|c|c|c|c|}
\hline 1 & 2 & 3 & 4 & 5 \\
\hline Not at all & A little bit & Moderately & Quite a bit & Extremely \\
\hline
\end{tabular}

How self-conscious do you think the average AMERICAN would be while engaging in the illegal or unethical behavior (e.g., drinking, buying, or trying to buy alcohol before the age of 21)?

\begin{tabular}{|c|c|c|c|c|}
\hline 1 & 2 & 3 & 4 & 5 \\
\hline Not at all & A little bit & Moderately & Quite a bit & Extremely \\
\hline
\end{tabular}


How happy-go-lucky do you think the average AMERICAN would be while engaging in the illegal or unethical behavior (e.g., drinking, buying, or trying to buy alcohol before the age of 21)?

\begin{tabular}{|c|c|c|c|c|}
\hline 1 & 2 & 3 & 4 & 5 \\
\hline Not at all & A little bit & Moderately & Quite a bit & Extremely \\
\hline
\end{tabular}

How surprised do you think the average AMERICAN would be while engaging in the illegal or unethical behavior (e.g., drinking, buying, or trying to buy alcohol before the age of 21)?

\begin{tabular}{|c|c|c|c|c|}
\hline 1 & 2 & 3 & 4 & 5 \\
\hline Not at all & A little bit & Moderately & Quite a bit & Extremely \\
\hline
\end{tabular}

How strong do you think the average AMERICAN would be while engaging in the illegal or unethical behavior (e.g., drinking, buying, or trying to buy alcohol before the age of 21)?

\begin{tabular}{|c|c|c|c|c|}
\hline 1 & 2 & 3 & 4 & 5 \\
\hline Not at all & A little bit & Moderately & Quite a bit & Extremely \\
\hline
\end{tabular}

How hostile do you think the average AMERICAN would be while engaging in the illegal or unethical behavior (e.g., drinking, buying, or trying to buy alcohol before the age of 21)?

\begin{tabular}{|c|c|c|c|c|}
\hline 1 & 2 & 3 & 4 & 5 \\
\hline Not at all & A little bit & Moderately & Quite a bit & Extremely \\
\hline
\end{tabular}


Appendix F

\section{Barratt Impulsiveness Scale}

Directions: People differ in ways they act and think in different situations. This is a test to measure some of the ways in which you act and think. Read each statement and put an $\mathrm{X}$ on the appropriate box on the right side of this page. Do not spend too much time on any statement. Answer quickly and honestly. You may only choose one answer option for each question.

\begin{tabular}{|c|c|c|c|c|}
\hline & $\begin{array}{c}\text { Rarely/ } \\
\text { Never }\end{array}$ & Occasionally & Often & $\begin{array}{c}\text { Almost } \\
\text { Always/ } \\
\text { Always }\end{array}$ \\
\hline 1. I plan tasks carefully. ${ }^{\text {a }}$ & $\square$ & $\square$ & $\square$ & $\square$ \\
\hline 2. I do things without thinking. & $\square$ & $\square$ & $\square$ & $\square$ \\
\hline 3. I make-up my mind quickly. & $\square$ & $\square$ & $\square$ & $\square$ \\
\hline 4. I am happy-go-lucky. & $\square$ & $\square$ & $\square$ & $\square$ \\
\hline 5. I don't "pay attention." & $\square$ & $\square$ & $\square$ & $\square$ \\
\hline 6. I have "racing" thoughts. & $\square$ & $\square$ & $\square$ & $\square$ \\
\hline 7. I plan trips well ahead of time. ${ }^{\mathrm{a}}$ & $\square$ & $\square$ & $\square$ & $\square$ \\
\hline 8. I am self-controlled. ${ }^{\mathrm{a}}$ & $\square$ & $\square$ & $\square$ & $\square$ \\
\hline 9. I concentrate easily. ${ }^{a}$ & $\square$ & $\square$ & $\square$ & $\square$ \\
\hline 10. I save regularly. & $\square$ & $\square$ & $\square$ & $\square$ \\
\hline 11. I "squirm" at plays or lectures. & $\square$ & $\square$ & $\square$ & $\square$ \\
\hline 12. I am a careful thinker. ${ }^{\text {a }}$ & $\square$ & $\square$ & $\square$ & $\square$ \\
\hline 13. I plan for job security. ${ }^{\mathrm{a}}$ & $\square$ & $\square$ & $\square$ & $\square$ \\
\hline 14. I say things without thinking. & $\square$ & $\square$ & $\square$ & $\square$ \\
\hline $\begin{array}{l}\text { 15. I like to think about complex } \\
\text { problems. }\end{array}$ & $\square$ & $\square$ & $\square$ & $\square$ \\
\hline 16. I change jobs. & $\square$ & $\square$ & $\square$ & $\square$ \\
\hline 17. I act "on impulse." & $\square$ & $\square$ & $\square$ & $\square$ \\
\hline $\begin{array}{l}\text { 18. I get easily bored when solving } \\
\text { thought problems. }\end{array}$ & $\square$ & $\square$ & $\square$ & $\square$ \\
\hline 19. I act on the spur of the moment. & $\square$ & $\square$ & $\square$ & $\square$ \\
\hline 20. I am a steady thinker. ${ }^{\text {a }}$ & $\square$ & $\square$ & $\square$ & $\square$ \\
\hline 21. I change residences. & $\square$ & $\square$ & $\square$ & $\square$ \\
\hline 22. I buy things on impulse. & $\square$ & $\square$ & $\square$ & $\square$ \\
\hline $\begin{array}{l}\text { 23. I can only think about one thing at } \\
\text { a time. }\end{array}$ & $\square$ & $\square$ & $\square$ & $\square$ \\
\hline 24. I change hobbies. & $\square$ & $\square$ & $\square$ & $\square$ \\
\hline $\begin{array}{l}\text { 25. I spend or charge more than I } \\
\text { earn. }\end{array}$ & $\square$ & $\square$ & $\square$ & $\square$ \\
\hline $\begin{array}{l}\text { 26. I often have extraneous thoughts } \\
\text { when thinking }\end{array}$ & $\square$ & $\square$ & $\square$ & $\square$ \\
\hline
\end{tabular}


27. I am more interested in the present than the future.

28. I am restless at the theater or lectures.

29. I like puzzles. ${ }^{\text {a }}$

30. I am future oriented. ${ }^{\mathrm{a}}$

\begin{tabular}{l|l|l|l}
$\square$ & $\square$ & $\square$ & $\square$ \\
$\square$ & $\square$ & $\square$ & $\square$ \\
$\square$ & $\square$ & $\square$ & $\square$ \\
$\square$ & $\square$ & $\square$ & $\square$ \\
\hline
\end{tabular}

${ }^{\mathrm{a}}$ Item scored 4, 3, 2, 1. 
Appendix G

\section{Circle Tracing Task}

**Make sure you have the stopwatch with you before you begin!**

1. Did you have the participant trace the circle as slowly as possible? $\square$ Yes $\square$ No

2. How long did it take the participant to trace the circle?

(Legibly record the time displayed on the stopwatch) 


\section{Future Orientation Questionnaire}

Directions: Please choose which item in the pair of statements best describes you. Then rate whether that item only is "Sort of true" or "Really true" for you. You may only choose one answer option for each question.

\begin{tabular}{|c|c|c|c|c|c|c|c|}
\hline & $\begin{array}{l}\text { Really } \\
\text { True } \\
\text { for Me }\end{array}$ & $\begin{array}{l}\text { Sort of } \\
\text { True } \\
\text { for } \mathrm{Me}\end{array}$ & & & & $\begin{array}{l}\text { Sort of } \\
\text { True } \\
\text { for Me }\end{array}$ & $\begin{array}{c}\text { Really } \\
\text { True } \\
\text { for } \\
\text { Me }\end{array}$ \\
\hline $1 .^{a}$ & $\square$ & $\square$ & $\begin{array}{l}\text { Some people like to plan } \\
\text { things out one step at a time }\end{array}$ & BUT & $\begin{array}{l}\text { Other people like to jump } \\
\text { right into things without } \\
\text { planning them out } \\
\text { beforehand }\end{array}$ & $\square$ & $\square$ \\
\hline 2. & $\square$ & $\square$ & $\begin{array}{l}\text { Some people spend very } \\
\text { little time thinking about } \\
\text { how things might be in the } \\
\text { future }\end{array}$ & BUT & $\begin{array}{l}\text { Other people spend a lot } \\
\text { of time thinking about } \\
\text { how things might be in } \\
\text { the future }\end{array}$ & $\square$ & $\square$ \\
\hline $3 .^{a}$ & $\square$ & $\square$ & $\begin{array}{l}\text { Some people like to think } \\
\text { about all of the possible } \\
\text { good and bad things that } \\
\text { can happen before making a } \\
\text { decision }\end{array}$ & BUT & $\begin{array}{l}\text { Other people don't think } \\
\text { it's necessary to think } \\
\text { about every little } \\
\text { possibility before making } \\
\text { a decision }\end{array}$ & $\square$ & $\square$ \\
\hline $4 .^{\mathrm{a}}$ & $\square$ & $\square$ & $\begin{array}{l}\text { Some people usually think } \\
\text { about the consequences } \\
\text { before they do something }\end{array}$ & BUT & $\begin{array}{l}\text { Other people just act-they } \\
\text { don't waste time thinking } \\
\text { about the consequences }\end{array}$ & $\square$ & $\square$ \\
\hline 5. & $\square$ & $\square$ & $\begin{array}{l}\text { Some people would rather } \\
\text { be happy today than take } \\
\text { their chances on what might } \\
\text { happen in the future }\end{array}$ & BUT & $\begin{array}{l}\text { Other people will give up } \\
\text { their happiness now so } \\
\text { that they can get what } \\
\text { they want in the future }\end{array}$ & $\square$ & $\square$ \\
\hline
\end{tabular}




\begin{tabular}{|c|c|c|c|c|c|c|c|}
\hline & $\begin{array}{l}\text { Really } \\
\text { True } \\
\text { for Me }\end{array}$ & $\begin{array}{l}\text { Sort of } \\
\text { True } \\
\text { for Me }\end{array}$ & & & & $\begin{array}{l}\text { Sort of } \\
\text { True } \\
\text { for Me }\end{array}$ & $\begin{array}{l}\text { Really } \\
\text { True } \\
\text { for } \\
\text { Me }\end{array}$ \\
\hline $6 .^{a}$ & $\square$ & $\square$ & $\begin{array}{l}\text { Some people are always } \\
\text { making lists of things to do }\end{array}$ & BUT & $\begin{array}{l}\text { Other people find making } \\
\text { lists of things to do a } \\
\text { waste of time }\end{array}$ & $\square$ & $\square$ \\
\hline 7. & $\square$ & $\square$ & $\begin{array}{l}\text { Some people make } \\
\text { decisions and then act } \\
\text { without making a plan }\end{array}$ & BUT & $\begin{array}{l}\text { Other people usually } \\
\text { make plans before going } \\
\text { ahead with their decisions }\end{array}$ & $\square$ & $\square$ \\
\hline $8 .^{a}$ & $\square$ & $\square$ & $\begin{array}{l}\text { Some people would rather } \\
\text { save their money for a rainy } \\
\text { day than spend it right } \\
\text { away on something fun }\end{array}$ & BUT & $\begin{array}{l}\text { Other people would } \\
\text { rather spend their money } \\
\text { right away on something } \\
\text { fun than save it for a } \\
\text { rainy day }\end{array}$ & $\square$ & $\square$ \\
\hline 9. & $\square$ & $\square$ & $\begin{array}{l}\text { Some people have trouble } \\
\text { imagining how things } \\
\text { might play out over time }\end{array}$ & BUT & $\begin{array}{l}\text { Other people are usually } \\
\text { pretty good at seeing in } \\
\text { advance how one thing } \\
\text { can lead to another }\end{array}$ & $\square$ & $\square$ \\
\hline 10. & $\square$ & $\square$ & $\begin{array}{l}\text { Some people don't spend } \\
\text { much time worrying about } \\
\text { how their decisions will } \\
\text { affect others }\end{array}$ & BUT & $\begin{array}{l}\text { Other people think a lot } \\
\text { about how their decisions } \\
\text { will affect others }\end{array}$ & $\square$ & $\square$ \\
\hline $11 .^{\mathrm{a}}$ & $\square$ & $\square$ & $\begin{array}{l}\text { Some people often think } \\
\text { what their life will be like } \\
10 \text { years from now }\end{array}$ & BUT & $\begin{array}{l}\text { Other people don't even } \\
\text { try to imagine what their } \\
\text { life will be like in } 10 \\
\text { years }\end{array}$ & $\square$ & $\square$ \\
\hline 12. & $\square$ & $\square$ & $\begin{array}{l}\text { Some people think that } \\
\text { planning things out in } \\
\text { advance is a waste of time }\end{array}$ & BUT & $\begin{array}{l}\text { Other people think that } \\
\text { things work out better if } \\
\text { they are planned out in } \\
\text { advance }\end{array}$ & $\square$ & $\square$ \\
\hline
\end{tabular}




\begin{tabular}{|c|c|c|c|c|c|c|c|}
\hline & $\begin{array}{l}\text { Really } \\
\text { True } \\
\text { for Me }\end{array}$ & $\begin{array}{l}\text { Sort of } \\
\text { True } \\
\text { for Me }\end{array}$ & & & & $\begin{array}{l}\text { Sort of } \\
\text { True } \\
\text { for Me }\end{array}$ & $\begin{array}{c}\text { Really } \\
\text { True } \\
\text { for } \\
\text { Me }\end{array}$ \\
\hline 13. & $\square$ & $\square$ & $\begin{array}{l}\text { Some people like to take } \\
\text { big projects and break them } \\
\text { down into small steps } \\
\text { before starting to work on } \\
\text { them }\end{array}$ & BUT & $\begin{array}{l}\text { Other people find that } \\
\text { breaking big projects } \\
\text { down into small steps } \\
\text { isn't really necessary }\end{array}$ & $\square$ & $\square$ \\
\hline $14 .^{\mathrm{a}}$ & $\square$ & $\square$ & $\begin{array}{l}\text { Some people take life one } \\
\text { day at a time without } \\
\text { worrying about the future }\end{array}$ & BUT & $\begin{array}{l}\text { Other people are always } \\
\text { thinking about what } \\
\text { tomorrow will bring }\end{array}$ & $\square$ & $\square$ \\
\hline 15. & $\square$ & $\square$ & $\begin{array}{l}\text { Some people think it's } \\
\text { better to run through all the } \\
\text { possible outcomes of a } \\
\text { decision in your mind } \\
\text { before deciding what to do }\end{array}$ & BUT & $\begin{array}{l}\text { Other people think it's } \\
\text { better to make up your } \\
\text { mind without worrying } \\
\text { about things you can't } \\
\text { predict }\end{array}$ & $\square$ & $\square$ \\
\hline
\end{tabular}

Scoring: All items are scored left to right on a scale of 1-4. ${ }^{a}$ Reverse score items: $1,3,4,6,8,11$, and 14 , so that higher scores indicate a stronger future orientation. Future Orientation total scores is the unweighted average of all 15 items. Anticipation of Future Consequences is the unweighted averaged of items 3, 4, 9, 10, and 15. 
Appendix I

\section{Sensation Seeking Questionnaire}

Directions: Read each statement and put an $\mathrm{X}$ on the appropriate box on the right side of this page. You may only choose one answer option for each question.

\begin{tabular}{lc|c|c|c} 
& $\begin{array}{r}\text { Strongly } \\
\text { Agree }\end{array}$ & Agree & Disagree & $\begin{array}{c}\text { Strongly } \\
\text { Disagree }\end{array}$ \\
\hline $\begin{array}{l}\text { 1. I often get in a jam because I do } \\
\text { things without thinking. }\end{array}$ & $\square$ & $\square$ & $\square$ & $\square$ \\
2. I think that planning takes the fun out & $\square$ & $\square$ & $\square$ & $\square$ \\
of things. & $\square$ & $\square$ & $\square$ & $\square$ \\
3. I have to use a lot of self-control to \\
keep out of trouble.
\end{tabular}


Appendix J

\section{CMR-R-II \\ (Comprehension of Miranda Rights - Recognition - II)}

All participants were instructed to respond to these statements by indicating whether the three subsequent sentences meant the same thing as or something different as the original sentence.

1. You have the right to remain silent.

a. It is not right to tell lies.

b. You should not say anything until the police ask you questions.

c. You do not have to say anything about what you did.

2. Anything you say can be used against you in court.

a. What you say might be used to prove you are guilty.

b. If you won't talk to the police, then that will be used against you in court.

c. If you tell the police anything it can be repeated in court.

3. You have the right to talk to a lawyer before we ask you any questions and to have him or her with you during questioning.

a. You can talk to your social worker before anything happens.

b. A lawyer is coming to see you after the police are done with you.

c. You can have a lawyer now if you ask for one.

4. If you cannot afford a lawyer, one will be appointed for you before questioning if you wish.

a. If you don't have the money for a lawyer the court will appoint a social worker to help you.

b. You can get legal help if you are poor.

c. The court will give you a lawyer free if you don't have the money to pay for one.

5. If you decide to answer questions now without a lawyer present, you still have the right to stop questioning at any time until you talk to a lawyer.

a. Even though you answered some of the police officer's questions, you still can ask for a lawyer at any time.

b. No matter when you ask for a lawyer, you will not get one until after the police question you about the crime.

c. Even if you ask for a lawyer during questioning, you cannot speak with the lawyer until the day you go to court. 


\section{Appendix K}

\section{FRI}

\section{(Function of Rights in Interrogation)}

All participants were shown a picture of a particular situation. The participant was then asked to respond to questions regarding what was going on in the picture.

Picture \#1. Joe's Interrogation: a suspect sitting at a table across from two police officers.

1. What is it that the policemen will want Joe to do?

2. Finish this sentence. The police think that Joe

3. What is the most important thing the police might want Joe to tell them?

4. How are the policemen probably feeling?

5. How is Joe probably feeling?

Picture \#2: Tim and His Lawyer: a suspect and a lawyer in consultation in a room.

1. What is the main job of the lawyer?

2. While he is with his lawyer, what is Tim supposed to do?

3. What is the main thing Tim's lawyer will be talking to Tim about?

4. Imagine that Tim's lawyer is saying, "I want you to tell me exactly what you did and tell me the truth about what happened." Then Tim tells him that he did the crime. Why would Tim's lawyer want to know that?

Picture \#3: Greg's Interrogation: a suspect in a room with two police officers.

1. Finish this sentence. If Greg decides to tell the police about what he did, then the things Greg says

2. If Greg decides not to talk, what is the most important thing the police are supposed to do?

3. If Greg says he doesn't want to talk but the police tell him he has to talk, what should happen then?

Picture \#4: Greg's Court Hearing: a courtroom hearing with a judge, police officers, parents, the defendant's lawyer, and the defendant.

1. If Greg's lawyer did just what he is supposed to do here in court, how would Greg be feeling?

2. If the judge finds out that Greg wouldn't talk to the police, then what should happen?

3. Greg did not tell the police anything about what he did. Here in court, if he were told to talk about what he did that was wrong, will he have to talk about it? 
Appendix L

\section{Demographics and Legal System Involvement (Q 3)}

1. What is your age?

2. When is your birthday?

3. What is your gender?

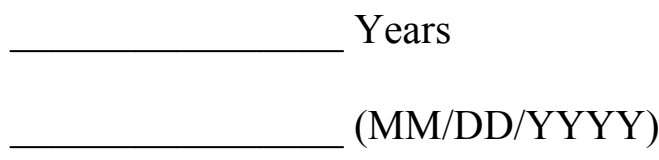

Check one: Male Female

4. Which of the following categories best reflects your ethnic/racial identity? (check only one)

African American

_ Caucasian: Non-Hispanic

Native American
Asian/Pacific Island

Hispanic

Other

5. What is the highest education level you have completed?

$6^{\text {th }}$ grade

$7^{\text {th }}$ grade

$8^{\text {th }}$ grade

Freshman year in HS

Sophomore year in HS

Junior year in HS

High School graduate

Freshman year in college
Sophomore year in college
Junior year in college
Senior year in college
Graduate school
Law school
Other
No

6. Is English your primary/native language?

Yes Years

If no, how long have you spoken English fluently?

If English is not your native language, what is your native language? 
7. What is your current grade point average (GPA)? (choose one)

\begin{tabular}{cccc} 
& 4.0 Scale & Percent Grade & Letter Grade \\
\hline$\square$ & 4.0 & $97-100$ & $\mathrm{~A}+$ \\
$\square$ & 3.9 & $93-96$ & $\mathrm{~A}$ \\
$\square$ & 3.7 & $90-92$ & $\mathrm{~A}-$ \\
$\square$ & 3.3 & $87-89$ & $\mathrm{~B}+$ \\
$\square$ & 3.0 & $83-86$ & $\mathrm{~B}$ \\
$\square$ & 2.7 & $80-82$ & $\mathrm{~B}-$ \\
$\square$ & 2.3 & $77-79$ & $\mathrm{C}+$ \\
$\square$ & 2.0 & $73-76$ & $\mathrm{C}$ \\
$\square$ & 1.7 & $70-72$ & $\mathrm{C}-$ \\
$\square$ & 1.3 & $67-69$ & $\mathrm{D}+$ \\
$\square$ & 1.0 & $65-66$ & $\mathrm{D}$ \\
$\square$ & 0.0 & Below 65 & $\mathrm{~F}$
\end{tabular}

8. Have you ever taken or are you currently taking any of the following courses: (check all that apply)

$\square \quad$ Introductory Social Psychology (SOP 3004)

$\square \quad$ Cognitive Processes (EXP 4604)

$\square \quad$ Memory \& Memory Improvement (EXP 3523)

$\square \quad$ Legal Psychology (SOP 4842)

$\square \quad$ The Criminal Justice System (CCJ 3024)

$\square \quad$ Criminal Justice Administration (CCJ 3450)

$\square \quad$ Criminological Theory (CCJ 4014)

$\square \quad$ Ethics in Criminal Justice (CCJ 4054)

$\square$ Seminar in Juvenile Delinquency (CCJ 5525)

$\square \quad$ Law Enforcement (CJE 3110)

$\square \quad$ Criminal Investigation (CJE 3610)

$\square \quad$ Juvenile Justice (CJJ 3010)

$\square \quad$ Correctional Law (CJL 4074)

$\square \quad$ I have never taken any of these courses 
Directions: The next few questions ask about your prior contact with police. It is important that you answer these questions honestly.

1. Have you ever been arrested? (circle one)

0

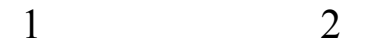

Never

1 time 2-3 times

3

4-5 times
4

6 or more

times

\section{If you answered 0 , skip to question 2.}

1a. If you have been arrested, when was the last time that you were arrested?

(check one)

$\square$ less than 6 months ago

$\square$ between 6-12 months ago

$\square$ between 1 and 2 years ago

$\square$ between 2-3 years ago

$\square$ between 3-4 years ago

$\square 5$ or more years ago

1b. If you have been arrested, how many times have you been arrested?

2. Not counting any arrests, have you ever been questioned by the police about your possible involvement in a delinquent or criminal offense? (circle one)

\section{Yes No}

\section{If you answered No, skip to question 3.}

2a. If you have been questioned by police, when was the last time this occurred? (check one)

$\square$ less than 6 months ago

$\square$ between 6-12 months ago

$\square$ between 1 and 2 years ago

$\square$ between 2-3 years ago

$\square$ between 3-4 years ago

$\square 5$ or more years ago

2b. If you have been questioned by police, how many times has this occurred? 
3. Have you ever been placed in juvenile detention or jail? (circle one)

$\begin{array}{ccccc}0 & 1 & 2 & 3 & 4 \\ \text { Never } & 1 \text { time } & 2-3 \text { times } & 4-5 \text { times } & \begin{array}{c}6 \text { or more } \\ \text { times }\end{array}\end{array}$

\section{If you answered 0, skip to question 4.}

3a. If you have been placed in juvenile detention or jail, when was the last time that you were placed in juvenile detention or jail? (check one)

$\square$ less than 6 months ago

$\square$ between 6-12 months ago

$\square$ between 1 and 2 years ago

$\square$ between 2-3 years ago

$\square$ between 3-4 years ago

$\square 5$ or more years ago

3b. If you have been placed in juvenile detention or jail, how many times has this occurred?

4. Have you ever gone to court or been placed on probation? (circle one)

$\begin{array}{ccccc}0 & 1 & 2 & 3 & 4 \\ \text { Never } & 1 \text { time } & 2-3 \text { times } & 4-5 \text { times } & \begin{array}{c}6 \text { or more } \\ \text { times }\end{array}\end{array}$

\section{If you answered 0 , you are done with this questionnaire.}

4a. If you have gone to court or been placed on probation, when was the last time that you went to court or were placed on probation? (check one)

$\square$ less than 6 months ago

$\square$ between 6-12 months ago

$\square$ between 1 and 2 years ago

$\square$ between 2-3 years ago

$\square$ between 3-4 years ago

$\square 5$ or more years ago

4b. If you have gone to court or been placed on probation, how many times has this occurred? 


\section{Appendix M}

\section{Manipulation Checks and Perceived Question and Police Aversiveness (Q 2)}

1. Did you answer any additional questions about Floridians and Americans as a result of some of your responses to the criminal and unethical behaviors survey? (check one)

$\square$ Yes $\quad$ (Continue to Question \#2)

$\square$ No (Skip to Question \#7)

2. Did you answer the additional questions about Floridians and Americans when you gave a 'no' response or a 'yes' response to the illegal behavior survey?

(check one)

$\square$ when I gave a 'no' response

$\square$ when I gave a 'yes' response

$\square$ sometimes when I gave a 'no' response and sometimes when I gave a 'yes' response

3. The additional questions about Floridians and Americans were... (circle one for each)

$\begin{array}{rllllll}\text { soothing } & 1 & 2 & 3 & 4 & 5 & \text { irritating } \\ \text { varied } & 1 & 2 & 3 & 4 & 5 & \text { repetitive } \\ \text { interesting } & 1 & 2 & 3 & 4 & 5 & \text { boring } \\ \text { pleasant } & 1 & 2 & 3 & 4 & 5 & \text { unpleasant } \\ \text { enjoyable } & 1 & 2 & 3 & 4 & 5 & \text { annoying }\end{array}$

4. If you could have, how much would you have liked to have skipped the additional questions about Floridians and Americans altogether? (circle one)

\begin{tabular}{|c|c|c|c|c|}
\hline 1 & 2 & 3 & 4 & 5 \\
\hline Not at all & A little bit & Moderately & Quite a bit & A lot \\
\hline
\end{tabular}

5. Overall, how tempted were you to give a particular answer on the criminal and unethical behaviors survey just to avoid having to answer the additional questions about Floridians and Americans again? (circle one)

\begin{tabular}{|c|c|c|c|c|}
\hline 1 & 2 & 3 & 4 & 5 \\
\hline $\begin{array}{c}\text { Not at all } \\
\text { tempted }\end{array}$ & $\begin{array}{c}\text { A little } \\
\text { tempted }\end{array}$ & $\begin{array}{c}\text { Moderately } \\
\text { tempted }\end{array}$ & $\begin{array}{c}\text { Quite } \\
\text { tempted }\end{array}$ & Very tempted \\
\hline
\end{tabular}


6. How glad were you when the additional questions about Floridians and Americans were completely done? (circle one)

\begin{tabular}{|c|c|c|c|c|}
\hline 1 & 2 & 3 & 4 & 5 \\
\hline $\begin{array}{c}\text { Not at all } \\
\text { glad }\end{array}$ & A little glad & $\begin{array}{c}\text { Moderately } \\
\text { glad }\end{array}$ & Quite glad & Very glad \\
\hline
\end{tabular}

The experimenter is currently scoring your responses to the criminal and unethical behaviors survey. Depending on your score, you may be signed up to meet with a police officer in a few weeks to discuss your answers.

7. Did the experimenter tell you that you might have to meet with a police officer to discuss your answers to the criminal and unethical behaviors survey? (check one) $\square$ Yes $\square$ No

8. Please indicate how you feel about having to possibly meet with a police officer to discuss your answers. (circle one for each)

I am...

$\begin{array}{rllllll}\text { nervous } & 1 & 2 & 3 & 4 & 5 & \text { calm } \\ \text { reluctant } & 1 & 2 & 3 & 4 & 5 & \text { eager } \\ \text { unenthused } & 1 & 2 & 3 & 4 & 5 & \text { enthused } \\ \text { concerned } & 1 & 2 & 3 & 4 & 5 & \text { unconcerned } \\ \text { not looking } & 1 & 2 & 3 & 4 & 5 & \begin{array}{l}\text { looking } \\ \text { forward to }\end{array}\end{array}$

9. How likely do you believe it is that the police officer will contact you for a meeting? (circle one)

\begin{tabular}{|c|c|c|c|c|}
\hline 1 & 2 & 3 & 4 & 5 \\
\hline $\begin{array}{c}\text { Not at all } \\
\text { likely }\end{array}$ & A little likely & $\begin{array}{c}\text { Moderately } \\
\text { likely }\end{array}$ & Quite likely & Very likely \\
\hline
\end{tabular}

10. Please complete the following statement with a percentage $(0-100 \%)$ :

I am $\%$ certain that I will have to meet with the police officer. 
11. When do you think that you will meet with the police officer? (check one)

$\square$ In one week

$\square$ In 3 to 4 weeks

$\square$ Not sure

12. How likely do you think it is that your score on the criminal and unethical behaviors survey will require that you meet with a police officer to discuss your answers?

\begin{tabular}{|c|c|c|c|c|}
\hline 1 & 2 & 3 & 4 & 5 \\
\hline $\begin{array}{c}\text { Not at all } \\
\text { likely }\end{array}$ & A little likely & $\begin{array}{c}\text { Moderately } \\
\text { likely }\end{array}$ & Quite likely & Very likely \\
\hline
\end{tabular}

13. How much do you hope that you won't have to meet with a police officer to discuss your answers to the criminal and unethical behaviors survey?

\begin{tabular}{|c|c|c|c|c|}
\hline 1 & 2 & 3 & 4 & 5 \\
\hline Not at all & A little & Moderately & Quite a bit & A lot \\
\hline
\end{tabular}

14. What were you told about the criminal and unethical behaviors survey prior to being interviewed? (check one)

$\square$ I was told that I would be signed up to meet with a police officer to discuss my answers if I said 'YES' to the questions on the criminal and unethical behaviors survey

$\square$ I was told that I would be signed up to meet with a police officer to discuss my answers if I said 'NO' to the questions on the criminal and unethical behaviors survey

$\square$ I was NEVER told that I might have to meet with a police officer to discuss my answers to the criminal and unethical behaviors survey 


\section{Appendix N}

\section{Suspicion Check (Q 1)}

1. Sometimes experiments study questions that are not obvious. Do you believe that is the case in this experiment? $\square$ No $\square$ Yes

If yes, please indicate what research questions you believe might be under investigation in this experiment.

2. Please indicate what you knew about this experiment before participating. 
Appendix O

\section{Debriefing Statement}

Legibly write down the participant's responses to these questions.

1. Do you have any questions about the study?

2. What did you think about this experiment?

3. Did anything stand out as unusual?

4. Can you explain to me the purpose of the study?

5. Do you think you were misled in any way during the study? (If yes)...Can you explain how? 
6. Before we started the criminal and unethical behaviors survey, when I first told you about the police officer, how sure were you that you would have to have this meeting if your score required it?

\begin{tabular}{|c|c|c|c|c|c|c|}
\hline 1 & 2 & 3 & 4 & 5 & 6 & 7 \\
\hline $\begin{array}{c}\text { Not at all } \\
\text { sure }\end{array}$ & & & $\begin{array}{c}\text { Moderately } \\
\text { sure }\end{array}$ & & Very sure \\
\hline
\end{tabular}

7. Before the criminal and unethical behaviors survey, when I first told you about the police officer, how likely did you think it was that you could somehow get out of the meeting even if your score required it?

\begin{tabular}{|c|c|c|c|c|c|c|}
\hline 1 & 2 & 3 & 4 & 5 & 6 & 7 \\
\hline $\begin{array}{c}\text { Not at all } \\
\text { likely }\end{array}$ & & $\begin{array}{c}\text { Moderately } \\
\text { likely }\end{array}$ & & Very likely \\
\hline
\end{tabular}


Those are all of the questions I had for you. Now I'd like to tell you more about the study.

First, all of your responses are anonymous, will be combined with the responses of other participants, and will be kept in a secured, locked office, and password protected computer that can only be accessed by members of the research team.

All participants in the study completed a battery of surveys designed to assess their demographic information, personality traits, illegal behaviors, and perceptions and experiences. While completing the survey about criminal and unethical behaviors, some participants were also asked additional follow-up questions every time they gave a 'no' response to the survey. Did you understand that you had to answer the additional followup questions every time you answered NO/YES to a question on the criminal and unethical behaviors survey?

\section{RECORD ANSWER HERE:}

Participants were also told that, depending on how they answered the criminal and unethical behaviors survey, they might be signed up to meet with a police officer in a few weeks. Did you understand that you might have to meet with a police officer if you answered YES/NO to most of the questions?

\section{RECORD ANSWER HERE:}

No participants were actually signed up to meet with a police officer. In fact, there are no police officers involved with this study and there are no legal consequences for the responses you provided today.

Additionally, all participants were told that it was very likely that they would have to meet with the police officer based on their responses to the criminal and unethical behaviors survey. Some of these participants were told that they could get out of this meeting if they agreed to work in our lab for 30 hours over the course of the next month. No participants who agreed to this deal will have to come into the lab to assist us with our research. The purpose of offering the deal was to examine what situational and dispositional factors would be most likely to induce participants to take a more certain and less severe possible punishment for their interview responses in order to avoid the possible meeting with the police officer.

The purpose of the additional questions and possible meeting with the police officer was to examine how strongly immediate consequences, like the additional questions, versus distal consequences, like meeting with a police officer, influence people's willingness to confess to criminal and unethical behaviors. We were specifically interested in whether there were differences in this tendency based upon age group (adults vs. adolescents). 
Both real world and laboratory research studies have consistently shown that youth are at an increased likelihood of providing false information, often in the form of false confession, during police questioning. The primary purpose of this study is to attempt to determine why that is the case by examining factors characteristic of youth development (e.g., increased impulsivity, increased focus on present consequences, increased sensation seeking, etc.) that possibly underlie youths' increased interrogative vulnerability. The questionnaires that we administered to you today were designed to measure some of those characteristics.

Because you responded to the criminal and unethical behaviors survey in the context of an experiment that included experimental manipulations and other controlled factors, the research team cannot assume that your responses to the survey reflect your actual past behaviors.

It is very important that you not share this information with others who might participate in our study in the future. If a participant knew what the study was about before participating, their data would be invalid and our study would be ruined. That is, if people know the true purpose of the study before they participate, we will no longer be able to conduct this research.

Do you promise not to share the true purpose of the study with other people?

\section{RECORD ANSWER HERE:}

If somebody asks you what the study is about, you can tell them it's about criminal and unethical behaviors.

Next, we would like to document your commitment to ensuring complete confidentiality of the study procedures and purpose by having you sign this 'Confidentiality Agreement'. (HAND PARTICIPANT CONFIDENTIALITY AGREEMENT. WHEN THE PARTICIPANT HAS COMPLETED IT, TAKE THE FORM FROM THEM AND SAY...) We sincerely appreciate your cooperation with ensuring the most accurate results of this important study.

The findings of this research have the potential to provide important insights into the way in which situational factors present during police questioning can influence a suspect's willingness to confess to a crime and how and why this varies by age. We did not tell you this information before because knowing the true purpose of a study can lead participants to consciously or unconsciously alter their responses. If that were to occur, the integrity of the research findings would be compromised.

In closing, I'd like to thank you for volunteering to be in this study. Your participation has been very valuable because it will further the field's understanding of circumstances that can influence how confessions are shaped by situational and dispositional factors. A 
blank consent form containing contact information is available for you at the exit if you would like to take it.

Do you have any questions about the information I've just shared with you about the true purpose of the study?

RECORD RESPONSE HERE (record a yes or no response and record the participant's questions if they have any):

(REITERATE TO THE PARTICIPANT FOUR IMPORTANT ELEMENTS FROM THE DEBRIEFING. (1) THERE ARE NO POLICE OFFICERS INVOLVED IN THE STUDY; (2) THERE ARE NO LEGAL CONSEQUENCES OR ANY OTHER CONSEQUENCES FOR THEM BASED ON THEIR RESPONSES TO THE SURVEY; (3) NO INFORMATION THAT THEY PROVIDED US TODAY WILL BE SHARED WITH ANYONE OUTSIDE OF THE RESEARCH TEAM IN A WAY THAT WILL ALLOW OTHERS TO DIRECTLY LINK THAT INFORMATION BACK TO THEM; (4) NO ONE WHO SIGNED THE AGREEMENT TO WORK IN OUR LAB IN ORDER TO GET OUT OF THE POSSIBLE MEETING WITH THE POLICE OFFICER WILL ACTUALLY HAVE TO COME WORK IN OUR LAB.)

Before you go, there is one last thing I need you to do. Now that you know the true purpose of the study, it's really important for us to get a TRUE assessment of how often you've actually engaged in these behaviors. So what I'm going to have you do is complete the criminal and unethical behaviors survey again. However, this time you will complete the survey alone and there will be no consequences based on your responses. That is, there will be no additional questions on the computer or possible meeting with a police officer based on your responses - remember there are no police officers actually involved in the study. Your responses will be anonymous, will not be able to be traced back to you, and no one outside of the research team will have access to this information. It is normal for participants in your situation to say they have/haven't engaged in certain criminal and unethical acts during the face-to-face interview when they in fact have not/have, in order to avoid answering the additional questions. This time we ask that you please answer all questions honestly even if that means giving different responses than you provided earlier. 
Appendix P

\section{Confidentiality Agreement}

\section{FIU}

\section{Confidentiality Agreement}

I agree not to discuss or share any information about the details or purpose of this experiment with anyone. I understand that by discussing this experiment with anyone who may potentially participate, I will compromise the integrity of the experiment and break this confidentiality agreement. The above stated has been explained to me and by signing this form, I agree to keep all details of this experiment confidential.

(Participant's printed name)

(Date)

(Participant's signature)

(Research Assistant's printed name)

(Date)

(Research Assistant's signature) 
Appendix Q

\section{CUB Interview Questions (Self-Administered)}

\section{Have you ever...}

1. Drank (even just one sip), bought, or tried to buy alcohol $\quad \square$ Yes $\quad \square$ No before you were 21 ?

2. Tried, used, or experimented with any illegal drugs such as $\quad \square$ Yes $\quad \square$ No marijuana, cocaine, crack, LSD, or any other kind of drug even just one time?

3. Cheated on an exam, paper, homework assignment, or $\square$ Yes $\quad \square$ No school project by taking credit for someone else's work, ideas, or answers as your own (plagiarism) or helped another person cheat?

4. Used something that belonged to somebody else without permission, such as something that belonged to a family member, friend, roommate, or acquaintance?

5. Made a harassing, threatening, or prank phone call, text message, or social media post or private message?

6. Failed to wear a seat belt?

$\square$ Yes $\square$ No

7. Knowingly kept something of value that you received in $\square$ Yes $\square$ No error, such as extra change given to you by a cashier or extra merchandise from a store or from an internet purchase?

8. Vandalized property, like keying a car, slashing a tire, $\quad \square$ Yes $\quad \square$ No spraying graffiti, or egging a house or car?

9. Invaded another's privacy such as by reading another's $\quad \square$ Yes $\quad \square$ No diary, text messages, or emails without permission?

10. Jumped or cut in line such as at the dining hall, movie theater, or grocery store?

11. Purposefully not returned something that you borrowed like $\quad \square$ Yes $\quad \square$ No a book, clothing, or money?

12. Engaged in a nonviolent sex offense such as exposing yourself to someone by mooning or flashing them or engaged in voyeurism, which is being a peeping Tom? 
13. Started or spread a rumor about someone? $\quad \square$ Yes $\quad \square$ No

14. Assaulted someone with the intent of harming him or her, $\quad \square$ Yes $\quad \square$ No either with your bare hands or with any kind of object or weapon? In other words, have you ever been in a physical fight for the purposes of harming someone else?

15. Smoked (even just one puff), bought, or tried to buy cigarettes before you were 18 ?

16. Trespassed or broken into a building for fun or to look $\quad \square$ Yes $\quad \square$ No around?

17. Lied to your parents about where you were, who you were $\quad \square$ Yes $\quad \square$ No with, or how much money you spent on something?

18. Carried an illegal or concealed weapon, like a gun, knife, or $\quad \square$ Yes $\quad \square$ No club?

19. Shoplifted something such as makeup products, clothing, $\quad \square$ Yes $\quad \square$ No office supplies, food, or electronics?

20. Illegally downloaded music, movies, software, or anything $\quad \square$ Yes $\quad \square$ No else? 
Appendix R

\section{Protocol for Terminating Study Sessions due to Participant Stress}

If the participant becomes overly stressed during any portion of the study, it is important that we terminate the study session immediately and fully debrief participants as to the true purpose of the study. For our purposes we will define overly stressed as the participant displaying 2 or more of the following behavioral indicators of stress (as cited by The American Institute of Stress):

- Gritting, grinding teeth

- Tremors, trembling of lips, hands

- Muscle spasms

- Complaints of light headedness, faintness, dizziness

- Frequent blushing, sweating

- Comments about experiencing dry mouth or difficulty swallowing

- Developing visible rashes, itching, or hives

- Difficulty breathing, frequent sighing

- Comments about experiencing chest pain, palpitations, or rapid pulse

- Excess anxiety, worry, guilt, nervousness

- Increased anger, frustration, hostility

- Comments indicating that the individual is having difficulty concentrating or experiencing racing thoughts

- Comments indicating the individual is feeling overloaded or overwhelmed

- Frequent or long-lasting crying spells

- Nervous habits, fidgeting, feet tapping

- Increased frustration, irritability, edginess

- Rapid or mumbled speech

- Excessive defensiveness

- Social withdrawal and isolation

- Vomiting or comments about experiencing heartburn, stomach pain, or nausea

If the participant is displaying only 1 of these indicators but you feel that it is excessive and cause for concern, you should immediately express to the participant that you've noticed they are upset or anxious about this process and you want to make sure that they are not overly upset. Then ask the participant to indicate how stressed they are feeling about this situation on a scale from 0 (not at all stressed) to 10 (overly stressed) about the current situation. If the participant indicates being at an 8 or higher, you should immediately terminate the study session and fully debrief the participant to the true purpose of the study. 
VITA

ANDREA ARNDORFER

Born: Algona, Iowa

2010

B.S., Psychology

B.S., Criminal Justice Studies

Iowa State University

Ames, Iowa

2014

M.S., Legal Psychology

Florida International University

Miami, Florida

2014-2016

Doctoral Candidate

Florida International University

Miami, Florida

\section{PUBLICATIONS AND PRESENTATIONS}

Arndorfer, A., \& Malloy, L. C. (Accepted for publication). Law. In M. H. Bornstein, M. E. Arterberry, K. L. Fingerman, \& J. E. Lansford (Eds.), Encyclopedia of Lifespan Human Development. New York, NY: Sage.

Malloy, L. C., Mugno, A. P., \& Arndorfer, A. (Accepted for publication). Interviewing Children with Autistic Spectrum Disorders: The NICHD Protocol and Ten Step Investigative Interview. In G. S. Goodman, J. L. Johnson, \& P. C. Mundy (Eds.) Wiley Handbook of Autobiographical Memory, Autism Spectrum Disorder, and the Law.... . XX, XX: Wiley.

Arndorfer, A., \& Malloy, L. C. (2016, November). Taking a deal: Exploring influences on plea decisions among adolescents and adults. Paper accepted to the American Society of Criminology Conference, New Orleans, LA.

Arndorfer, A., Malloy, L. C., \& Cauffman, E. (2015). Interrogations, confessions, and adolescent offenders' perceptions of the legal system. Law and Human Behavior, 39, 503-513. http://dx.doi.org/10.1037/lhb0000138

Pimentel, P., Arndorfer, A., \& Malloy, L. C. (2015). Taking the blame for someone else's wrongdoing: The effects of age and reciprocity. Law and Human Behavior, 30, 219-231. http://dx.doi.org/10.1037/lhb0000132

Malloy, L. C., \& Arndorfer, A. (2015, October 16). Teens, false confessions, and perceptions of the police. The Psych Report.

http://thepsychreport.com/science/teens-false-confessions-and-perceptions-of-thepolice/ 
Arndorfer, A., \& Charman, S. D. (2015, April). Examining best practice guidelines for eliciting eyewitness identification confidence: Are laboratory or ecologically valid confidence assessment methods more indicative of identification accuracy? Paper presented at the Graduate Student Scholarly Forum, Miami, Florida.

Arndorfer, A., \& Charman, S. D. (2015, March). Laboratory vs. real world confidence assessment methods: Is the confidence-accuracy relation scale dependent? Paper presented at the American Psychology-Law Society Conference, San Diego, California.

Arndorfer, A., \& Charman, S. D. (2015, March). An ROC analysis of exposure time on witness identification accuracy. Paper presented at the American Psychology-Law Society Conference, San Diego, California.

Arndorfer, A., Malloy, L. C., \& Cauffman, E. (2015, March). False confession and interrogation experiences influence juvenile offenders' perceptions of police (In)justice. Paper presented at the Academy of Criminal Justice Sciences Conference, Orlando, Florida.

Arndorfer, A., \& Charman, S. (2014, April). Using witnesses' memory for lineup fillers to postdict identification accuracy: Does memory strength moderate the effect? Paper presented at the Graduate Student Scholarly Forum, Miami, Florida.

Arndorfer, A., \& Charman, S. (2014, March). Using witnesses' memory for lineup fillers to postdict identification accuracy: Does memory strength moderate the effect? Poster presented at the American Psychology-Law Society Conference, New Orleans, Louisiana.

Molinaro, P., Arndorfer, A., \& Charman, S. (2013). Appearance-change instruction effects on eyewitness lineup identification accuracy are not moderated by amount of appearance change. Law and Human Behavior, 37(6), 432-440.

Arndorfer, A., \& Malloy, L. C. (2013, Summer). Actual Innocence research: Interrogations, confessions, and the vulnerability of youth. American PsychologyLaw Society Newsletter, 20-25.

Arndorfer, A., \& Charman, S. (2013, March). Eyewitnesses' memory for lineup fillers: Testing the robustness of a novel postdictor of identification accuracy. Paper presented at the American Psychology-Law Society Conference, Portland, Oregon.

Arndorfer, A., Malloy, L. C., \& Cauffman, E. (2013, March). False confession and interrogation experiences influence adolescent offenders' perceptions of procedural justice. Paper presented at the American Psychology-Law Society Conference, Portland, Oregon. 